Portland State University

PDXScholar

Spring 7-19-2018

\title{
Cyclists' Queue Discharge Characteristics at Signalized Intersections
}

Kirk Thomas Paulsen

Portland State University

Follow this and additional works at: https://pdxscholar.library.pdx.edu/open_access_etds

Part of the Transportation Engineering Commons

Let us know how access to this document benefits you.

\section{Recommended Citation}

Paulsen, Kirk Thomas, "Cyclists' Queue Discharge Characteristics at Signalized Intersections" (2018). Dissertations and Theses. Paper 4458.

https://doi.org/10.15760/etd.6342

This Thesis is brought to you for free and open access. It has been accepted for inclusion in Dissertations and Theses by an authorized administrator of PDXScholar. Please contact us if we can make this document more accessible: pdxscholar@pdx.edu. 
Cyclists' Queue Discharge Characteristics at Signalized Intersections

by

Kirk Thomas Paulsen

A thesis submitted in partial fulfillment of the requirements for the degree of

Master of Science

in

Civil and Environmental Engineering

Thesis Committee:

Christopher M. Monsere, Chair

Miguel Figliozzi

Avi Unnikrishnan

Portland State University

2018 


\begin{abstract}
Wider bike facilities intuitively accommodate a greater number of cyclists in the same amount of time, but specific queue discharge characteristics associated with varying widths and/or types of bike facilities have not been thoroughly documented.
\end{abstract}

The focus of this research analyzed queues of cyclists at four signalized intersections in Portland, OR with varying widths on the approach and downstream intersection legs. A total of 2,820 cyclists within 630 groups of queued cyclists were observed at five different intersection layouts in Portland, Oregon. The layouts consisted of: a standard bike lane six feet wide connecting bicyclists to a standard bike lane six feet wide, a standard bike lane five feet wide connecting bicyclists to two standard bike lanes each five feet wide, a buffered bike lane 12 feet wide connecting bicyclists to a standard bike lane 6.5 feet wide, a bike box 21 feet wide connecting bicyclists to a buffered bike lane 10 feet wide, and a bike box 15 feet wide connecting bicyclists to two standard bike lanes each five feet wide.

For each configuration, the following aspects were analyzed: average headway per cyclist within each queue, the time required for queues to enter the intersection, the time required for queues to clear the intersection, the number of cyclists within queues, the width of the bicycle facilities, the approach grade, and the utilization of a bike box at the intersection approach if it was present.

The first major focus of the analysis reviewed the average headway values associated with each observed queue of cyclists. The queue size with the lowest mean of the average 
headway was for groups of seven cyclists with an average headway of approximately 0.8 seconds per cyclist. For queues larger than seven in size, the mean of the average headway remained relatively stable until queues of 12 in size and started to slightly increase toward approximately 1.0 seconds for queues larger than 12 cyclists. In addition, it appears that utilization of a bike box has a potential relationship with a reduced average headway as compared to queues that do not utilize a bike box. The associated reduction in the mean of the average headway was approximately 0.2 to 0.3 seconds per cyclist for queues of three or more in size.

The second major focus of the analysis reviewed the queue discharge rate associated with each observed queue of cyclists. The results appear to potentially indicate that wider bike facilities approaching an intersection, wider receiving bike facilities, or utilization of a bike box generally discharge queues of bicyclists into the intersection over a shorter amount of time as compared to facilities that are narrower or underutilized. The installation of a bike box at one of the study intersections increased the approach width from five to 15 feet and resulted in consistently lower average discharge times for all queue sizes, a reduction of greater than one second for queues of two cyclists to as much as about four seconds for queues of nine cyclists.

The third major focus of the analysis reviewed the intersection clearance time associated with each observed queue of cyclists. The results appear to potentially indicate that wider bike facilities approaching an intersection, wider receiving bike facilities, or utilization of a bike box generally clear queues of bicyclists through the intersection over a shorter amount of time as compared to facilities that are narrower or underutilized. 


\section{Dedication}

I would like to dedicate this document to John and Amy Roberson, my grandparents.

John Roberson influenced me at a young age to consider engineering as a future life path by providing gifts of his Engineering Fluid Mechanics textbooks that he was a co-author of. He planted the engineering 'seed' with those textbooks, and I grew up to follow in his footsteps by attending Washington State University where he had previously been a professor in the engineering department.

Since my time spent in Pullman, my engineering focus has certainly evolved to match what

I am truly passionate about: designing active transportation facilities. While active transportation is not exactly fluid mechanics, it's a joy to be able to share the latest career developments with my grandfather knowing he contributed the perfect amount of 'water' to grow the seed that he helped plant.

Amy Roberson played an important and often overlooked role with assisting John on the development of his textbooks, as well as raising their kids and using her green thumb to grow amazing vegetable gardens. It was her work that planted the literal seeds of life that sustained their family, much knowledge of which was passed along to me. Such knowledge has helped guide me forward in life by providing reminders to not forget about the basic aspects that connect each and every one of us. 


\section{Acknowledgements}

I would like to acknowledge the support of my partner, my family, my friends, and staff at PSU as I proceeded with the development of this document.

My family has always been there for me, providing positive support combined with encouraging thoughts during periods of less optimism.

My friends have always provided a beam of happiness that is frequently distracting, but extremely appreciated.

The staff at PSU have always been helpful and responsive, no matter when it was that I reached out for assistance.

Finally, I want to acknowledge the loving support provided by my partner, Erinne. I cannot even begin to express how much her presence in my life has meant to me. 


\section{Table of Contents}

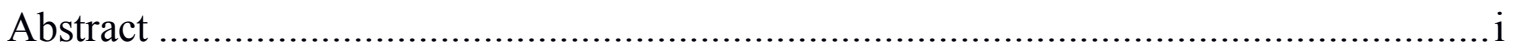

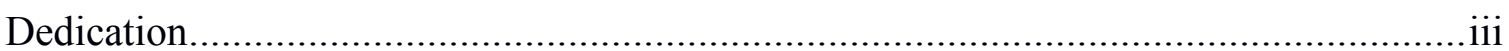

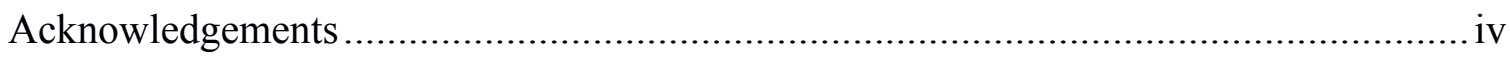

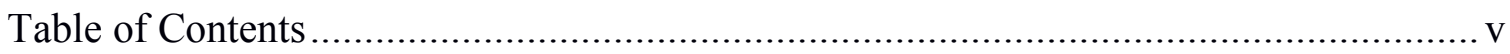

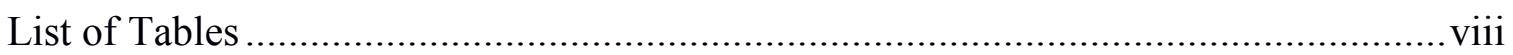

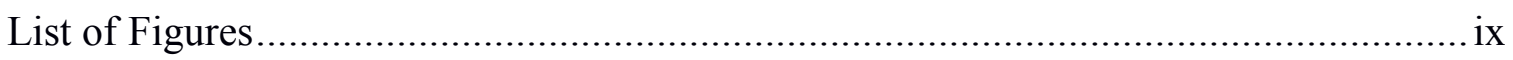

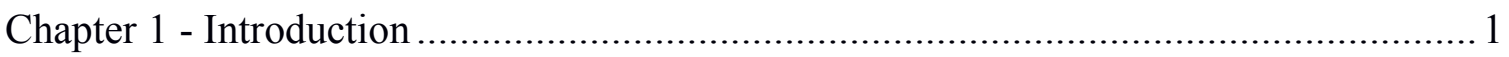

1.1 Background .................................................................................. 1

1.2 Research Objectives............................................................................ 2

1.3 Organization ..................................................................................... 3

Chapter 2 - Literature Review ........................................................................ 4

2.1 General Effect of Queues of Bicyclists at Signalized Intersections .................. 4

2.2 Bicycle Saturation Flow Rates ............................................................. 6

2.3 Bicyclist Perception/Reaction and Start-up Lost Time................................. 7

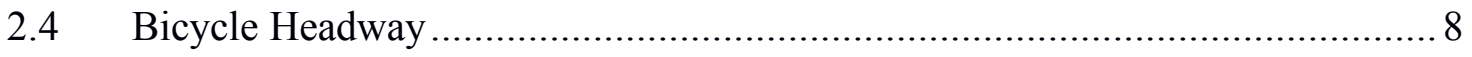

2.5 Bicycle Queue Discharge Times ................................................... 9

2.6 Bicycle Queue Intersection Clearance Times ...................................... 10

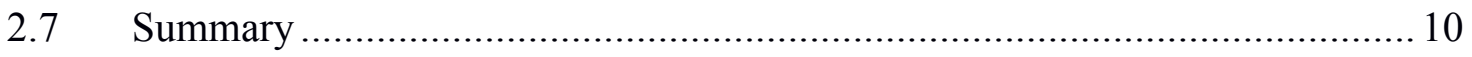

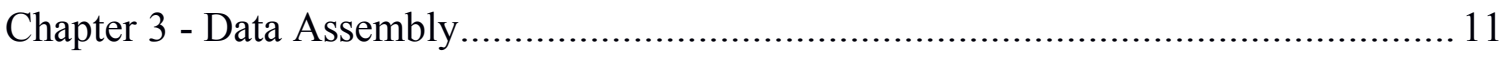

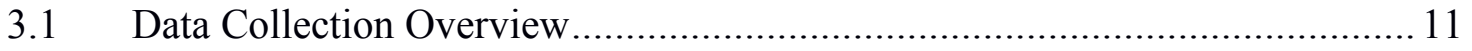

3.2 Video Recording Descriptions ........................................................... 14

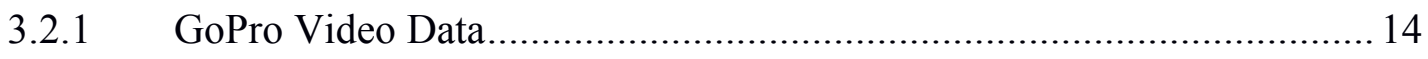

3.2.2 Portland State University Type 1 Video Data ...................................... 15

3.2.3 Portland State University Type 2 Video Data ...................................... 16

Intersection Descriptions................................................................... 16

3.3.1 N Williams Avenue at N Russell Street........................................... 17

3.3.2 SE Hawthorne Boulevard at SE Grand Avenue ................................... 19

3.3.3 NW Broadway at NW Hoyt Street................................................... 20

3.3.4 SE Madison Street at SE Grand Avenue - Before Bike Box .................. 22

3.3.5 SE Madison Street at SE Grand Avenue - After Bike Box ..................... 23

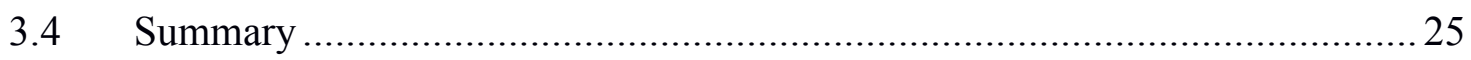




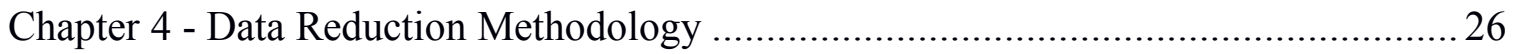

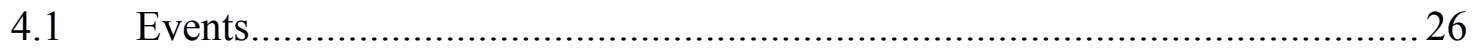

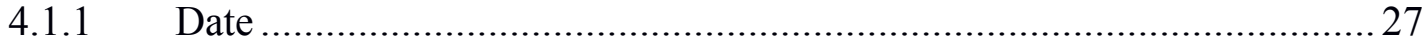

4.1.2 Start of Walk or Start of Red or Start of Green.....................................2 27

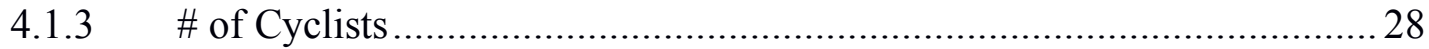

4.1.4 Time Front Wheel of $1^{\text {st }}$ Bike Crossed Far Line of Near X-walk. ............ 31

4.1.5 Time Front Wheel of Last Bike Crossed Far Line of Near X-walk........... 31

4.1.6 Time Back Wheel of Last Bike Crossed First Line of Far X-walk. .......... 31

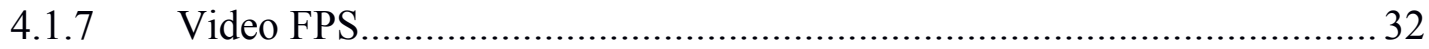

4.2 Bicycle Queue Performance Characteristics .................................................. 32

4.2.1 Average Headway within Queues of Bicycle Traffic ................................ 32

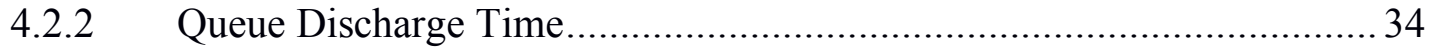

4.2.3 Queue Intersection Clearance Time......................................................... 35

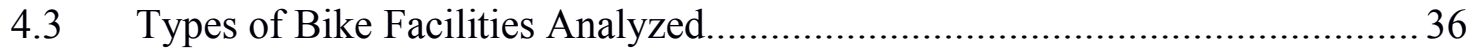

4.3.1 Standard Bike Lane to Standard Bike Lane .............................................36

4.3.2 Standard Bike Lane to Two Standard Bike Lanes..................................... 37

4.3.3 Buffered Bike Lane to Standard Bike Lane ........................................... 38

4.3.4 Bike Box to Buffered Bike Lane ............................................................ 38

4.3.5 Bike Box to Two Standard Bike Lanes..................................................... 39

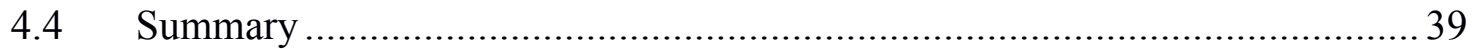

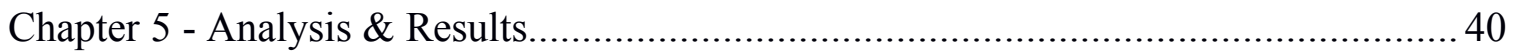

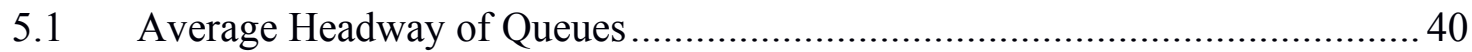

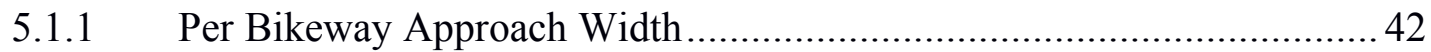

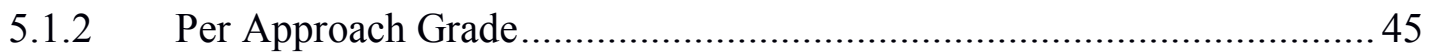

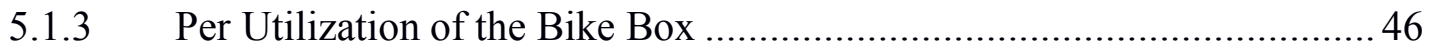

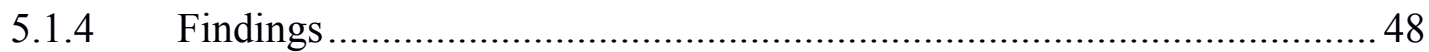

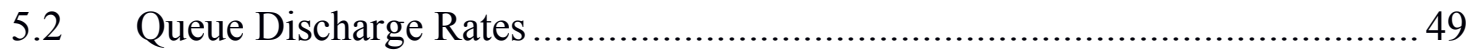

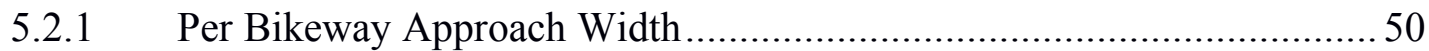

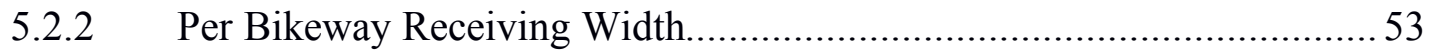

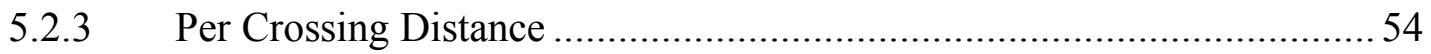

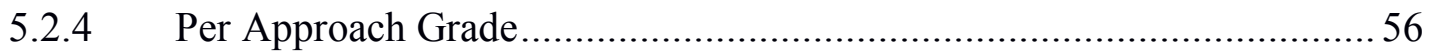

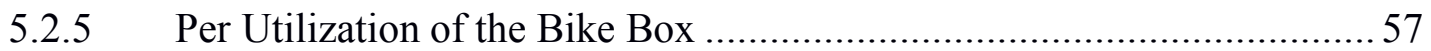

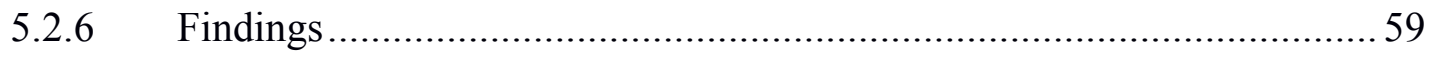




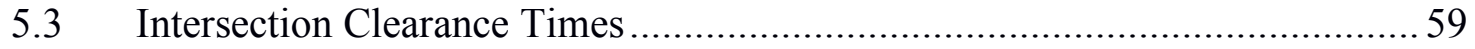

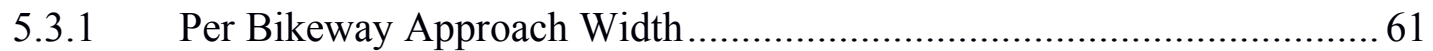

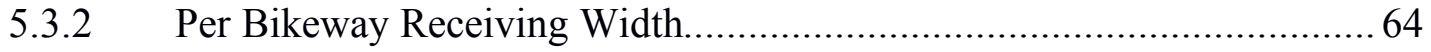

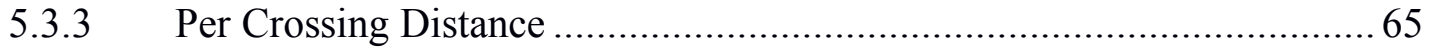

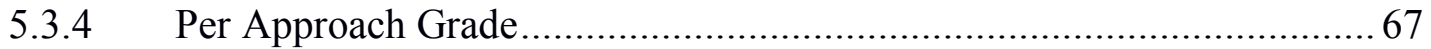

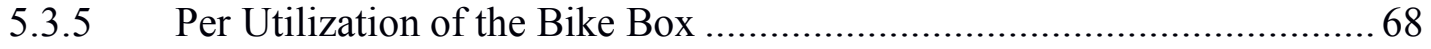

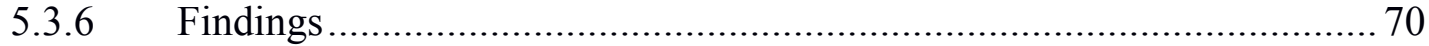

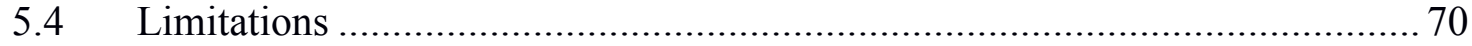

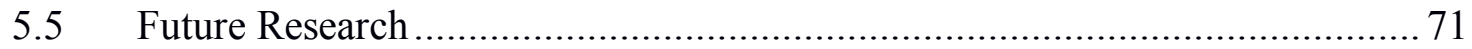

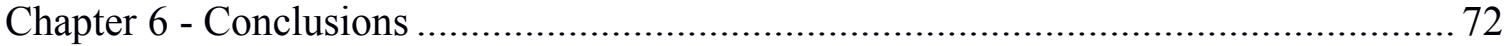

6.1 Implications for Design or Operation of Bicycle Facilities .................................. 73

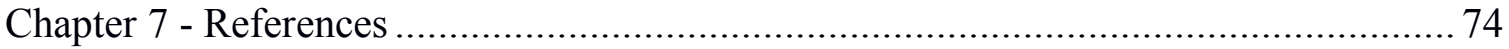

Chapter 8 - Appendix: Excel Spreadsheet of Video Footage Data................................. 75 


\section{List of Tables}

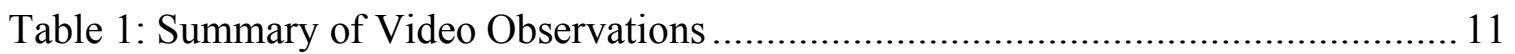

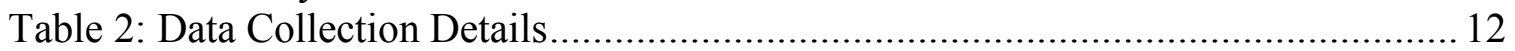

Table 3: Study Approach and Intersection Details ............................................... 17

Table 4: Average, Standard Deviation and Number of Observations of Average Headway

Table 5: Average, Standard Deviation and Number of Observations of Average Headway

based on Bikeway Approach Width................................................................. 43

Table 6: Average, Standard Deviation and Number of Observations of Average Headway

based on Approach Grade ............................................................................. 45

Table 7: Average, Standard Deviation and Number of Observations of Average Headway

based on Utilization of Bike Box............................................................................ 47

Table 8: Average, Standard Deviation and Number of Observations of Queue Discharge

Table 9: Average, Standard Deviation and Number of Observations of Queue Discharge based on Bikeway Approach Width............................................................. 51

Table 10: Average, Standard Deviation and Number of Observations of Queue Discharge

based on Bikeway Receiving Width ............................................................... 53

Table 11: Average, Standard Deviation and Number of Observations of Queue Discharge

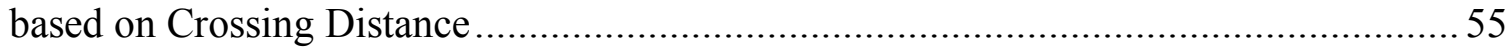

Table 12: Average, Standard Deviation and Number of Observations of Queue Discharge

based on Approach Grade ................................................................................. 56

Table 13: Average, Standard Deviation and Number of Observations of Queue Discharge

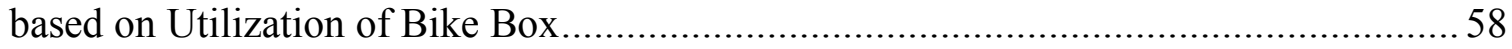

Table 14: Average, Standard Deviation and Number of Observations of Intersection

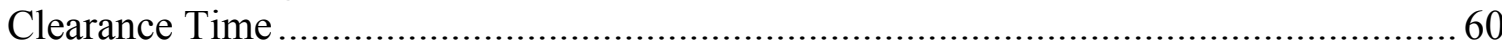

Table 15: Average, Standard Deviation and Number of Observations of Intersection

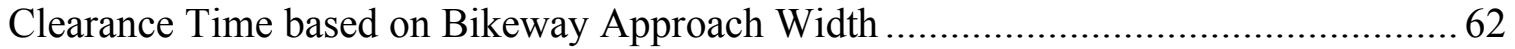

Table 16: Average, Standard Deviation and Number of Observations of Intersection

Clearance Time based on Bikeway Receiving Width................................................ 64

Table 17: Average, Standard Deviation and Number of Observations of Intersection

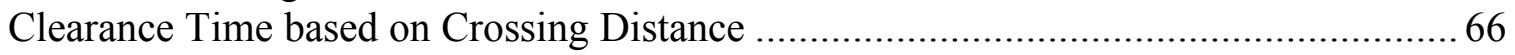

Table 18: Average, Standard Deviation and Number of Observations of Intersection

Clearance Time based on Approach Grade

Table 19: Average, Standard Deviation and Number of Observations of Intersection

Clearance Time based on Utilization of Bike Box 


\section{List of Figures}

Figure 3-1 Histogram of Size of All Observed Queues ................................................. 13

Figure 3-2 Histogram of All Observed Queues at Each Intersection Layout.................... 13

Figure 3-3 Example of the GoPro Data Collection Setup ............................................... 15

Figure 3-4 Example of the Portland State University Type 1 Data Collection Setup ...... 16

Figure 3-5 Vicinity Map / Aerial Photo, N Williams Avenue at Russell Street............... 18

Figure 3-6 Vicinity Map / Aerial Photo, SE Hawthorne Boulevard at Grand Avenue..... 20

Figure 3-7 Vicinity Map / Aerial Photo, NW Broadway at Hoyt Street.......................... 21

Figure 3-8 Vicinity Map / Aerial Photo, SE Madison Street at Grand Avenue (Before) . 23

Figure 3-9 Vicinity Map / Aerial Photo, SE Madison Street at Grand Avenue (After).... 25

Figure 4-1 General Locations of Possible Cyclist Positions for a Standard Bike Lane Approach (Source Image: NACTO Urban Bikeway Design Guide) ...............................29

Figure 4-2 General Locations of Possible Cyclist Positions for a Standard Bike Lane +

Bike Box Approach (Source Image: NACTO Urban Bikeway Design Guide) ................ 30

Figure 5-1 Average Headway for All Observed Queues ............................................... 41

Figure 5-2 Average Headway based on Bikeway Approach Width ................................. 44

Figure 5-3 Average Headway based on Approach Grade .............................................. 46

Figure 5-4 Average Headway based on Utilization of Bike Box ................................... 47

Figure 5-5 Queue Discharge Time for All Observed Queues .........................................50

Figure 5-6 Queue Discharge Time based on Bikeway Approach Width......................... 52

Figure 5-7 Queue Discharge Time based on Bikeway Receiving Width ........................ 54

Figure 5-8 Queue Discharge Time based on Bikeway Crossing Distance ....................... 55

Figure 5-9 Queue Discharge Time based on Approach Grade......................................... 57

Figure 5-10 Queue Discharge Time based on Utilization of the Bike Box .....................58

Figure 5-11 Intersection Clearance Time for All Observed Queues ...............................6 60

Figure 5-12 Intersection Clearance Time based on Bikeway Approach Width ................63

Figure 5-13 Intersection Clearance Time based on Bikeway Receiving Width................65

Figure 5-14 Intersection Clearance Time based on Bikeway Crossing Distance..............66

Figure 5-15 Intersection Clearance Time based on Approach Grade..............................6 68

Figure 5-16 Intersection Clearance Time based on Utilization of the Bike Box............... 69 


\section{Chapter 1 - Introduction}

Improved design of bicycle facilities constructed across the world have been shown to attract a wider-range of bicycle riders and are key to developing more cohesive bike networks within urban and suburban regions. Some routes have attracted a significant increase of cyclists, resulting in revisions to bike facilities along roadways and/or at intersections to better accommodate the increase of bike traffic.

Wider bike facilities intuitively accommodate a greater number of cyclists in the same amount of time, but the specific characteristics associated with widely varying widths and/or types of bike facilities has not been thoroughly documented, especially in a North American context.

Better understanding the performance characteristics associated with bicyclists at signalized intersections will aid in improving the accuracy of traffic models for complex intersections where the flow of bike traffic can substantially influence the flow of motorized vehicle traffic. As urban and suburban intersections become more congested while our regions grow in population, such knowledge could allow for the identification of solutions that improve intersection operation efficiencies for both bike traffic and motorized vehicle traffic.

\subsection{Background}

This research is a partial continuation of previous research (Monsere, et al. 2013). Section 5.2 of the prior research reviewed discharge characteristics of cyclist queues at the 
intersection of SE Madison Street at SE Grand Avenue in Portland, Oregon, based on video footage from before and after installation of a bike box at the intersection.

The prior research identified that discharge characteristics of queues of cyclists starting from bike boxes had not been previously quantified. The research examined 99 queues that occurred before the installation of the bike box and 143 queues that occurred after the installation of the bike box.

The prior research was used and expanded upon to develop this research. Additional observations of queues at the prior study intersection were performed, as well as observations at various other intersections, to create a more robust set of data.

\section{$1.2 \quad$ Research Objectives}

The objective of this research was to quantify and build upon a basic understanding of performance characteristics associated with stopped groups of cyclists at signalized intersections, based on the type of bike facility. The different types of bike facilities were compared to identify physical aspects that may contribute to more efficient intersection operations.

The focus of this research analyzed different study intersections with queues of cyclists based on: the average headway within queues, the time required for queues to enter the intersection, the time required for queues to clear the intersection, the number of cyclists within the queues, the width of the bicycle facilities, the approach grade, and the utilization of a bike box at the intersection approach if it was present. 


\subsection{Organization}

The remainder of this report is organized in the following chapters:

- Chapter 2 - Literature Review: Current knowledge and published literature was reviewed for material related to the topic.

- Chapter 3 - Data Assembly: A description of the data assembled for the research.

- Chapter 4 - Data Reduction Methodology: A description of how data were extracted from the video footage for analysis.

- Chapter 5 - Analysis and Results: A summary of the comparative analysis of bicycle performance characteristics associated with stopped groups of cyclists at a variety of signalized intersections.

- Chapter 6 - Conclusions: Conclusions and findings of the research.

- Chapter 7 - References: References mentioned within the research.

The appendix of the research includes the following:

- Chapter 8 - Appendix: Excel Spreadsheet of Video Footage Data 


\section{Chapter 2 - Literature Review}

The literature currently available that is related to performance characteristics of queues of bicyclists stopped at signalized intersections is presented within this chapter. The performance characteristics of focus for this research consist of headway, queue discharge rates, and intersection clearance time.

\subsection{General Effect of Queues of Bicyclists at Signalized Intersections}

It is likely intuitive, yet important to note, that heterogeneous / mixed traffic systems operate very differently compared to homogeneous traffic systems. Traffic in mixed flow conditions can be comprised of a combination of motorized and non-motorized vehicles (Dey, Nandal and Kalyan 2013).

While substantial information is known about the capacity of signalized intersections with respect to motorized vehicles, as recent as two decades ago research had acknowledged relatively little empirical research had been conducted regarding the effect of bicycles on signalized intersection capacity (Allen, et al. 1998). The purpose of the research was to quantify the effects of bicycles on signalized intersection capacity through the videotaping of several intersections that had significant bicycle traffic. The proposed procedure yielded lower saturation flows and capacities as compared to the Highway Capacity Manual (HCM) procedure that was available at the time. Based on the empirical data, when combined with pedestrian effects, it was found that the impact of bicycles on the saturation flow of automotive lanes containing right-turning vehicles was probably more detrimental than previously believed, and the motor vehicle capacities of intersections with significant bicycle and pedestrian traffic may be overestimated if using the HCM procedure. 
Later research had similar findings, where the analytical results indicated capacity was being overestimated through the HCM 2000 capacity model (Wang, et al. 2011).

The importance of better understanding the relationship between bicycle traffic and motorized vehicle traffic flows was documented within research (Tarko and Tracz 2000) that stated "existing capacity manuals for signalized intersections admit rather considerable standard errors of saturation flow prediction reaching $8-10 \%$. Errors in saturation flow predictions carry over to delay estimates and, consequently, they may lead to erroneous LOS estimates." The research also mentioned that there is a strong need to improve the predictive methods of saturation flow rates as prediction errors in saturation flow rates may cause difficulties in correct determination of level of service (LOS) - one of the main objectives in evaluating signalized intersections. Based on the findings of the research, an incorrect LOS may be different from the actual one by up to three category levels.

In the goal to develop a relationship between bicycle traffic and motorized vehicle traffic, research found that bicycle fluid diffusion at a signalized intersection had a great impact on straight and right-turning vehicles, particularly right-turning vehicles (Lilan, et al. 2009). Similarly, it was found that straight and right-turning vehicles also produce an impact on the normal flow of bicycle traffic. This mutual influence constraints the performance of each, causing slow down for both bicycles and motorized vehicles through the intersection.

Similar research also studied the capacity of signalized intersections influenced by bicycle traffic (Chen, Shao and Yue 2007). In a quantitative form, one study found that the capacity 
of right-turning motorized vehicles at signalized intersections is greatly impacted when hourly bicycle volumes enter the range of 500 to 1,500 bicycles (Qian and Niu 2010).

Other research explored strategies that segregate distinct modes along the approach and more effectively resolve the disruptive capacity-reducing conflicts that arise between through moving and turning traffic traveling in adjacent lanes. One paper proposed schemes that produce capacities that consistently and significantly reduce travel delays for all modes (Xuan, et al. 2009). One such scheme consisted of priority treatment, which enables one mode to proceed through the intersection ahead of the other mode, such as a bicycle box.

However, more recent research has made the point that the characteristics of bicycle movements at signalized intersections in China, where much of the referenced research has taken place, are very different from those in the United States (Guo, et al. 2012). The research produced a model, the results of which were compared to real-world observations and was reportedly a better match as compared to the HCM model. The research team made the claim that their model could supplement the content of the signalized intersection capacity analysis method in the HCM and provide the basis for design of intersection signal timing and capacity calculation under mixed traffic conditions at signalized intersections.

\subsection{Bicycle Saturation Flow Rates}

The saturation flow rate for bicycles at intersections represents the potential number of bicycles per hour that could pass through a signalized intersection if the green signal indication was provided for the full hour (Raksuntorn and Khan 2003). The research went

on to describe how bicycles may form more than one queue within a bike lane at the 
approach to the intersection. Since bicycles maintain a certain distance from the adjacent lane and the curb, the number of queues formed varies based on the width of the bike lane. Therefore, the saturation flow rate for a bicycle lane depends on the width of the bike lane.

The saturation flow rate for bicycles is estimated from a procedure similar to determining the saturation flow rate for motorized vehicles, based on calculating the saturation headway using Equation ( 1 ).

$$
s_{b}=3600 / h_{b}
$$

Where:

$s_{b}=$ saturation flow rate for the bike facility (bikes per hour)

$h_{b}=$ saturation headway for bicycles (seconds)

With the lack of robust data related to this topic, research has recommended future studies be performed based on additional data collected at intersections with high bicycle volumes to examine the factors affecting the saturation flow rate for bicycles at signalized intersections (Raksuntorn and Khan 2003).

For purposes of comparison, the 2010 Highway Capacity Manual (HCM 2010) recommends a saturation flow rate of 2,000 bicycles per hour for a bike lane at a signalized intersection (Transportation Research Board 2010).

\subsection{Bicyclist Perception/Reaction and Start-up Lost Time}

To determine the saturation flow rate of a bike facility, it is required to understand that the beginning of all queues encounter a perception/reaction and start-up lost time associated with perceiving and reacting to a change in the traffic signal indication, and then accelerating up to speed (Monsere, et al. 2013). 
Understanding the perception/reaction and start-up lost time helps determine the saturation headway that can be sustained once the queue is large enough to experience such an effect. The perception/reaction time is typically accounted for at the very beginning of the queue as the traffic signal changes to green. The start-up lost time typically continues from the beginning of the queue until a certain number of vehicles have entered the intersection and start-up lost time no longer influences the headways within the queue. From this point on headways within the queue will remain relatively constant until all vehicles in the queue have passed or the green time has ended (Dey, Nandal and Kalyan 2013).

Research that explored start-up lost time noted the first five bicyclists in a queue tended to experience a combined 2.5 seconds of start-up lost time. After the fifth bicyclist, the effects of start-up lost time were minimal as the headways between the bicyclists remained constant (Raksuntorn and Khan 2003).

\subsection{Bicycle Headway}

The HCM 2010 states that the headway for the first vehicle is the "elapsed time, in seconds, between the initiation of the green and the front wheels of the first vehicle crossing over the stop line" (Transportation Research Board 2010). Headways for subsequent vehicles are equal to the elapsed time between the front wheels of said vehicle and the one prior (Monsere, et al. 2013).

Recent research resulted in a saturation headway of approximately 1.0 second per cyclist within a bike lane five feet wide for cyclists positioned fifth or higher within the queue, equivalent to a saturation flow rate of 3,610 cyclists per hour (Monsere, et al. 2013). Earlier 
research of a bike lane eight feet wide demonstrated that headways between bicycles remained constant after the fifth bicycle in the queue, the saturation headway was 0.8 seconds, and the equivalent saturation flow rate was estimated to be 4,500 bicycles per hour of green (Raksuntorn and Khan 2003).

The research reported that both saturation headway and saturation flow rate may be a function of the width of the bicycle lane (Raksuntorn and Khan 2003). However, since bicycles maintain a certain distance from adjacent lanes and curbs, there is unused travel space on both sides of the bike lane. The proportion of the unused travel space relative to the total width decreases as the width of the bike lane increases. Therefore, with a wider bike lane, a higher proportion of space is available as effective travel space as compared to a narrow bike lane. For example, the research identified the following number of bicycle sub-lanes per bike facility width: one sub-lane for a facility three feet wide, one to two at four feet wide, two at five to six feet wide, three at eight feet wide, and four to five at 10 feet wide.

\subsection{Bicycle Queue Discharge Times}

Prior research determined queue discharge characteristics for one signalized intersection using footage from before and after installation of a bike box (Monsere, et al. 2013). A clear relationship between queue size and discharge time was evident for both study scenarios. The addition of a bike box decreased the discharge time for queues of equal length, as compared to a bike lane without a bike box at the same intersection. Additionally, the reduction in discharge time associated with the introduction of the bike box increased with larger queue sizes. 


\subsection{Bicycle Queue Intersection Clearance Times}

Research found that the time required for a queue to clear an intersection, for queues of four or fewer cyclists, appears to be similar for both standard width bike lanes or relatively wider bike facilities (Monsere, et al. 2013). However, the intersection clearance times for queues of five or more cyclists tend to be less for wider bike facilities.

The research identified that the relationship of queue size to intersection clearance time for a standard bike lane was positive and linear, whereas with a bike box the relationship was positive and nonlinear. The addition of the bike box resulted in reduced intersection clearance times.

\subsection{Summary}

While the general effects of queues of bicyclists at signalized intersections on overall traffic operations are well known, the precise impact to traffic flow based on queue size and width of bike facility is not fully known.

The review of several queue discharge characteristics of queues of bicyclists at various signalized intersections will assist in developing a better understanding of the flow of bicycle traffic.

Chapter 3 will review the data collection procedures and data sources that were used to expand upon the prior research described within this chapter. 


\section{Chapter 3 - Data Assembly}

This chapter describes data collection procedures and data sources used to obtain desirable video footage. Data collection took place at several signalized intersections within Portland, Oregon.

\subsection{Data Collection Overview}

The objective of the video data collection was to obtain observations of cyclists discharging from a stationary queue of cyclists at signalized intersections in Oregon. Table 1 presents a summary of observations collected from video footage; a total of 2,820 cyclists within 630 groups of queued cyclists were observed at five different intersection layouts.

Table 1: Summary of Video Observations

\begin{tabular}{llcc}
\hline Study Roadway & Intersecting Roadway & $\begin{array}{c}\text { \# of Queues } \\
\text { Observed }\end{array}$ & $\begin{array}{c}\text { Total \# of Queued } \\
\text { Cyclists Observed }\end{array}$ \\
\hline N Williams Avenue & N Russell Street & 169 & 565 \\
$\begin{array}{l}\text { SE Hawthorne } \\
\text { Boulevard }\end{array}$ & SE Grand Avenue & 52 & 194 \\
$\begin{array}{l}\text { NW Broadway } \\
\begin{array}{l}\text { SE Madison Street } \\
\text { (Before Bike Box) }\end{array}\end{array}$ & NE Hoyt Street & 136 & 564 \\
$\begin{array}{l}\text { SE Madison Street } \\
\text { (After Bike Box) }\end{array}$ & SE Grand Avenue & 104 & 594 \\
\hline & & 169 & 903 \\
\hline
\end{tabular}

The dates of data collection and additional details about footage obtained at each intersection are summarized in Table 2. 
Table 2: Data Collection Details

\begin{tabular}{|c|c|c|c|c|c|c|c|}
\hline \multirow[t]{2}{*}{ Intersection } & \multicolumn{7}{|c|}{ Footage Details } \\
\hline & $\begin{array}{l}\text { Date(s) } \\
(\mathbf{M M / D D / Y Y Y Y )}\end{array}$ & $\begin{array}{l}\text { Day of } \\
\text { Week }\end{array}$ & $\begin{array}{l}\text { Start } \\
\text { Time }\end{array}$ & $\begin{array}{l}\text { End } \\
\text { Time }\end{array}$ & Hours & $\begin{array}{l}\text { \# of } \\
\text { Queues }\end{array}$ & $\begin{array}{l}\text { \# of } \\
\text { Cyclists }\end{array}$ \\
\hline $\begin{array}{l}\text { N Williams Avenue } \\
\text { at } \\
\text { N Russell Street }\end{array}$ & $\begin{array}{l}8 / 20 / 2013 \\
8 / 21 / 2013 \\
8 / 22 / 2013 \\
8 / 23 / 2013\end{array}$ & $\begin{array}{l}\text { Tuesday } \\
\text { Wednesday } \\
\text { Thursday } \\
\text { Friday }\end{array}$ & $\begin{array}{l}17: 30 \\
17: 30 \\
16: 30 \\
16: 30\end{array}$ & $\begin{array}{l}18: 30 \\
18: 30 \\
18: 30 \\
18: 30\end{array}$ & $\begin{array}{l}1: 00 \\
1: 00 \\
2: 00 \\
2: 00\end{array}$ & $\begin{array}{l}31 \\
29 \\
59 \\
50\end{array}$ & $\begin{array}{l}111 \\
110 \\
193 \\
151\end{array}$ \\
\hline $\begin{array}{l}\text { SE Hawthorne } \\
\text { Boulevard at } \\
\text { SE Grand Avenue }\end{array}$ & $10 / 13 / 2014$ & Monday & $16: 15$ & $18: 00$ & $1: 45$ & 52 & 194 \\
\hline $\begin{array}{l}\text { NW Broadway at } \\
\text { NW Hoyt Street }\end{array}$ & $\begin{array}{l}8 / 13 / 2013 \\
8 / 14 / 2013 \\
8 / 15 / 2013 \\
8 / 16 / 2013\end{array}$ & $\begin{array}{l}\text { Tuesday } \\
\text { Wednesday } \\
\text { Thursday } \\
\text { Friday }\end{array}$ & $\begin{array}{l}06: 30 \\
06: 30 \\
06: 30 \\
06: 30\end{array}$ & $\begin{array}{l}09: 08 \\
09: 30 \\
09: 30 \\
09: 30\end{array}$ & $\begin{array}{l}2: 38 \\
3: 00 \\
3: 00 \\
3: 00\end{array}$ & $\begin{array}{l}35 \\
29 \\
44 \\
28\end{array}$ & $\begin{array}{l}146 \\
134 \\
177 \\
107\end{array}$ \\
\hline $\begin{array}{l}\text { SE Madison Street at } \\
\text { SE Grand Avenue } \\
\text { (Before Bike Box) }\end{array}$ & $\begin{array}{l}9 / 23 / 2010 \\
9 / 24 / 2010 \\
9 / 28 / 2010\end{array}$ & $\begin{array}{l}\text { Thursday } \\
\text { Friday } \\
\text { Tuesday }\end{array}$ & $\begin{array}{l}\text { 06:00 } \\
\text { 08:00 } \\
07: 00\end{array}$ & $\begin{array}{l}10: 00 \\
10: 00 \\
10: 00\end{array}$ & $\begin{array}{l}4: 00 \\
2: 00 \\
3: 00\end{array}$ & $\begin{array}{l}51 \\
32 \\
21\end{array}$ & $\begin{array}{l}215 \\
187 \\
192\end{array}$ \\
\hline $\begin{array}{l}\text { SE Madison Street at } \\
\text { SE Grand Avenue } \\
\text { (After Bike Box) }\end{array}$ & $\begin{array}{l}2 / 9 / 2012 \\
2 / 10 / 2012 \\
6 / 28 / 2013 \\
7 / 1 / 2013\end{array}$ & $\begin{array}{l}\text { Thursday } \\
\text { Friday } \\
\text { Friday } \\
\text { Monday }\end{array}$ & $\begin{array}{l}06: 00 \\
06: 00 \\
06: 30 \\
06: 30\end{array}$ & $\begin{array}{l}09: 00 \\
09: 00 \\
10: 00 \\
10: 00\end{array}$ & $\begin{array}{l}3: 00 \\
3: 00 \\
3: 30 \\
3: 30\end{array}$ & $\begin{array}{l}78 \\
22 \\
26 \\
43\end{array}$ & $\begin{array}{l}297 \\
104 \\
186 \\
316\end{array}$ \\
\hline
\end{tabular}

All observed queues are displayed in Figure 3-1 as a histogram based on queue size. A histogram of all observed queues at each intersection layout is displayed in Figure 3-2. 


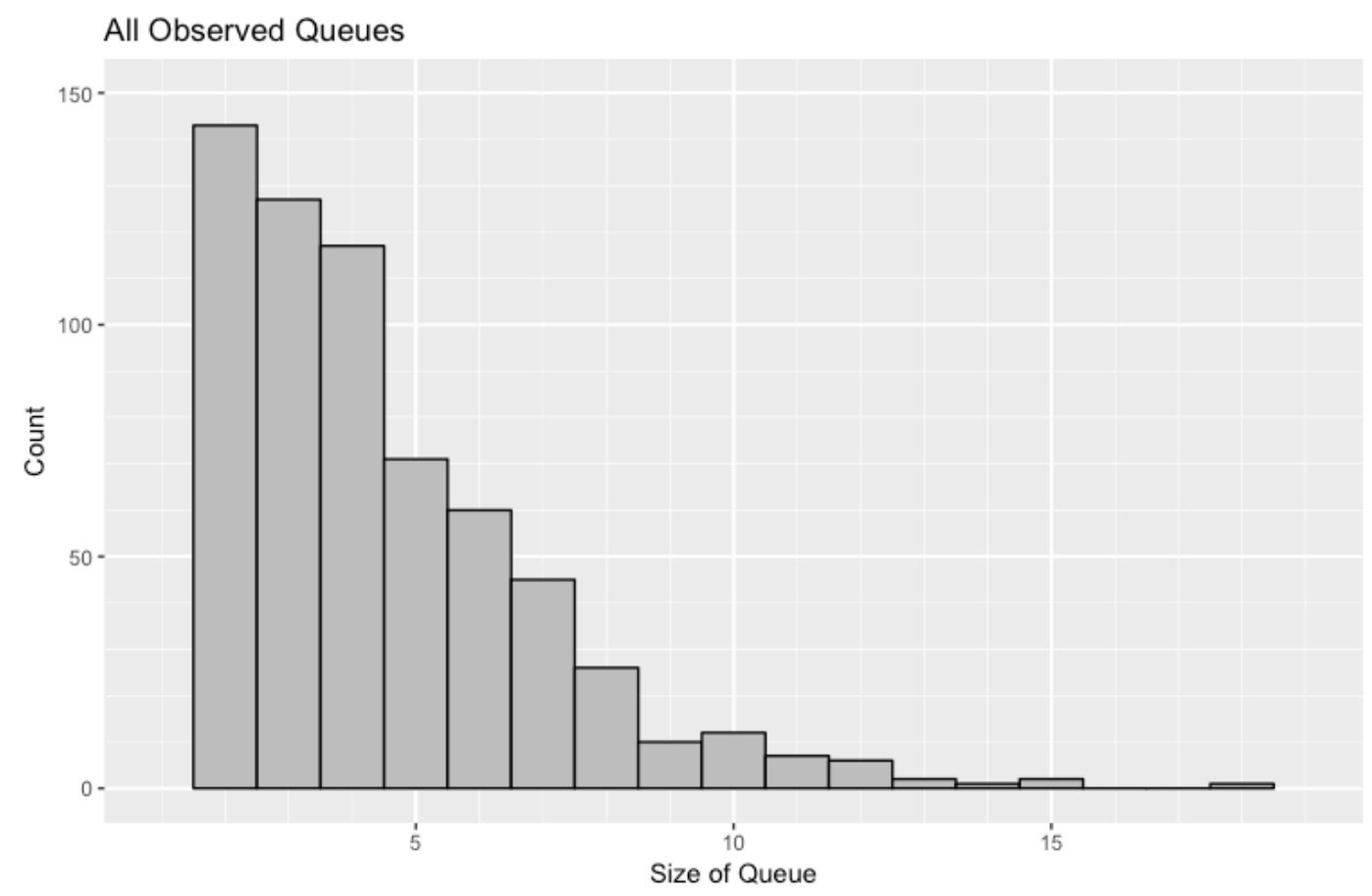

Figure 3-1 Histogram of Size of All Observed Queues
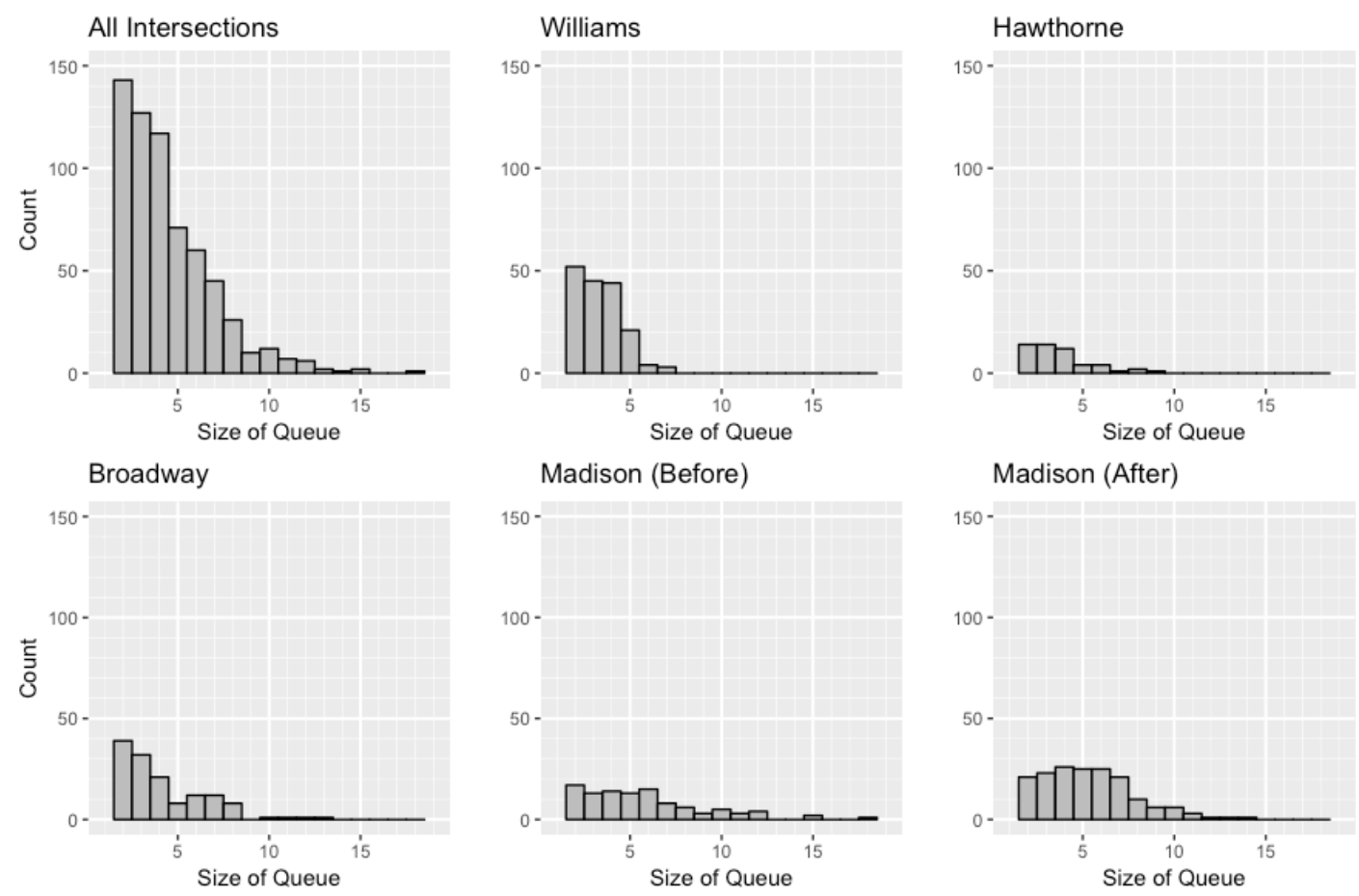

Figure 3-2 Histogram of All Observed Queues at Each Intersection Layout 
The following subsections describe the data collection methods and setup procedures employed at the various study intersections, as well as a detailed description of each intersection where data were collected.

\subsection{Video Recording Descriptions}

Three different methods for obtaining video footage were utilized for this research, described in detail within this subsection.

\subsubsection{GoPro Video Data}

Video footage recorded by a GoPro video unit was collected at one location within Portland, Oregon:

- SE Hawthorne Boulevard at SE Grand Avenue

The setup consisted of a handheld personal GoPro video camera equipped with a single wide-angle lens video camera. The device has a battery and memory card self-contained within the unit. The camera was mounted to a camera tripod attached to a hand railing atop a pedestrian bridge above SE Hawthorne Boulevard. The camera was attended from a location that kept the attendant out of sight of the roadway, with the camera setup located outside the typical line of sight of roadway users.

An example of the setup can be seen in Figure 3-3. Footage from the single camera captured all desired movements that took place within the study intersection. 


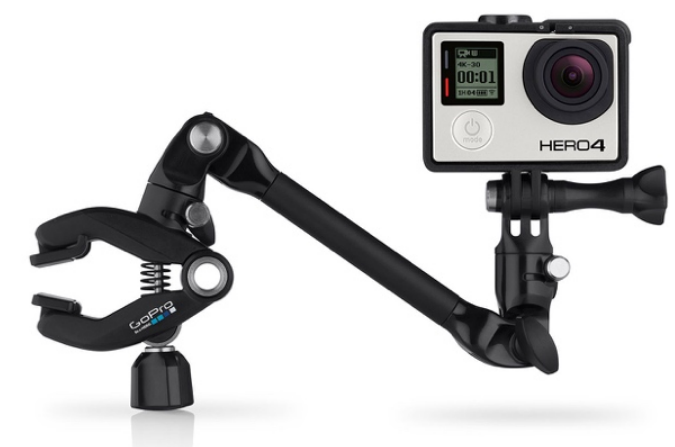

Figure 3-3 Example of the GoPro Data Collection Setup

\subsubsection{Portland State University Type 1 Video Data}

Portland State University Type 1 video footage was recorded at three locations within Portland, Oregon:

- N Williams Avenue at N Russell Street

- NW Broadway at NW Hoyt Street

- SE Madison Street at SE Grand Avenue (After Installation of Bike Box)

The setup consisted of a portable video footage collection system equipped with two camera inputs. The device also contained a battery and digital video recorder (DVR). Two wide-angle lens video cameras were utilized and were mounted on a pole separate from the recording device, with the cameras and recording device connected by electronic cables. The entire setup was located outside the typical line of sight of roadway users.

An example of the setup can be seen in Figure 3-4. Footage from the two cameras captured all desired movements that took place within the study intersection. 


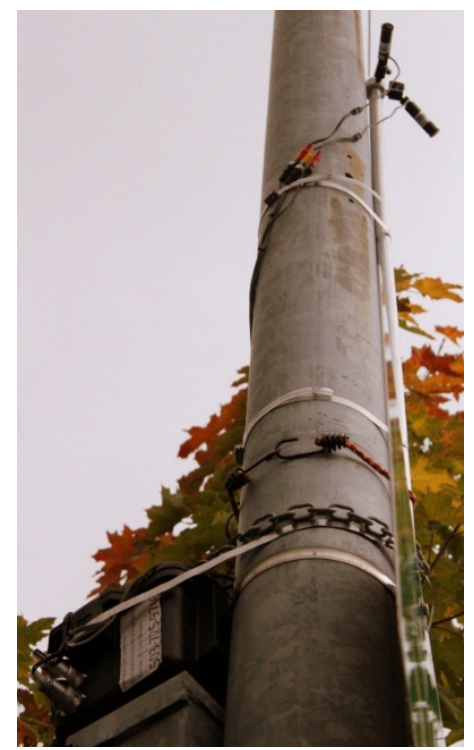

Figure 3-4 Example of the Portland State University Type 1 Data Collection Setup

\subsubsection{Portland State University Type 2 Video Data}

Video footage associated with one intersection was available from prior research that analyzed bicyclists' performance characteristics at signalized intersections (Wheeler, Conrad and Figliozzi 2010). Footage was recorded in a manner consistent with PSU Type 1 footage (as described within Section 3.2.2) at the following location:

- $\quad$ SE Madison Street at SE Grand Avenue (Before Installation of Bike Box)

The video footage allowed for a before/after analysis of two different intersection layouts associated with a restriping and lane reconfiguration that took place at a single location.

\subsection{Intersection Descriptions}

Data were collected from five different intersection layouts. This subsection provides a description of each intersection with the specific approach of main interest described first. An aerial photo and vicinity map is provided for each study intersection. The intersection 
approach for which data were collected is identified on the aerial image with a blue arrow.

Details are summarized in Table 3.

Table 3: Study Approach and Intersection Details

\begin{tabular}{|c|c|c|c|c|}
\hline Approach at Intersection & $\begin{array}{l}\text { Study } \\
\text { Approach }^{a} \\
\text { [ Grade] }\end{array}$ & $\begin{array}{l}\text { Approach } \\
\text { Features } \\
\text { [width or area] }\end{array}$ & $\begin{array}{l}\text { Receiving } \\
\text { Features } \\
\text { [widths] }\end{array}$ & $\begin{array}{l}\text { Intersection } \\
\text { Crossing } \\
\text { Distance (ft) }\end{array}$ \\
\hline $\begin{array}{l}\text { N Williams Avenue at } \\
\text { N Russell Street }\end{array}$ & $\mathrm{NB}[+1 \%]$ & $\mathrm{BL}\left[6^{\prime}\right]$ & BL [6’] & 60 \\
\hline $\begin{array}{l}\text { SE Hawthorne Boulevard at } \\
\text { SE Grand Avenue }\end{array}$ & EB $[-4 \%]$ & $\mathrm{BBL}\left[5^{\prime}+7^{\prime}\right]$ & $\mathrm{BL}\left[6.5^{\prime}\right]$ & 56 \\
\hline $\begin{array}{l}\text { NW Broadway at } \\
\text { NW Hoyt Street }\end{array}$ & SB $[-4 \%]$ & $\begin{array}{c}\text { BBL }\left[3^{\prime}+7^{\prime}\right] \\
+ \\
\text { BB [21x19'] }\end{array}$ & BBL $\left[3^{\prime}+7^{\prime}\right]$ & 46 \\
\hline $\begin{array}{l}\text { SE Madison Street at } \\
\text { SE Grand Avenue } \\
\text { (Before Bike Box) }\end{array}$ & WB $[+2 \%]$ & $\mathrm{BL}\left[5^{\prime}\right]$ & $\begin{array}{l}\mathrm{BL}\left[5^{\prime}\right] \\
\quad+ \\
\mathrm{BL}\left[5^{\prime}\right]\end{array}$ & 54 \\
\hline $\begin{array}{l}\text { SE Madison Street at } \\
\text { SE Grand Avenue } \\
\text { (After Bike Box) }\end{array}$ & $\mathrm{WB}[+2 \%]$ & $\begin{array}{c}\mathrm{BL}\left[5^{\prime}\right] \\
+ \\
\mathrm{BB}\left[15 \times 20^{\prime}\right]\end{array}$ & $\begin{array}{l}\text { BL }\left[5^{\prime}\right] \\
\quad+ \\
\text { BL }\left[5^{\prime}\right]\end{array}$ & 54 \\
\hline
\end{tabular}

a) $N B=$ northbound, $E B=$ eastbound, $S B=$ southbound, $W B=$ westbound; Grade was estimated from elevation data within Google Earth between 50-100 feet in advance of the stop bar.

b) $B L=$ bike lane [lane width], $B B L=$ buffered bike lane [buffer width + lane width], BB = bike box [width $x$ length]

\subsubsection{N Williams Avenue at N Russell Street}

This four-legged intersection consists of a one-way street ( $\mathrm{N}$ Williams Avenue) intersecting with a two-way street (N Russell Street).

At the time that data collection took place the $\mathrm{N}$ Williams Avenue approach had two motor vehicle lanes oriented in the northbound direction, a painted bike lane located to the right of the two motor vehicle lanes, and a parking lane on both sides of the roadway. The bike 
lane was measured to be six feet wide before and after the intersection. The distance between the two crosswalks perpendicular to the northbound bike lane was measured to be approximately 60 feet.

The N Russell Street approach had one standard motor vehicle lane in each direction, a painted bike lane located to the right of each standard motor vehicle lane, a dedicated leftturn lane within the eastbound approach, and a parking lane on both sides of the roadway west of N Williams Avenue.

Data were collected in August 2013 in clear weather conditions. Bicyclists were controlled by standard vehicle signals on both approaches. An aerial photo and vicinity map of the intersection is shown in Figure 3-5.

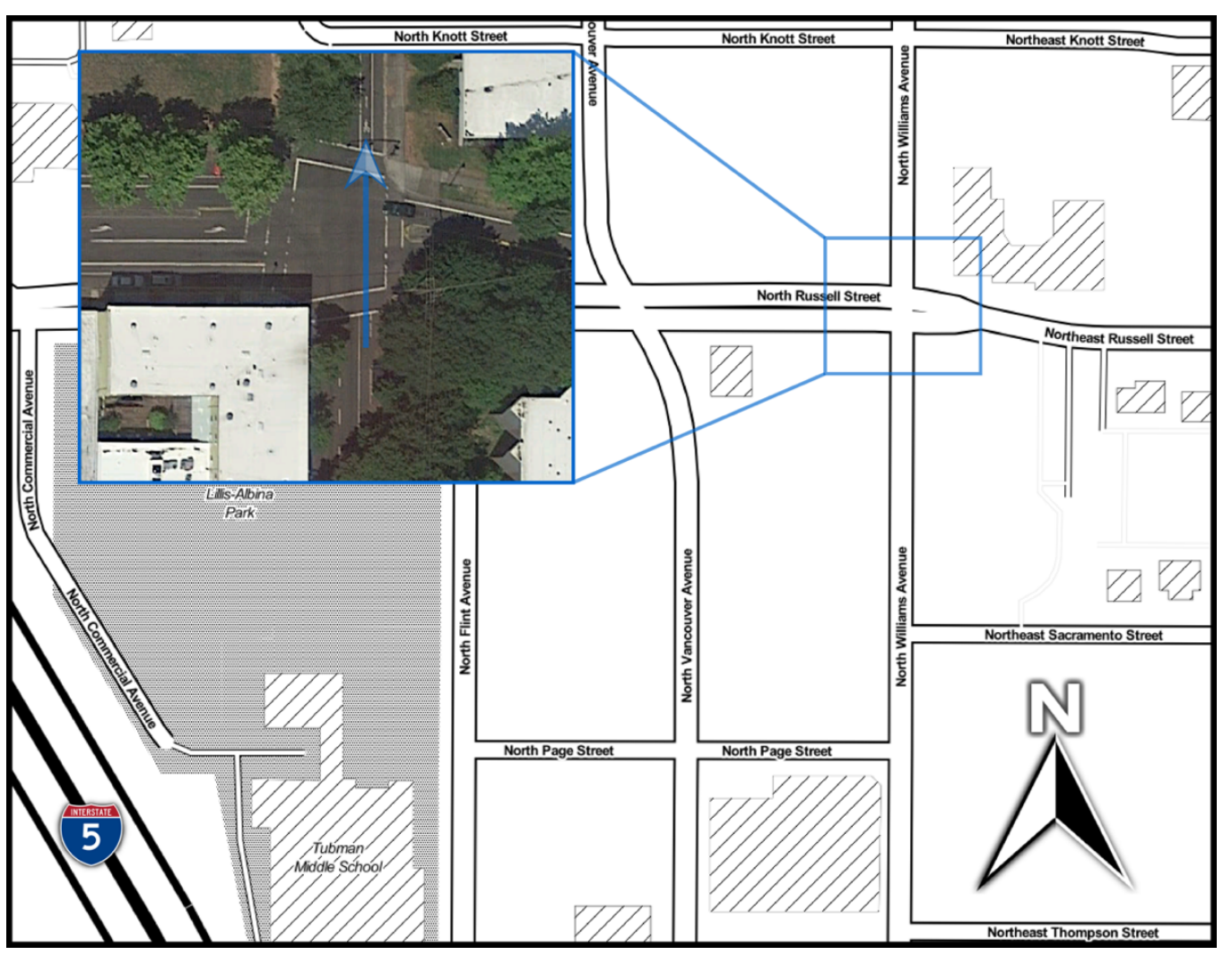

Figure 3-5 Vicinity Map / Aerial Photo, N Williams Avenue at Russell Street 


\subsubsection{SE Hawthorne Boulevard at SE Grand Avenue}

This four-legged intersection consists of a one-way street (SE Hawthorne Boulevard) intersecting with another one-way street (SE Grand Avenue).

At the time that data collection took place the SE Hawthorne Boulevard approach had two motor vehicle lanes oriented in the eastbound direction and a painted buffered bike lane located to the right of the two motor vehicle lanes. The painted buffer between the motor vehicle lanes and the bike lane in advance of the intersection was measured to be five feet wide. There was no painted buffer area after the intersection. The bike lane was measured to be seven feet wide in advance of the intersection and 6.5 feet wide after the intersection. The distance between the two crosswalks perpendicular to the eastbound bike lane was measured to be approximately 56 feet.

The SE Grand Avenue northbound approach had three standard vehicle lanes, a shared vehicle/streetcar lane to the right of the three standard lanes, and a parking lane on both sides of the roadway.

Data were collected in October 2014 in clear weather conditions. Bicyclists were controlled by standard vehicle signals on both approaches. An aerial photo and vicinity map of the intersection is shown in Figure 3-6. 


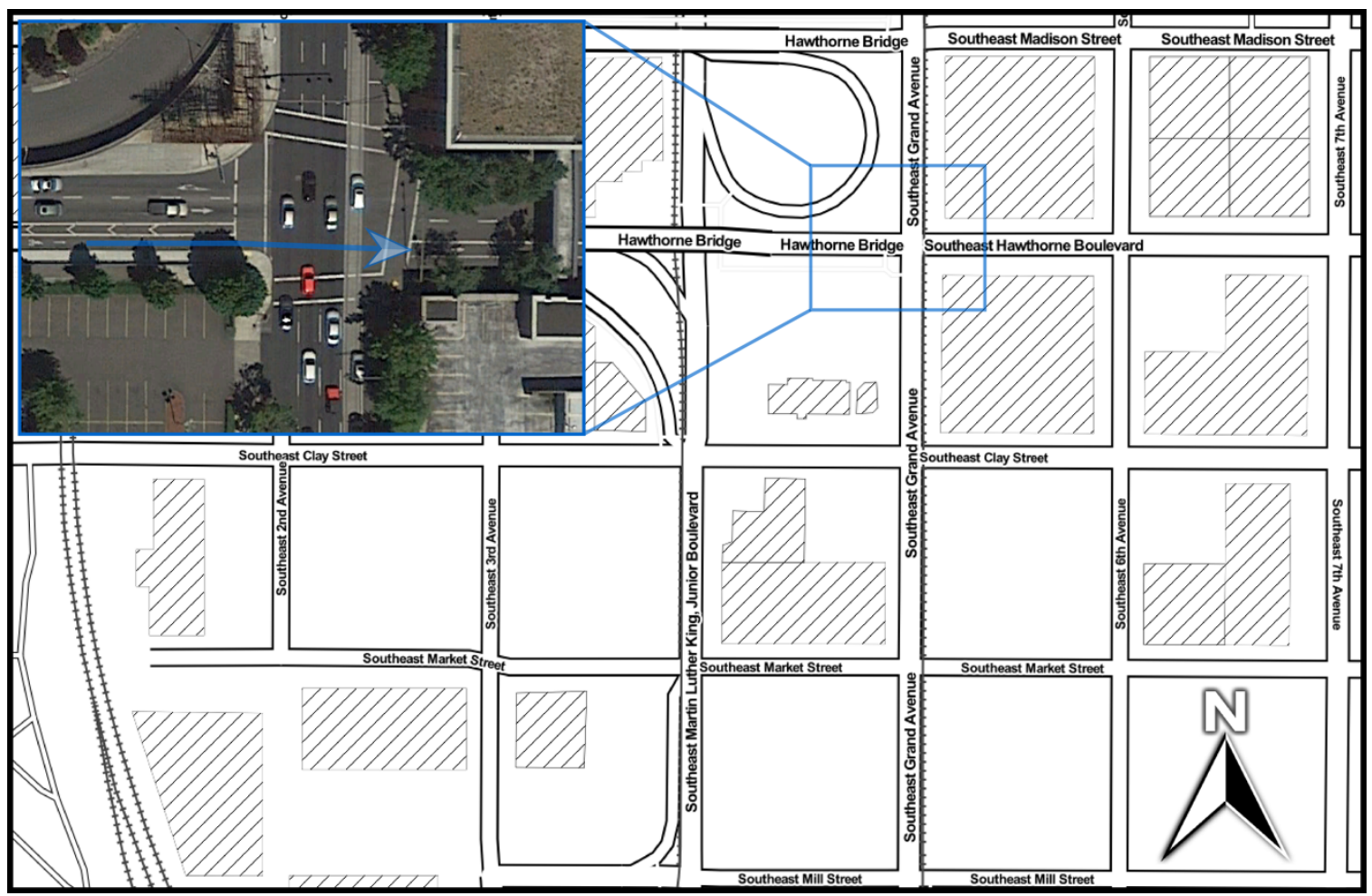

Figure 3-6 Vicinity Map / Aerial Photo, SE Hawthorne Boulevard at Grand Avenue

\subsubsection{NW Broadway at NW Hoyt Street}

This four-legged intersection consists of a two-way street (NW Broadway) intersecting with another two-way street (NW Hoyt Street).

The NW Broadway southbound approach had two motor vehicle lanes and a painted buffered bike lane located to the right of the two motor vehicle lanes. The painted buffer between the motor vehicle lanes and the bike lane was measured to be three feet wide. The bike lane was measured to be seven feet wide. The bike lane connected to an uncolored bike box at the intersection approach that was measured to be approximately 21 feet wide and 19 feet deep. The roadway layout associated with southbound travel lanes and dimensions of the painted buffered bike lane also apply to the segment of roadway 
immediately south of the study intersection. The distance between the two crosswalks perpendicular to the southbound bike lane was measured to be approximately 46 feet.

The NW Broadway northbound approach had a standard vehicle lane and a parking lane located to the right of the standard lane.

The NW Hoyt Street approaches had one standard vehicle lane in each direction, a dedicated left-turn lane within the eastbound approach, and a parking lane to the right of each standard lane.

Data were collected in August 2013 in clear weather conditions. Bicyclists were controlled by standard vehicle signals on all approaches. An aerial photo and vicinity map of the intersection is shown in Figure 3-7.

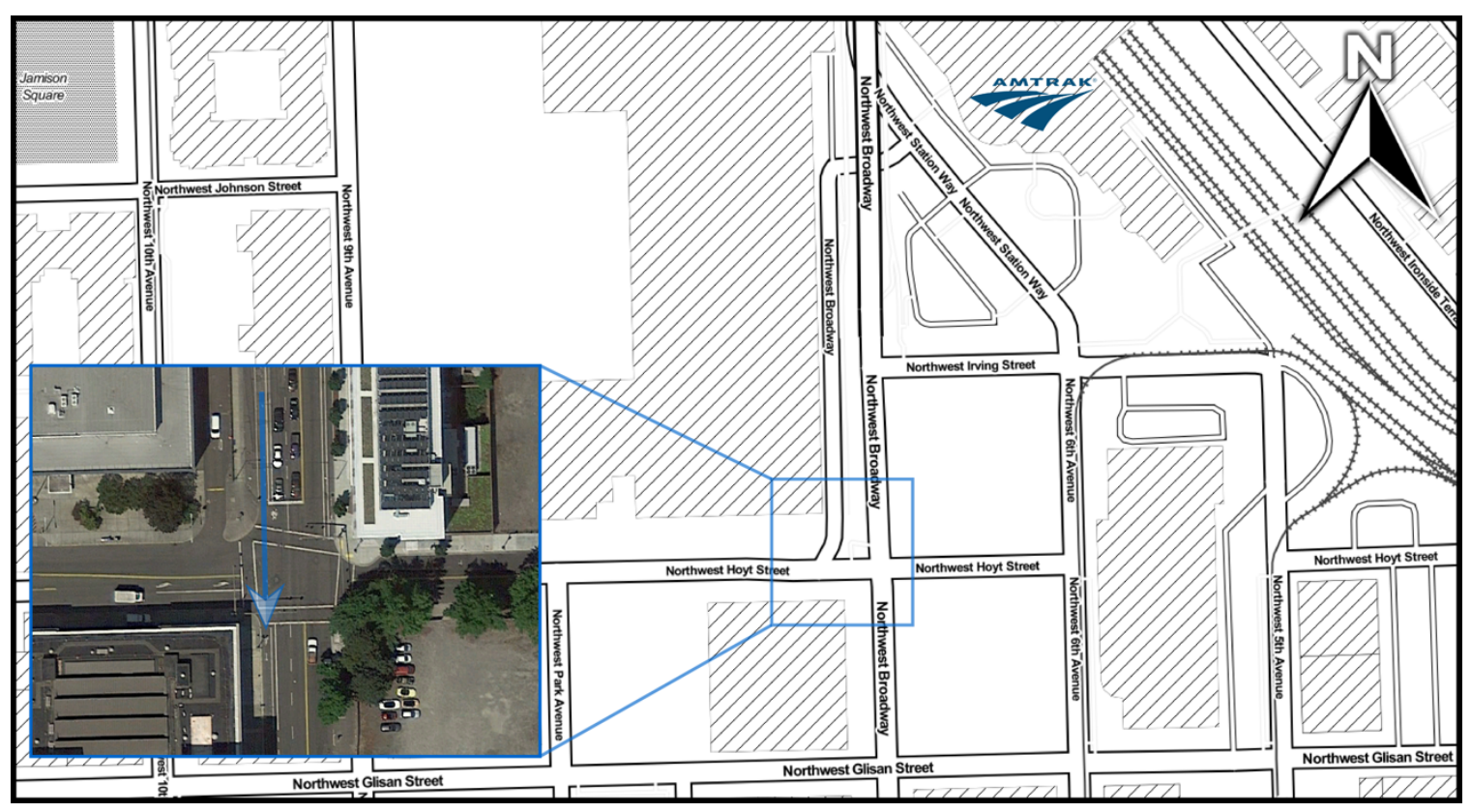

Figure 3-7 Vicinity Map / Aerial Photo, NW Broadway at Hoyt Street 


\subsubsection{SE Madison Street at SE Grand Avenue - Before Bike Box}

This four-legged intersection consists of a one-way street (SE Madison Street) intersecting with another one-way street (SE Grand Avenue).

At the time that data collection took place for this analysis scenario the SE Madison Street approach had two standard motor vehicle lanes oriented in the westbound direction, a painted bike lane located to the right of the two standard motor vehicle lanes, and a shared right-turn-only/except-bus lane to the right of the bike lane. The bike lane was measured to be five feet wide in advance of the intersection and as wide as 10 feet after the intersection. The receiving bike facility was marked as two bike lanes each five feet wide to accommodate the relatively large numbers of bicyclists that routinely travel westbound through the intersection during the weekday morning peak hours. The distance between the crosswalk perpendicular to the westbound bike lane and the area immediately west of the northbound travel lanes was measured to be approximately 54 feet.

The SE Grand Avenue northbound approach had four standard vehicle lanes and a parking lane on the east side of the roadway.

Data were collected in September 2010 in clear weather conditions. Bicyclists were controlled by standard vehicle signals on both approaches. An aerial photo and vicinity map of the intersection is shown in Figure 3-8. 


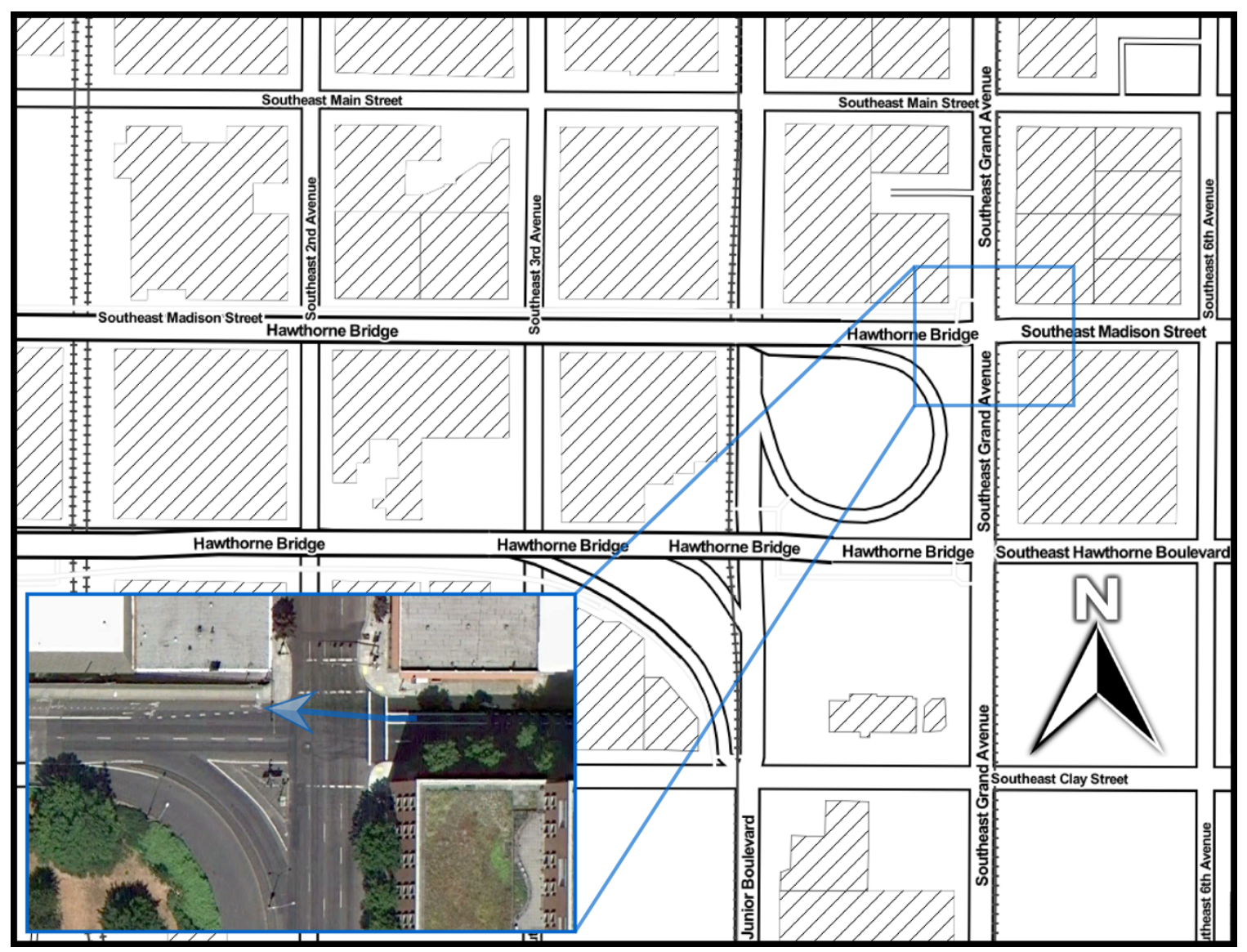

Figure 3-8 Vicinity Map / Aerial Photo, SE Madison Street at Grand Avenue (Before)

\subsubsection{SE Madison Street at SE Grand Avenue - After Bike Box}

This study intersection is the same intersection location as described within Section 3.3.4.

The differences between this analysis scenario and the scenario described within Section 3.3.4 relate to striping revisions associated with the SE Madison Street approach and physical revisions associated with the SE Grand Avenue approach. The revisions were implemented after video footage was recorded for the analysis scenario associated with Section 3.3.4 and before video footage was recorded for this analysis scenario. 
The SE Madison Street approach underwent the following revisions:

- The segment of the painted bike lane in advance of the intersection where motor vehicles are directed to cross over to access the dedicated right-turn lane was filled in with solid green paint.

- A green colored painted bike box was added to the existing bike lane immediately east of the study intersection. The existing bike lane connected to the bike box which was measured to be approximately 15 feet wide and 20 feet deep.

The SE Grand Avenue approach underwent the following revisions:

- Streetcar tracks were installed within the eastern standard travel lane converting the travel lane into a shared vehicle/streetcar lane.

- The southwest corner of the intersection was reconstructed to permit pedestrian access.

- Two crosswalks were installed connecting to the southwest corner of the intersection.

- The reconstructed southwest corner of the intersection revised the travel path for northbound vehicles turning left to travel westbound. Previously vehicles were required to transition onto an off-ramp prior to the intersection. The layout associated with this analysis scenario required vehicles to perform the left-turn maneuver directly around the southwestern intersection corner.

The distance between the two crosswalks perpendicular to the westbound bike lane was measured to be approximately 54 feet.

While numerous roadway revisions were implemented between the two analysis scenarios, the only revision of significance to westbound bicyclists was the introduction of the bike box. Therefore, the purpose of this analysis scenario was to obtain video footage that would 
allow for an extremely accurate before/after review regarding how such a revision affected the behavior of bicyclists within queues at the study intersection.

Data were collected in February 2012 in slightly rainy weather conditions as well as June and July of 2013 in clear weather conditions. Bicyclists were controlled by standard vehicle signals. An aerial photo and vicinity map of the intersection is shown in Figure 3-9.

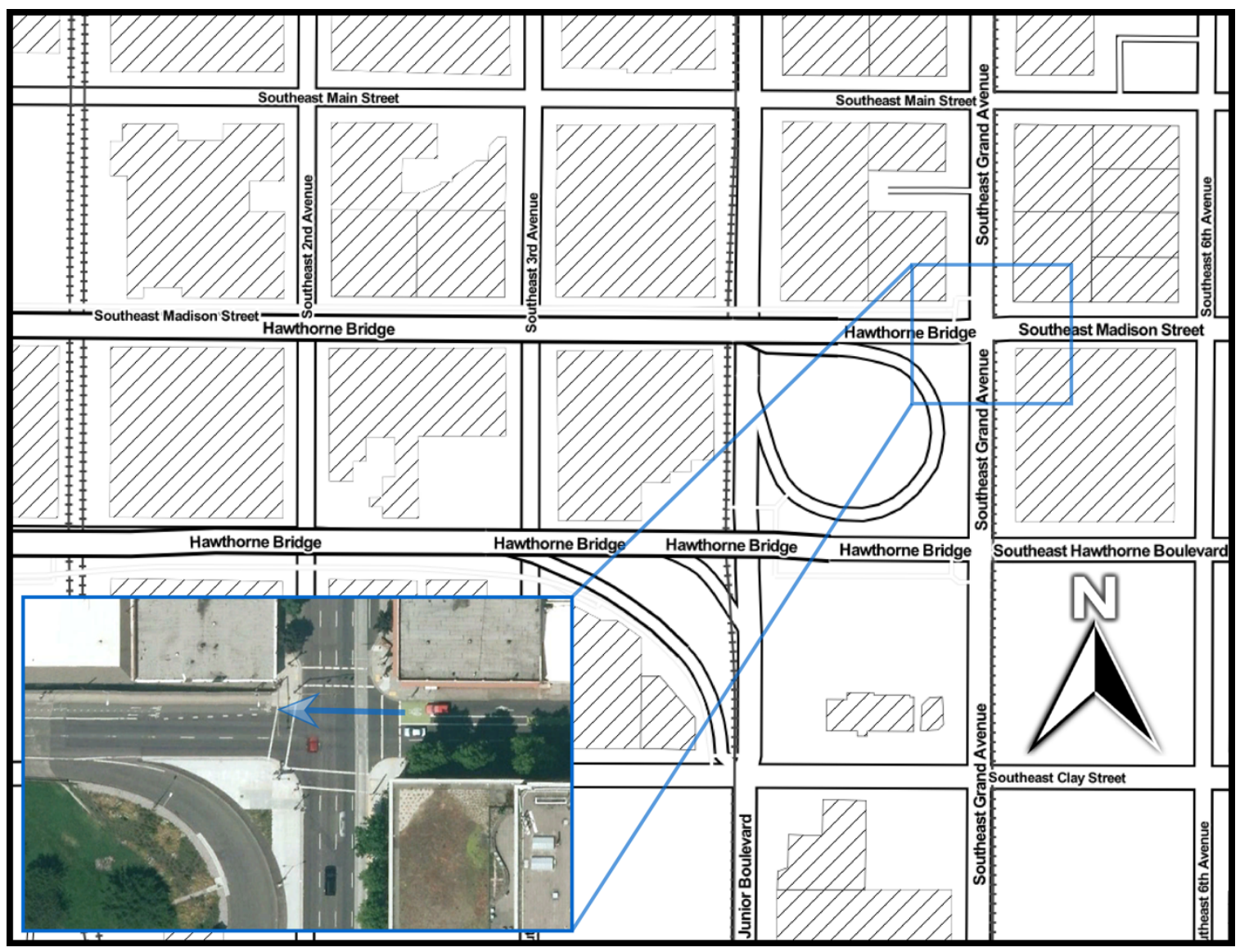

Figure 3-9 Vicinity Map / Aerial Photo, SE Madison Street at Grand Avenue (After)

\subsection{Summary}

The data collected at the five intersection analysis scenarios provide the ability to compare detailed queue characteristics associated with a wide range of bike facilities. The next chapter describes the methodology used to transform the data into a format that allowed for the desired analysis. 


\section{Chapter 4 - Data Reduction Methodology}

To acquire the necessary data to complete this research, video footage was reviewed and various data were extracted for each group of cyclists observed to have formed a queue. Data for each group of cyclists were recorded in an Excel spreadsheet. The description of each documented type of data is defined below in the following subsections.

\subsection{Events}

These data refer to a specific time that an event took place or the observed characteristics of an event.

Although a timestamp was displayed on many of the original video files that was accurate to within one second, greater precision was necessary for calculating time between events used in the various analyses.

The media software program QuickTime Player 7 (version 7.6.6) was used to view the video, as the software provides the ability to display the frame number associated with the video footage. The frame number at the start and/or end of each event was recorded. The number of frames per second (fps) at which the video file was created was referenced to convert the difference in frame numbers between two events to determine the elapsed time in seconds, resulting in precision of at least $1 / 10^{\text {th }}$ of a second.

The accuracy of this method was validated by comparing the passage of time displayed as part of the timestamps on the video footage to the amount of time calculated to have passed based on the difference of frame numbers. This validation process was completed for numerous sample video files for each study intersection. 


\subsubsection{Date}

The date that the group of cyclists were recorded, documented in the MM/DD/YYYY format.

\subsubsection{Start of Walk or Start of Red or Start of Green}

Each video file provided a display of the intersection focused on a limited viewing angle. The limited viewing angle was chosen with the intention of capturing at least one of the following three events related to specific phase changes of the traffic signal: start of walk, start of red, and start of green.

- Start of Walk: Time at the beginning of the walk indication provided to pedestrians traveling parallel to the bicyclists that are associated with this study, recorded as 'Hour' (military time), 'Minute', 'Second', and 'Frame \#'.

- Start of Red: Time at the beginning of the red indication provided to traffic traveling perpendicular to the bicyclists that are associated with this study, recorded as 'Hour' (military time), 'Minute', 'Second', and 'Frame \#'.

- Start of Green: Time at the beginning of the green indication provided to the bicyclists that are associated with this study, recorded as 'Hour' (military time), 'Minute', 'Second', and 'Frame \#'.

The values for 'Hour', 'Minute', and 'Second' were obtained from the timestamp displayed as part of the video footage. For video footage that did not display a timestamp (GoPro Video Data), the time that the video file was created was used for this category. The main purpose of documenting the time of the relevant video footage was to improve the ability to revisit the video files at a later date to find and review specific events within the numerous video files associated with the study. 
The value for 'Frame \#' was obtained from the software program QuickTime Player 7, as described earlier within subsection 4.1 .

Understanding the precise time of at least one of the three identified signal phase changes is necessary for an accurate comparative analysis of queue discharge rates associated with the various intersection layouts. The 'start of walk' and 'start of red' events were used to determine when the green indication was provided to the queue of bicyclists if the video footage did not contain a view that included the signal head controlling the movement for the queue of bicyclists. Based on the signal timing for the signalized intersection it was possible to deduce the time at which the green indication was provided to the queue of bicyclists relative to the 'start of walk' or 'start of red' event.

\subsection{3 \# of Cyclists}

The number of people operating bicycles determined to have come to a complete stop at the approach of the study intersection during the respective signal cycle.

The documentation of this event was separated into specific sub-events based on the general location of the bicyclist(s), with the type and number of sub-events documented dependent on the type of bike facility studied.

For standard bike lane approaches, the general location of where the bicyclist(s) were positioned while waiting at the red light was separated into the areas 1) within the bike lane, and 2) beyond the bike lane, as shown in Figure 4-1. The total number of stationary bicyclists within each general location was documented for each observed queue of bicyclists. 


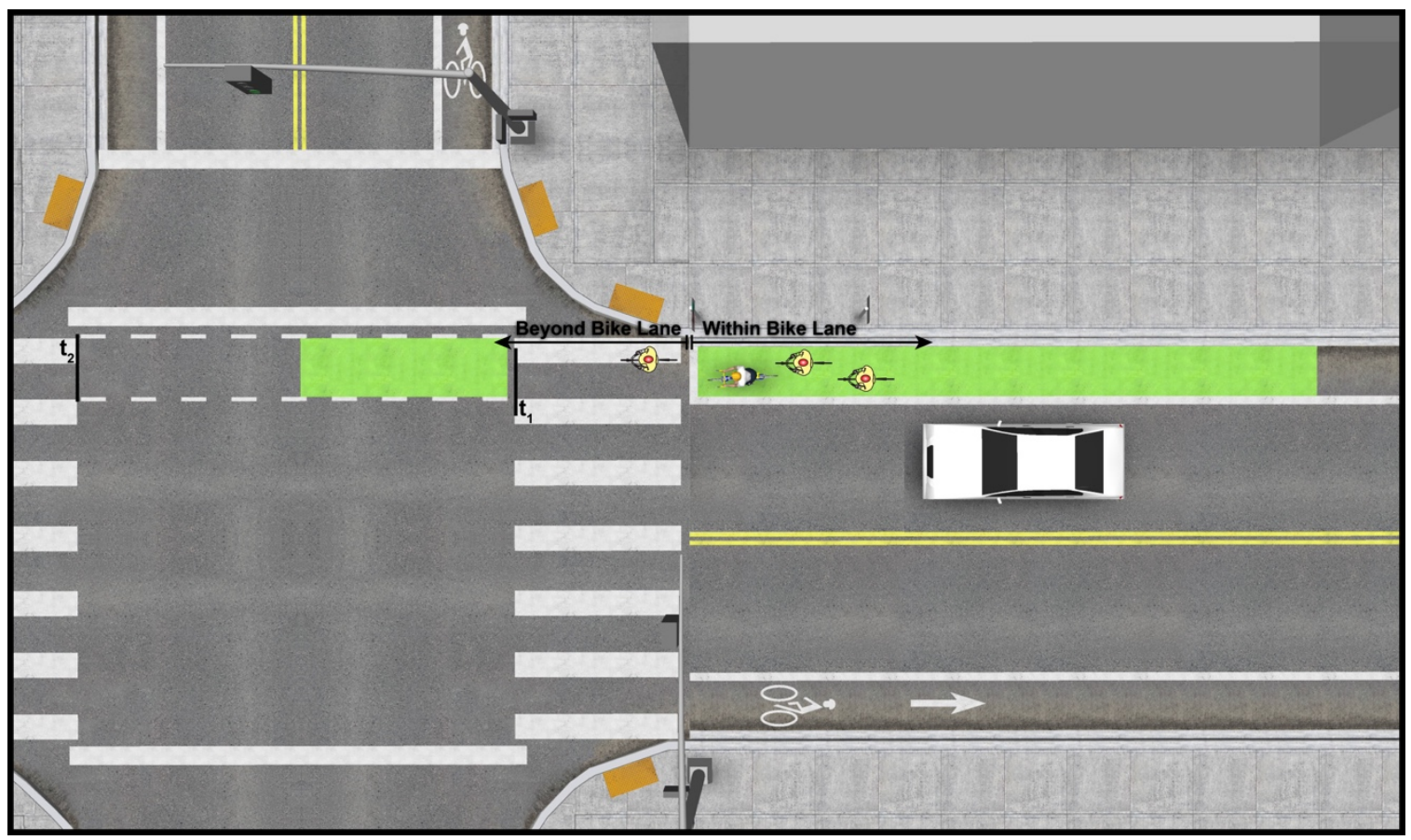

Figure 4-1 General Locations of Possible Cyclist Positions for a Standard Bike Lane Approach (Source Image: NACTO Urban Bikeway Design Guide)

For standard bike lane approaches that also contain a bike box as part of the intersection approach, the general location of where the bicyclist(s) were positioned while waiting at the red light was separated into the areas 1) within the bike lane in advance of the bike box or adjacent to the bike box, 2) within the bike box, and 3) beyond the bike box, as shown in Figure 4-2. 


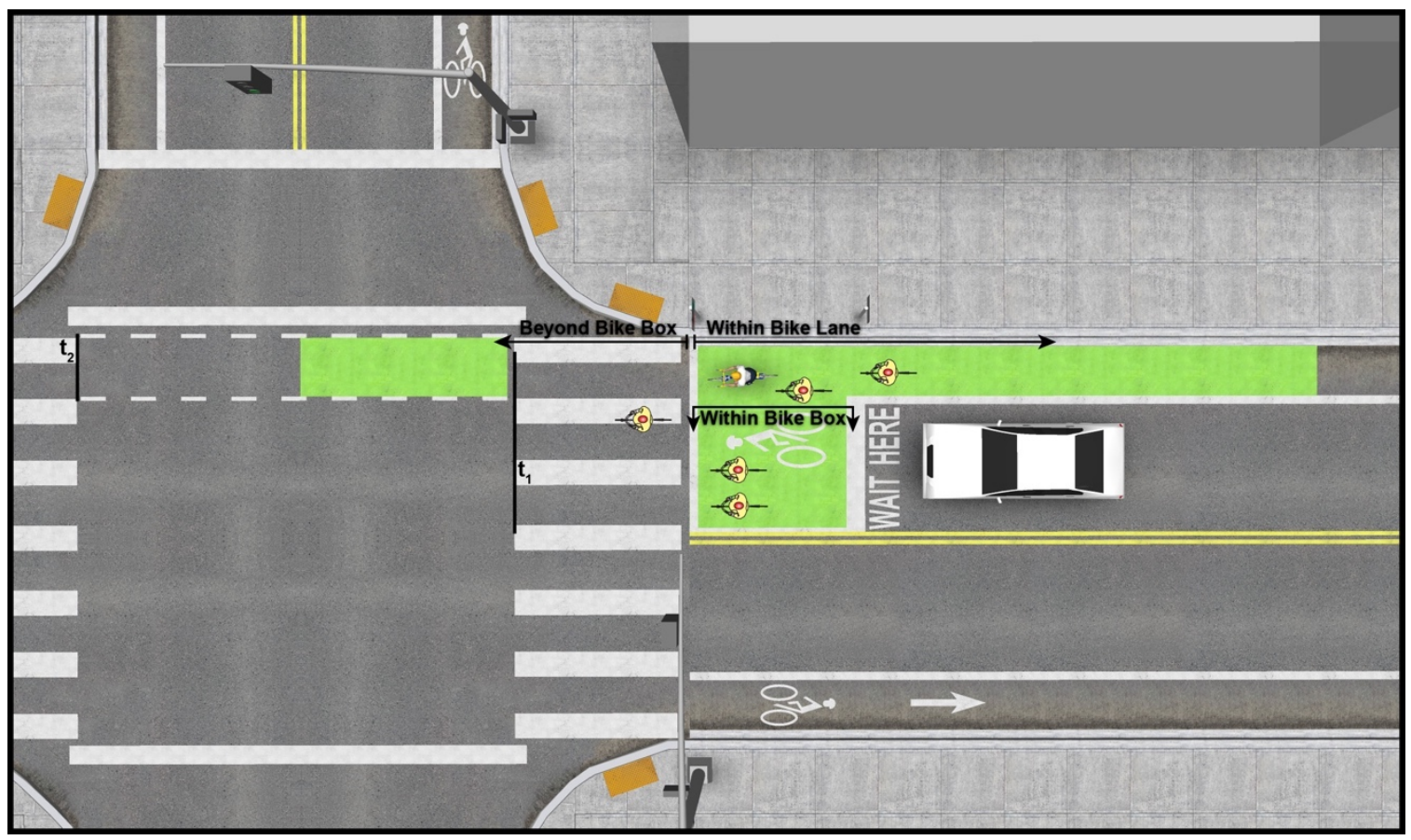

Figure 4-2 General Locations of Possible Cyclist Positions for a Standard Bike Lane + Bike Box Approach (Source Image: NACTO Urban Bikeway Design Guide)

The total number of stationary bicyclists within each general location was documented for each observed queue of bicyclists. Bicyclists that had their bike physically spanning across two of the general location areas were documented as being located within the area that contained most of their bike/body.

The bicyclists that were documented as being located beyond the bike facilities were not considered to be part of the total number of bicyclists within the queue. The reason being that the distance of the bicyclists located beyond the bike facility routinely varied and was therefore difficult to measure and accurately compare to other observed queues.

In some instances, the presence of a bus at a bus stop directly adjacent to the intersection approach would result in a large gap within the queue of cyclists as a portion of the cyclists would yield to the bus re-entering the traffic stream. In these instances, only cyclists within 
the initial queue before the bus re-entered the traffic stream were documented as being part of the queue to avoid involving artificially large headways associated with merging bus traffic.

\subsubsection{Time Front Wheel of $1^{\text {st }}$ Bike Crossed Far Line of Near X-walk.}

Time when the front wheel of the first bicyclist considered to be part of the queue crossed the far line of the nearside crosswalk (reference point $t_{1}$ in Figure 4-1 and Figure 4-2).

This was the time at which the queue of bicyclists was considered to have entered the intersection.

\subsubsection{Time Front Wheel of Last Bike Crossed Far Line of Near X-walk.}

Time when the front wheel of the last bicyclist considered to be part of the queue crossed the far line of the nearside crosswalk (reference point $t_{1}$ ).

This was the time at which the final member of the observed queue of bicyclists was considered to have entered the intersection.

\subsubsection{Time Back Wheel of Last Bike Crossed First Line of Far X-walk.}

Time when the back wheel of the last bicyclist considered to be part of the queue crossed the first line of the far crosswalk (reference point $t_{2}$ in Figure 4-1 and Figure 4-2).

This was the time at which the entire observed queue of bicyclists was considered to have departed the intersection. 


\subsubsection{Video FPS}

Number of frames per second of the video footage as calculated by the method described in Section 4.1.

\subsection{Bicycle Queue Performance Characteristics}

The purpose of the analysis is to compare the discharge characteristics of observed queues of bicyclists at a variety of signalized intersection approaches that contain dedicated bicycle facilities. The following subsections provide a description of the queue discharge characteristics that were the focus of analysis.

\subsubsection{Average Headway within Queues of Bicycle Traffic}

In HCM 2010, the headway for the first vehicle is the "elapsed time, in seconds, between the initiation of the green and the front wheels of the first vehicle crossing over the stop line."

Headway for the first cyclist in the queue is calculated using Equation ( 2 ).

$$
h_{1}=\left(R e f_{1[t 1]}-R e f_{G}\right) / F P S
$$

Where:

$h_{1}=$ headway (seconds) for the $1^{\text {st }}$ cyclist

$\operatorname{Re} f_{1[t 1]}=$ frame \# when $1^{\text {st }}$ cyclist's front wheel crossed reference line $t_{1}$ $R e f_{G}=$ frame \# when the signal phase changed to green for bicyclists $F P S=$ frames per second of the video file

Headways for subsequent vehicles are equal to the elapsed time between the front wheels of said vehicle and the one prior. 
Consistent with the HCM 2010 methods, the time used to calculate headways involved the time that a bicyclist's front wheel crossed a reference point. However, all study locations did not contain typical stop lines, resulting in the closest marking of the nearside crosswalk to be perceived and treated as a stop line by many of the vehicle operators.

Although the closest marking of the nearside crosswalk was frequently in front of the queue of motorized vehicles, numerous bicyclists located at the front of queues were observed to have come to a complete stop with their front wheel resting on or immediately beyond the closest marking of the nearside crosswalk. The routine placement of bicyclists' front wheels in such a location made it difficult to accurately discern when the first cyclist within the queue would initiate movement and cross the closest reference point typically used to determine headways. For this reason, the nearside crosswalk's marking located furthest away from the queue of bicyclists was chosen as the standard reference point to obtain more accurate timing comparisons used within this analysis. All study approaches contained similar crosswalk markings consisting of two lines perpendicular to the flow of approaching traffic.

Furthermore, in some scenarios the type and size of the bike facility did not constrain bicyclists to form a queue as a single-file line and instead allowed for lateral grouping of multiple bicyclists to occur. Such facilities also allowed faster bicyclists to overtake slower bicyclists when the queue dispersed in advance of reference point $t_{l}$, previously defined within Section 4.1. Therefore, individual headway information was determined to be too difficult to determine as part of this study. Thus, calculation of individual headways using the HCM 2010 method was not an easy method to replicate. 
However, there remained a desire to review the average of headways between the first and last cyclist within each queue so as to understand general flow rates amongst queues of various sizes.

This study identified the 'average headway' within each queue by determining the elapsed time between the first and last cyclist to have crossed reference point $t_{1}$ and dividing by the total number of cyclists within the queue after they first cyclist, calculated as shown in Equation ( 3 ).

$$
h_{\mathrm{A}}=\frac{\left(\operatorname{Re} f_{\mathrm{n}[t 1]}-\operatorname{Re} f_{1[t 1]}\right)}{(n-1) * F P S}
$$

Where:

$h_{A}=$ average headway (seconds) after $1^{\text {st }}$ cyclist within queue Re $f_{n[t 1]}=$ frame \# when $n^{\text {th }}$ cyclist's front wheel crossed reference line $t_{1}$ $R e f_{1[t 1]}=$ frame \# when $1^{\text {st }}$ cyclist's front wheel crossed reference line $t_{1}$ $n=\#$ of cyclists within queue

The resulting average headway value for each queue is based on queue size, without including delays associated with varied perception and reaction times of the traffic signal changing phases to display the green indication. For example, some queues of cyclists were observed to not see the traffic signal turn green until after a semi-truck passed completely through the intersection no longer blocking the cyclists' view of the signal. Therefore, the average headway value is independent of the varied perception and reaction times.

\subsubsection{Queue Discharge Time}

The 'queue discharge time' is a calculation of the time required for the entire queue of bicyclists to enter the intersection. The calculation was based on the difference of time 
between the 'start of green' and when the front wheel of the last bicyclist within the queue crossed reference point $t_{1}$, as shown in Equation ( 4 ).

$$
Q D=\left(R e f_{\mathrm{n}[t 1]}-S G\right) / F P S
$$

Where:

$Q D=$ time (seconds) for a queue of $n$ bicyclists to enter the intersection

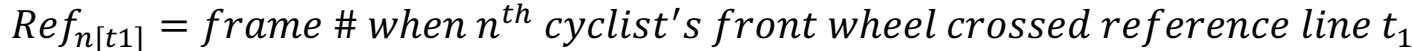
$S G=$ frame \# at the 'Start of Green'

The far line of the nearside crosswalk was chosen as reference point $t_{l}$, previously defined within Section 4.1, as this was the point at which bicyclists began to conflict with the path of motorized vehicles traveling along the intersecting roadway.

The queue discharge time incorporates delays associated with the perception and reaction time, which allows for a better understanding of intersection operations per signal cycle.

\subsubsection{Queue Intersection Clearance Time}

The 'intersection clearance time' is a calculation of the time required for the queue of bicyclists to clear the intersection. The calculation was based on the difference of time between the 'start of green' and when the back wheel of the last bicyclist within the queue crossed reference point $t_{2}$, as shown in Equation ( 5 ).

$$
I C=\left(R e f_{\mathrm{n}[t 2]}-S G\right) / F P S
$$

Where:

$I C=$ time (seconds) for a queue of $n$ bicyclists to clear an intersection

$R e f_{n[t 2]}=$ frame \# when $n^{\text {th }}$ cyclist's rear wheel crossed reference line $t_{2}$ $S G=$ frame \# at the 'Start of Green' 
The first line of the far-side crosswalk was chosen as reference point $t_{2}$, previously defined within Section 4.1, as this was the point at which bicyclists were no longer in conflict with the path of motorized vehicles traveling along the intersecting roadway.

Similar to the queue discharge time, the intersection clearance time incorporates delays associated with the perception and reaction time, which allows for a better understanding of intersection operations per signal cycle.

\subsection{Types of Bike Facilities Analyzed}

The queue discharge characteristics described within Section 4.2 were determined for five different types of bike facility layouts located at signalized intersections: a standard bike lane connecting to a standard bike lane, a standard bike lane connecting to two standard bike lanes, a buffered bike lane connecting to a standard bike lane, a bike box connecting to a buffered bike lane, and a bike box connecting to two standard bike lanes.

\subsubsection{Standard Bike Lane to Standard Bike Lane}

The analysis scenario that contained a standard bike lane in advance of the intersection as well as following the intersection was represented by the study intersection of $\mathrm{N}$ Williams Avenue at N Russell Street.

The bike lane that was the focus of this analysis was measured to be six feet wide before and after the intersection. There was a parking lane to the right of the bike lane in advance

of the intersection. The area to the right of the bike lane immediately following the intersection was designated as a 'No Parking / Bus Zone' curb area. 
While it is not intended for bicyclists to utilize the area to the right of the bike lane, it should be noted that the area was observed to have been utilized by a portion of the bicyclists when there was an absence of motorized vehicles in the respective spaces designated for such use. Both faster bicyclists as well as slower bicyclists were observed to use the area to the right of the bike lane, usually to pass other bicyclists or let other bicyclists pass them. The variation of the constrained width available for use by bicyclists at this intersection was not accounted for in the analysis.

The distance between the two crosswalks perpendicular to the northbound bike lane was measured to be approximately 60 feet.

\subsubsection{Standard Bike Lane to Two Standard Bike Lanes}

The analysis scenario that contained a standard bike lane in advance of the intersection and two standard bike lanes following the intersection was represented by the study intersection of SE Madison Street at SE Grand Avenue (Before Bike Box).

The bike lane was measured to be five feet wide before the intersection and as wide as 10 feet after the intersection. The receiving bike lane is marked as two bike lanes each five feet wide to intentionally accommodate large numbers of bicyclists.

The distance between the crosswalk perpendicular to the westbound bike lane and the area immediately west of the northbound travel lanes was measured to be approximately 54 feet. 


\subsubsection{Buffered Bike Lane to Standard Bike Lane}

The analysis scenario that contained a buffered bike lane in advance of the intersection and a standard bike lane following the intersection was represented by the study intersection of SE Hawthorne Boulevard at SE Grand Avenue.

The painted buffer between the motor vehicle lanes and the bike lane was measured to be five feet wide in advance of the intersection. There was no painted buffer area after the intersection. The bike lane was measured to be seven feet wide in advance of the intersection and 6.5 feet wide after the intersection.

The distance between the two crosswalks perpendicular to the eastbound bike lane was measured to be approximately 56 feet.

\subsubsection{Bike Box to Buffered Bike Lane}

The analysis scenario that contained a bike box in advance of the intersection and a buffered bike lane following the intersection was represented by the study intersection of NW Broadway at NW Hoyt Street.

The bike box at the intersection approach was measured to be approximately 21 feet wide and 19 feet deep. The painted buffer area between the motor vehicle lanes and the bike lane was measured to be three feet wide. The bike lane was measured to be seven feet wide. The measured widths of the bike lane and buffer area apply to the locations both in advance of the bike box and immediately after the intersection. 
The distance between the two crosswalks perpendicular to the southbound bike lane was measured to be approximately 46 feet.

\subsubsection{Bike Box to Two Standard Bike Lanes}

The analysis scenario that contained a bike box in advance of the intersection and two standard bike lanes following the intersection was represented by the study intersection of SE Madison Street at SE Grand Avenue (After Bike Box).

The bike box at the intersection approach was measured to be approximately 15 feet wide and 20 feet deep. The bike lane in advance of the bike box was measured to be five feet wide. The bike lanes immediately after the intersection was measured to be as wide as 10 feet. The two receiving lanes are intended to accommodate large numbers of bicyclists.

The distance between the crosswalk perpendicular to the westbound bike lane and the area immediately west of the northbound travel lanes was measured to be approximately 54 feet.

\subsection{Summary}

With the data events from video footage associated with different sized bike facilities successfully obtained, they were prepared for analysis in accordance with the desired performance characteristics of groups of cyclists queued at signalized intersections.

The next chapter presents the analysis and results from comparisons of data described within this chapter. 


\section{Chapter 5 - Analysis \& Results}

This chapter presents the analysis and results of the reduced data. The main aspects of the cyclist queue discharge characteristics that were analyzed consist of: average headway of queues, queue discharge rates, and intersection clearance times.

The queue characteristics were analyzed with respect to queue size, bikeway departure width, bikeway receiving width, bikeway crossing distance, intersection grade, and whether the bike box was utilized.

\subsection{Average Headway of Queues}

This section presents detailed analysis of the average headway of queues of cyclists based on their respective size. All observed queues are tabulated in Table 4 and displayed in Figure 5-1 as a scatterplot with a smoothed line showing the conditional mean and the 95 percent confidence interval as the shaded area. This line was plotted using $\mathrm{R}$ and the "+ stat_smooth(se=T)" option within the ggplot2 package. 
Table 4: Average, Standard Deviation and Number of Observations of Average Headway

\begin{tabular}{cccc}
\hline \multirow{2}{*}{ Queue Size } & \multicolumn{3}{c}{ All Observations } \\
\cline { 2 - 4 } & Avg (sec) & Std Dev (sec) & $\mathrm{n}$ \\
\hline $\mathbf{2}$ & 1.31 & 0.70 & 144 \\
$\mathbf{3}$ & 1.19 & 0.45 & 125 \\
$\mathbf{4}$ & 1.09 & 0.28 & 118 \\
$\mathbf{5}$ & 0.94 & 0.28 & 71 \\
$\mathbf{6}$ & 0.88 & 0.24 & 60 \\
$\mathbf{7}$ & 0.78 & 0.22 & 44 \\
$\mathbf{8}$ & 0.82 & 0.22 & 27 \\
$\mathbf{9}$ & 0.82 & 0.28 & 10 \\
$\mathbf{1 0}$ & 0.80 & 0.23 & 12 \\
$\mathbf{1 1}$ & 0.82 & 0.15 & 7 \\
$\mathbf{1 2}$ & 0.91 & 0.12 & 6 \\
$\mathbf{1 3}$ & 0.64 & 0.08 & 2 \\
$\mathbf{1 4}$ & 0.83 & 0.00 & 1 \\
$\mathbf{1 5}$ & 1.03 & 0.07 & 2 \\
$\mathbf{1 6}$ & - & - & - \\
$\mathbf{1 7}$ & - & - & - \\
$\mathbf{1 8}$ & 0.85 & 0.00 & 1 \\
\hline Total & - & - & 630 \\
\hline
\end{tabular}

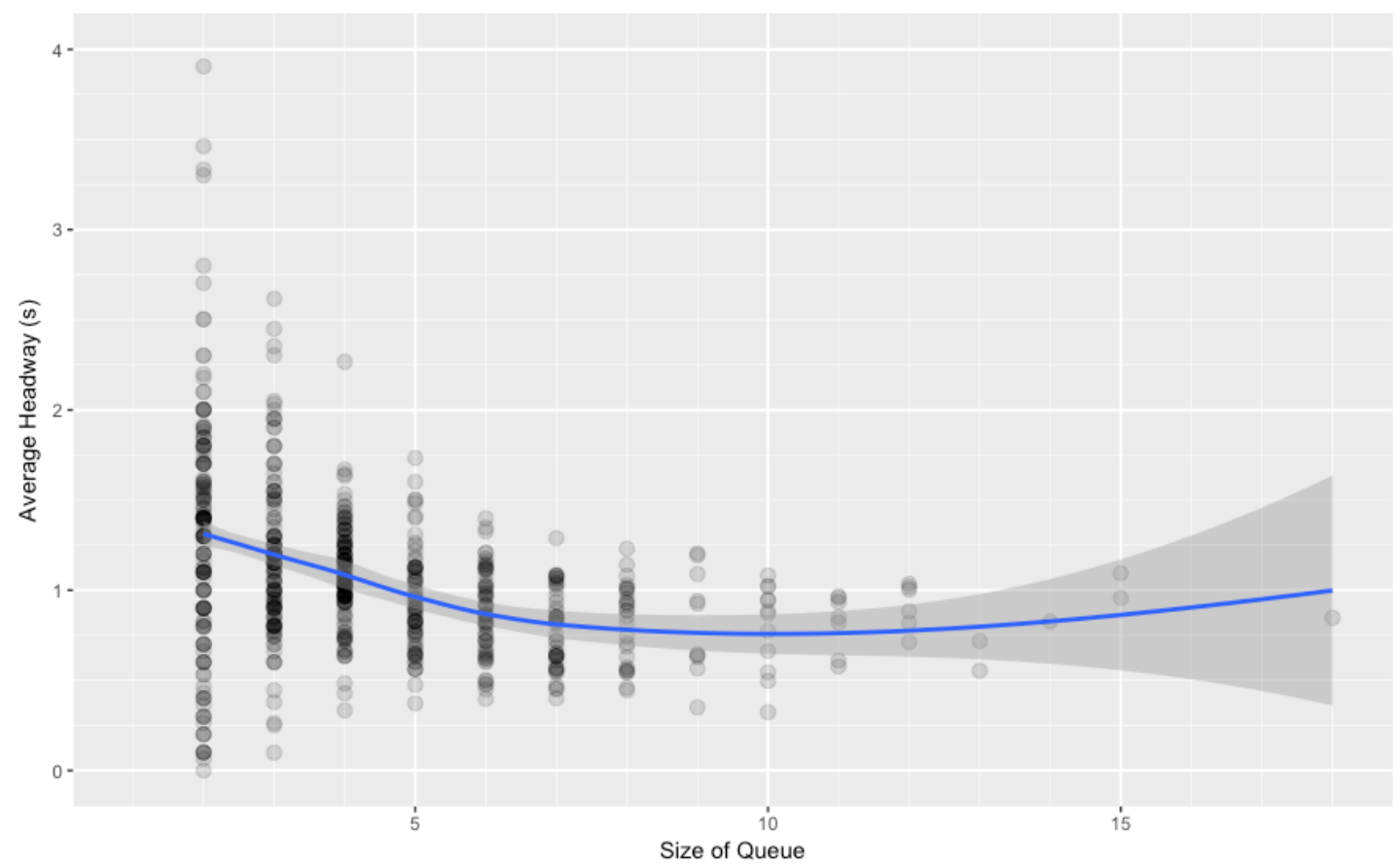

Figure 5-1 Average Headway for All Observed Queues 
As queues increase in size from two to seven cyclists, the mean of the average headway within queues starts at approximately 1.3 seconds and approaches 0.8 seconds. The mean of the average headway for queues of more than seven cyclists remains stable until queues of 12 in size and starts to slightly increase toward approximately 1.0 seconds for queues larger than 12 cyclists.

The queue characteristics that were analyzed in detail with respect to queue size consist of bikeway approach width, intersection grade, and whether the bike box was utilized. The queue characteristics associated with the intersection crossing distance and the bikeway receiving width were not evaluated with respect to the average headway as the two characteristics are more related to activity that occurs throughout the intersection whereas average headway is specific to activity that occurs at the near side of the intersection.

\subsubsection{Per Bikeway Approach Width}

The average headway data based on the queue size and bikeway approach width are tabulated in Table 5 and displayed in Figure 5-2 as a scatterplot with smoothed lines showing the conditional means associated with the various facility widths. The lines were plotted using R and the "+ stat_smooth(se=F)" option within the ggplot2 package. 


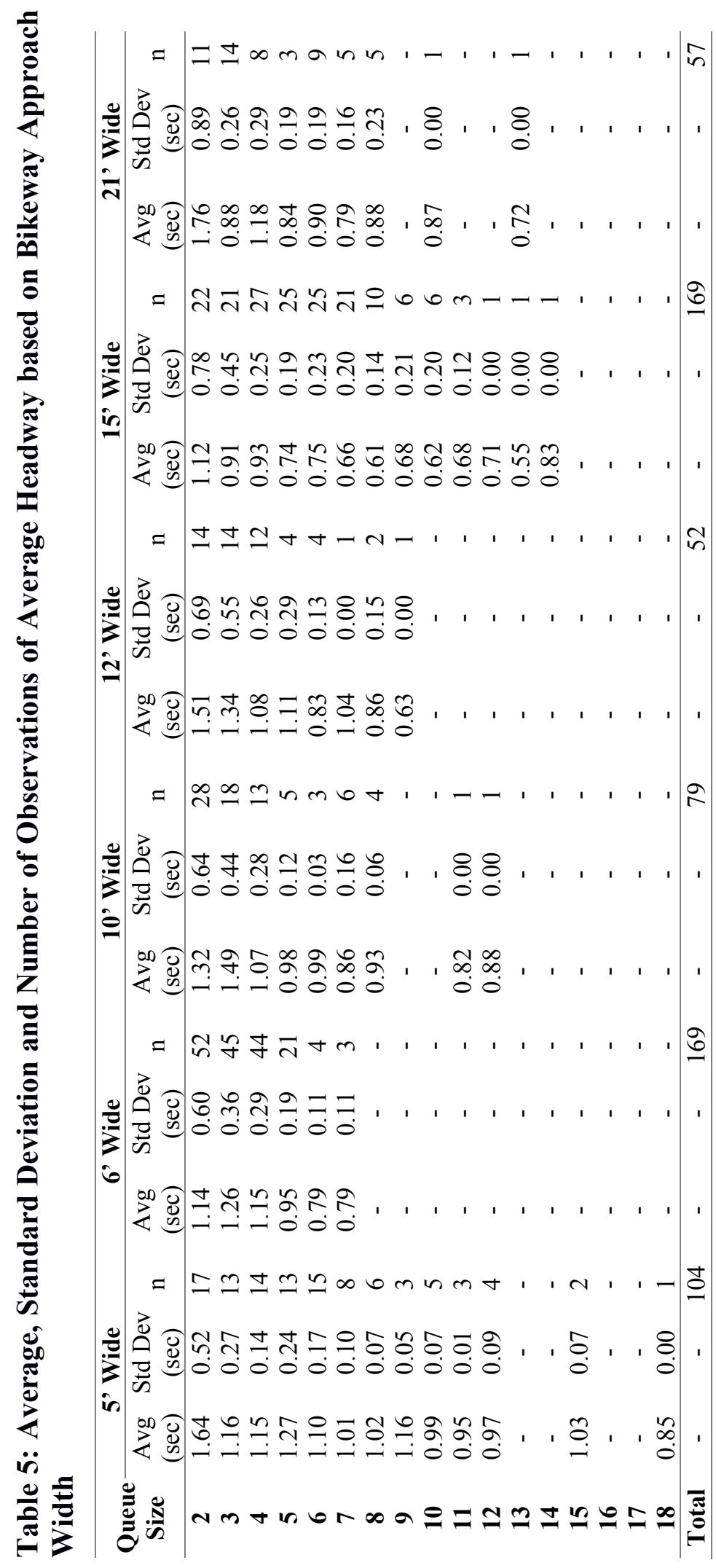




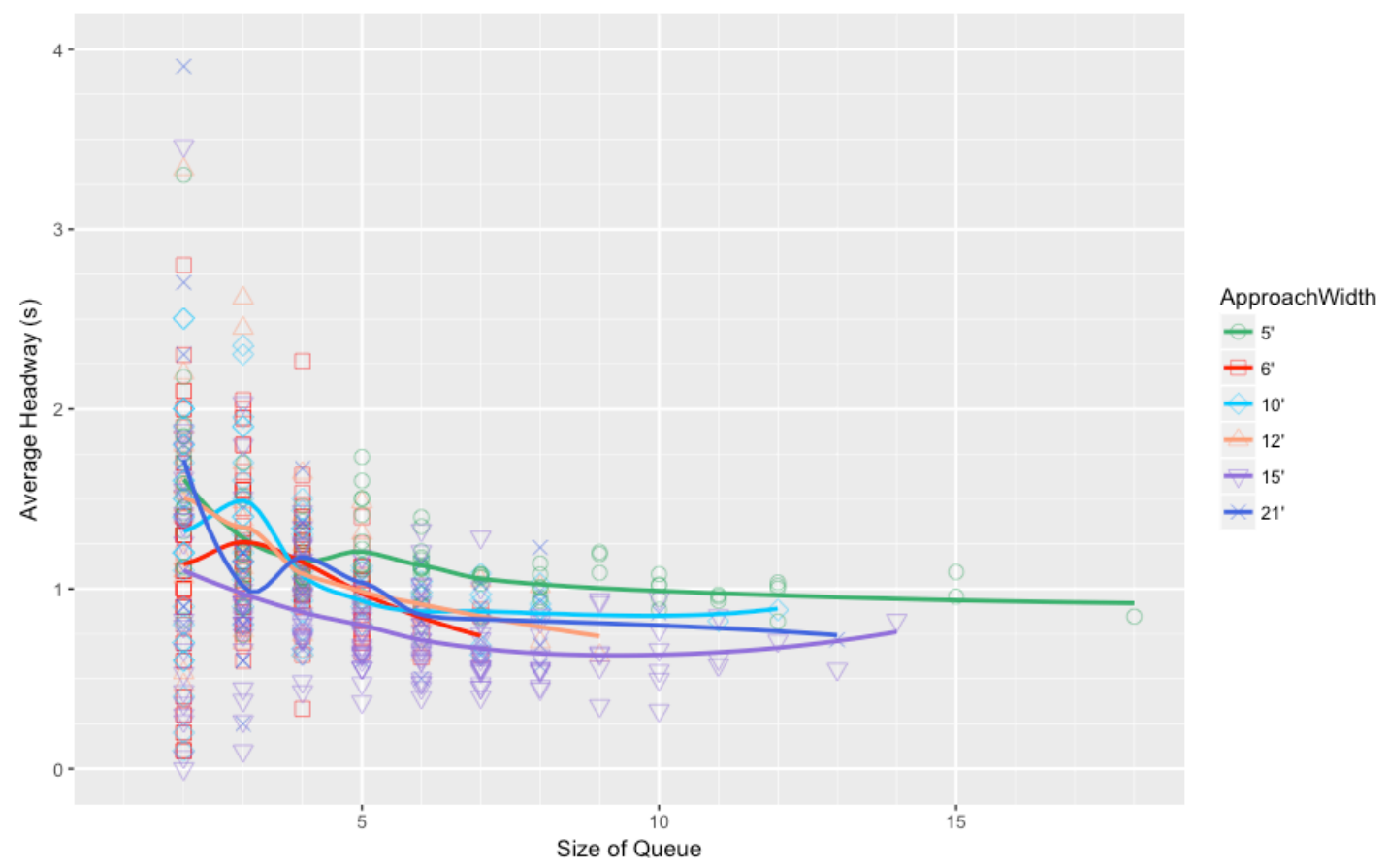

Figure 5-2 Average Headway based on Bikeway Approach Width

With the many overlapping trend lines, the results do not display an easily apparent relationship associated with the approach width of the facility.

However, there are notable differences amongst the approach widths. For example, the 5, trend line is consistently larger than the $15^{\prime}$ trend line. The lower average headway associated with the $15^{\prime}$ trend line is likely indicative of the time savings from installation of the bike box at the Madison Street approach. The difference in average headway between the two trends is approximately 0.5 seconds for queues of two cyclists and approximately 0.25 seconds for queues of 12 cyclists.

Similarly, given that the bike box at the Broadway approach was infrequently utilized, the queues that did not utilize any portion of the bike box were considered to have an approach width of 10 feet ( $7^{\prime}$ bike lane +3 ' buffer) rather than 21 feet that was available for queues 
that did utilize the bike box. However, the only apparent difference between the 10' and $21^{\prime}$ trend lines is a time savings for queues of three cyclists if at least one of the users is located within the bike box area. Aside from that difference, the trend lines are relatively similar.

\subsubsection{Per Approach Grade}

The average headway data based on the queue size and approach grade of the bikeway are tabulated in Table 6 and displayed in Figure 5-3 as a scatterplot with smoothed lines showing the conditional means associated with the various grades. The lines were plotted using R and the "+ stat_smooth(se=F)" option within the ggplot2 package.

Table 6: Average, Standard Deviation and Number of Observations of Average Headway based on Approach Grade

\begin{tabular}{cccccccccc}
\hline $\begin{array}{c}\text { Queue } \\
\text { Size }\end{array}$ & $\begin{array}{c}\text { Avg } \\
(\mathrm{sec})\end{array}$ & $\begin{array}{c}\text { Std Dev } \\
(\mathrm{sec})\end{array}$ & $\mathrm{n}$ & $\begin{array}{c}\text { Avg } \\
(\mathrm{sec})\end{array}$ & $\begin{array}{c}\mathbf{+ 1 \%} \\
\text { Std Dev } \\
(\mathrm{sec})\end{array}$ & $\mathrm{n}$ & $\begin{array}{c}\text { Avg } \\
(\mathrm{sec})\end{array}$ & $\begin{array}{c}\text { Std Dev } \\
(\mathrm{sec})\end{array}$ & $\mathrm{n}$ \\
\hline $\mathbf{2}$ & 1.46 & 0.73 & 53 & 1.14 & 0.60 & 52 & 1.35 & 0.73 & 39 \\
$\mathbf{3}$ & 1.26 & 0.50 & 46 & 1.26 & 0.36 & 45 & 1.01 & 0.41 & 34 \\
$\mathbf{4}$ & 1.10 & 0.28 & 33 & 1.15 & 0.29 & 44 & 1.01 & 0.24 & 41 \\
$\mathbf{5}$ & 0.99 & 0.23 & 12 & 0.95 & 0.19 & 21 & 0.92 & 0.33 & 38 \\
$\mathbf{6}$ & 0.90 & 0.17 & 16 & 0.79 & 0.11 & 4 & 0.88 & 0.27 & 40 \\
$\mathbf{7}$ & 0.84 & 0.17 & 12 & 0.79 & 0.11 & 3 & 0.76 & 0.24 & 29 \\
$\mathbf{8}$ & 0.89 & 0.18 & 11 & - & - & - & 0.77 & 0.23 & 16 \\
$\mathbf{9}$ & 0.63 & 0.00 & 1 & - & - & - & 0.84 & 0.28 & 9 \\
$\mathbf{1 0}$ & 0.87 & 0.00 & 1 & - & - & - & 0.79 & 0.24 & 11 \\
$\mathbf{1 1}$ & 0.82 & 0.00 & 1 & - & - & - & 0.82 & 0.16 & 6 \\
$\mathbf{1 2}$ & 0.88 & 0.00 & 1 & - & - & - & 0.92 & 0.13 & 5 \\
$\mathbf{1 3}$ & 0.72 & 0.00 & 1 & - & - & - & 0.55 & 0.00 & 1 \\
$\mathbf{1 4}$ & - & - & - & - & - & - & 0.83 & 0.00 & 1 \\
$\mathbf{1 5}$ & - & - & - & - & - & - & 1.03 & 0.07 & 2 \\
$\mathbf{1 6}$ & - & - & - & - & - & - & - & - & - \\
$\mathbf{1 7}$ & - & - & - & - & - & - & - & - & - \\
$\mathbf{1 8}$ & - & - & - & - & - & - & 0.85 & 0.00 & 1 \\
\hline Total & - & - & 188 & - & - & 169 & - & - & 273 \\
\hline
\end{tabular}




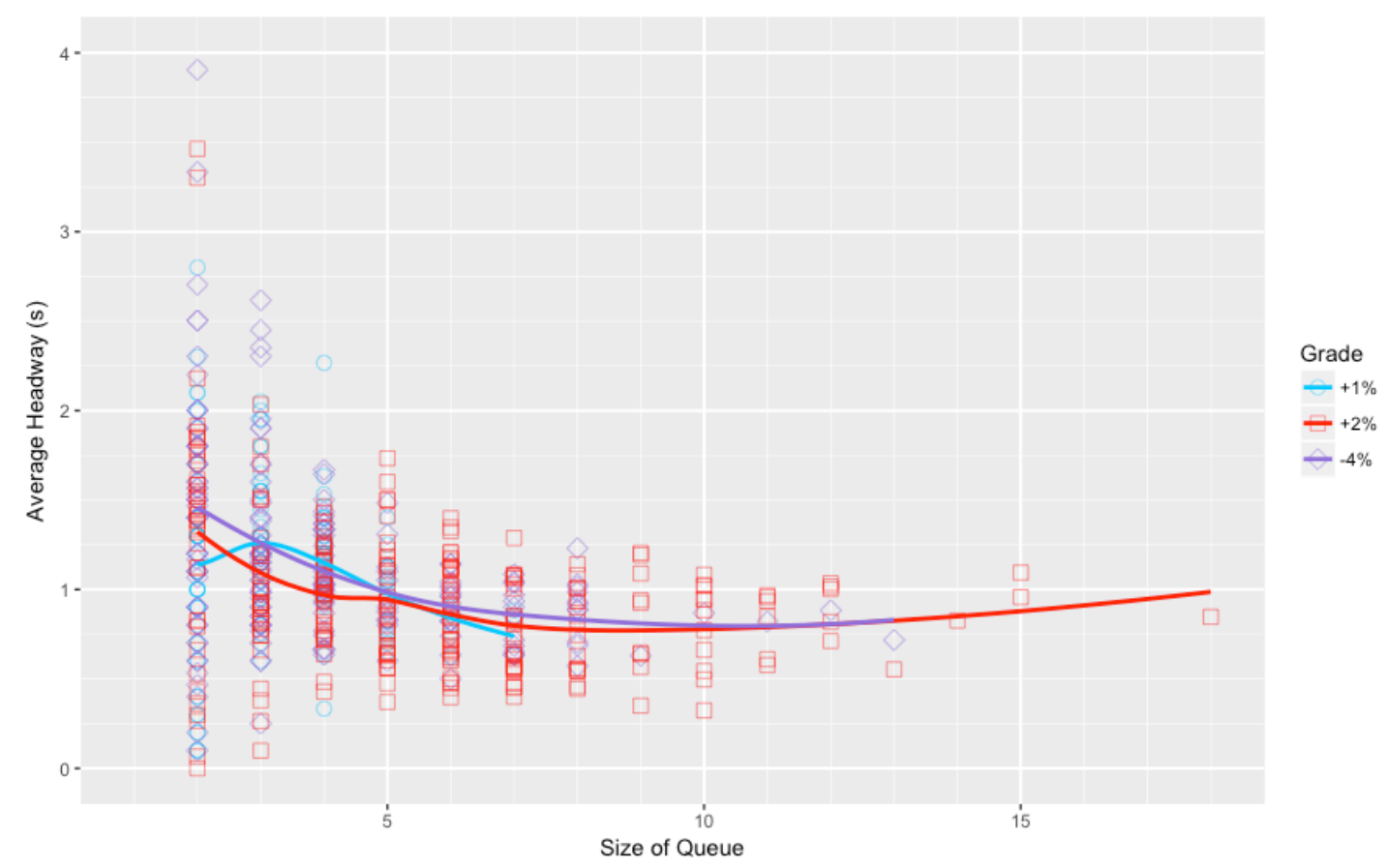

Figure 5-3 Average Headway based on Approach Grade

The results do not appear to indicate that the approach grade of the intersection has a significant relationship with the average headway as both downhill and uphill approaches experience similar average headway values.

\subsubsection{Per Utilization of the Bike Box}

The average headway data based on the queue size and utilization of the bike box at the intersection approach are tabulated in Table 7 and displayed in Figure 5-4 as a scatterplot with smoothed lines showing the conditional means and the 95 percent confidence interval as the shaded area. The lines were plotted using R and the "+ stat_smooth(se=T)" option within the ggplot2 package. 
Table 7: Average, Standard Deviation and Number of Observations of Average Headway based on Utilization of Bike Box

\begin{tabular}{ccccccc}
\hline \multirow{2}{*}{$\begin{array}{c}\text { Queue } \\
\text { Size }\end{array}$} & \multicolumn{3}{c}{ Bike Box Utilized } & \multicolumn{3}{c}{ Bike Box Not Utilized } \\
\hline & $\begin{array}{c}\text { Std Dev }) \\
(\mathrm{sec})\end{array}$ & $\mathrm{n}$ & $\begin{array}{c}\text { Avg } \\
(\mathrm{sec})\end{array}$ & $\begin{array}{c}\text { Std Dev } \\
(\mathrm{sec})\end{array}$ & $\mathrm{n}$ \\
\hline $\mathbf{2}$ & 1.33 & 0.87 & 33 & 1.31 & 0.64 & 111 \\
$\mathbf{3}$ & 0.90 & 0.39 & 35 & 1.31 & 0.41 & 90 \\
$\mathbf{4}$ & 0.99 & 0.28 & 35 & 1.13 & 0.26 & 83 \\
$\mathbf{5}$ & 0.75 & 0.20 & 28 & 1.07 & 0.26 & 43 \\
$\mathbf{6}$ & 0.79 & 0.23 & 34 & 1.00 & 0.19 & 26 \\
$\mathbf{7}$ & 0.69 & 0.20 & 26 & 0.93 & 0.15 & 18 \\
$\mathbf{8}$ & 0.70 & 0.21 & 15 & 0.96 & 0.11 & 12 \\
$\mathbf{9}$ & 0.68 & 0.21 & 6 & 1.03 & 0.24 & 4 \\
$\mathbf{1 0}$ & 0.66 & 0.20 & 7 & 0.99 & 0.07 & 5 \\
$\mathbf{1 1}$ & 0.68 & 0.12 & 3 & 0.92 & 0.06 & 4 \\
$\mathbf{1 2}$ & 0.71 & 0.00 & 1 & 0.95 & 0.09 & 5 \\
$\mathbf{1 3}$ & 0.64 & 0.08 & 2 & - & - & - \\
$\mathbf{1 4}$ & 0.83 & 0.00 & 1 & - & - & - \\
$\mathbf{1 5}$ & - & - & - & 1.03 & 0.07 & 2 \\
$\mathbf{1 6}$ & - & - & - & - & - & - \\
$\mathbf{1 7}$ & - & - & - & - & - & - \\
$\mathbf{1 8}$ & - & - & - & 0.85 & 0.00 & 1 \\
\hline Total & - & - & 226 & - & - & 404 \\
\hline
\end{tabular}

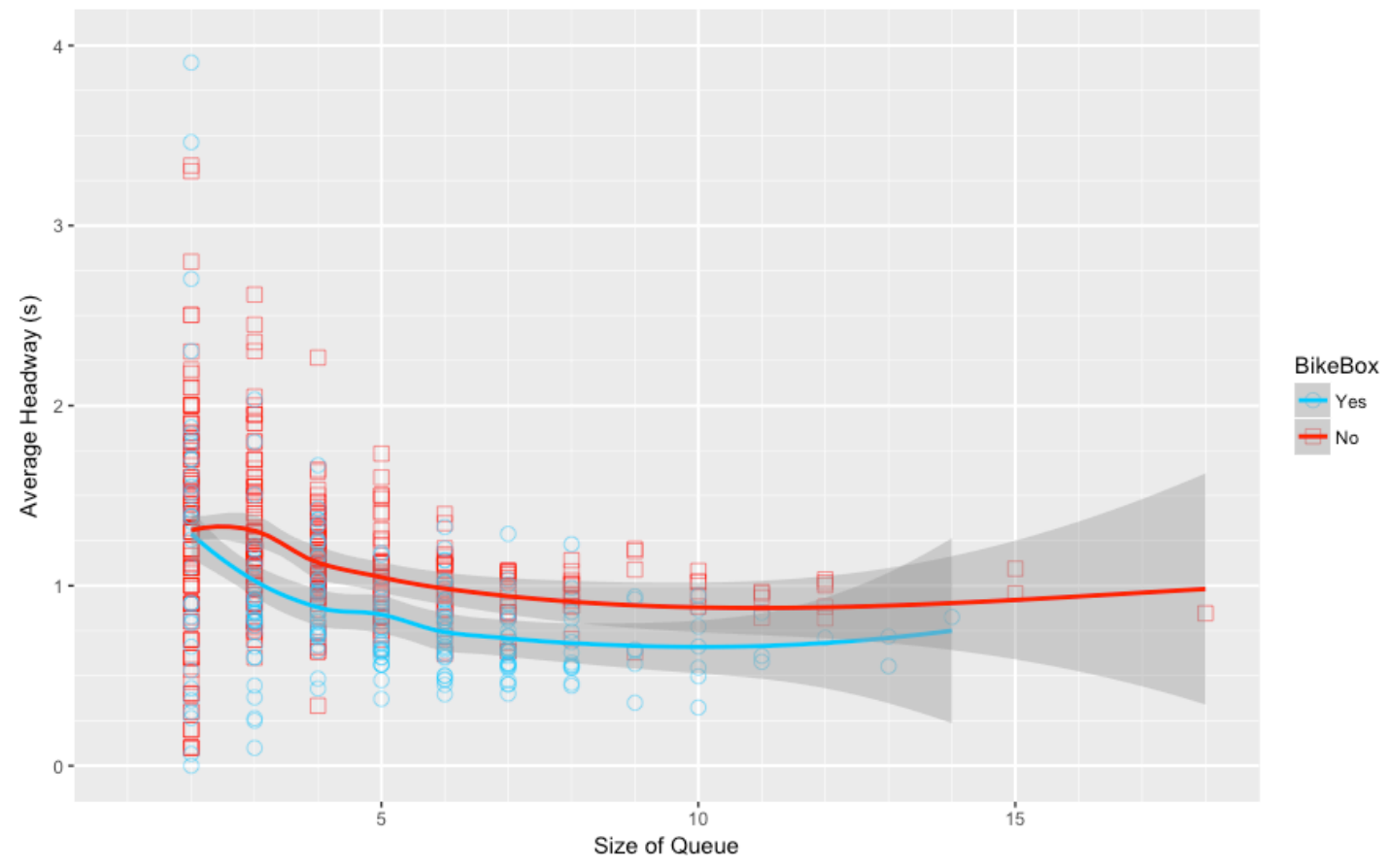

Figure 5-4 Average Headway based on Utilization of Bike Box 
The results appear to indicate that utilization of the bike box has a potential relationship with a reduced average headway as compared to queues that do not utilize the bike box. The associated reduction in average headway is approximately 0.2 to 0.3 seconds per cyclist for queues of three or more cyclists in size.

\subsubsection{Findings}

For all observations, the lowest mean of the average headway within queues is approximately 0.8 seconds per cyclist and occurs for groups of seven cyclists. For queues larger than seven in size, the mean of the average headway remains stable until queues of 12 in size and starts to slightly increase toward approximately 1.0 seconds for queues larger than 12 cyclists.

Regarding the mean of the average headway based on approach width, the direct 'before and after' comparison of the bike box study location appeared to demonstrate a potential reduction of average headway associated with the installation of the bike box. The remaining study approaches did not appear to demonstrate any significant trends.

Regarding the mean of the average headway based on utilization of a bike box, it appears that utilization of a bike box has a potential relationship with a reduced average headway as compared to queues that do not utilize the bike box. The associated reduction in average headway was approximately 0.2 to 0.3 seconds per cyclist for queues of three or more cyclists in size.

Regarding the mean of the average headway based on approach grade, there was no apparent relationship observed from the analysis. 


\subsection{Queue Discharge Rates}

This section presents detailed analysis of the queue discharge rates for queues of cyclists based on their respective size. All observed queues are tabulated in Table 8 and displayed in Figure 5-5 as a scatterplot with a smoothed line showing the mean and the 95 percent confidence interval as the shaded area. This line was plotted using $\mathrm{R}$ and the "+ stat_smooth(se=T)” option within the ggplot2 package.

Table 8: Average, Standard Deviation and Number of Observations of Queue Discharge

\begin{tabular}{cccc}
\hline \multirow{2}{*}{ Queue Size } & \multicolumn{3}{c}{ All Observations } \\
\cline { 2 - 4 } & $\operatorname{Avg}(\mathrm{sec})$ & Std Dev $(\mathrm{sec})$ & $\mathrm{n}$ \\
\hline $\mathbf{2}$ & 4.30 & 1.04 & 144 \\
$\mathbf{3}$ & 5.32 & 1.12 & 125 \\
$\mathbf{4}$ & 6.02 & 1.08 & 118 \\
$\mathbf{5}$ & 6.53 & 1.41 & 71 \\
$\mathbf{6}$ & 6.89 & 1.42 & 60 \\
$\mathbf{7}$ & 7.52 & 1.73 & 44 \\
$\mathbf{8}$ & 8.27 & 1.76 & 27 \\
$\mathbf{9}$ & 9.27 & 2.26 & 10 \\
$\mathbf{1 0}$ & 9.50 & 2.23 & 12 \\
$\mathbf{1 1}$ & 10.85 & 1.97 & 7 \\
$\mathbf{1 2}$ & 12.86 & 1.40 & 6 \\
\hline Total & - & - & 630 \\
\hline
\end{tabular}




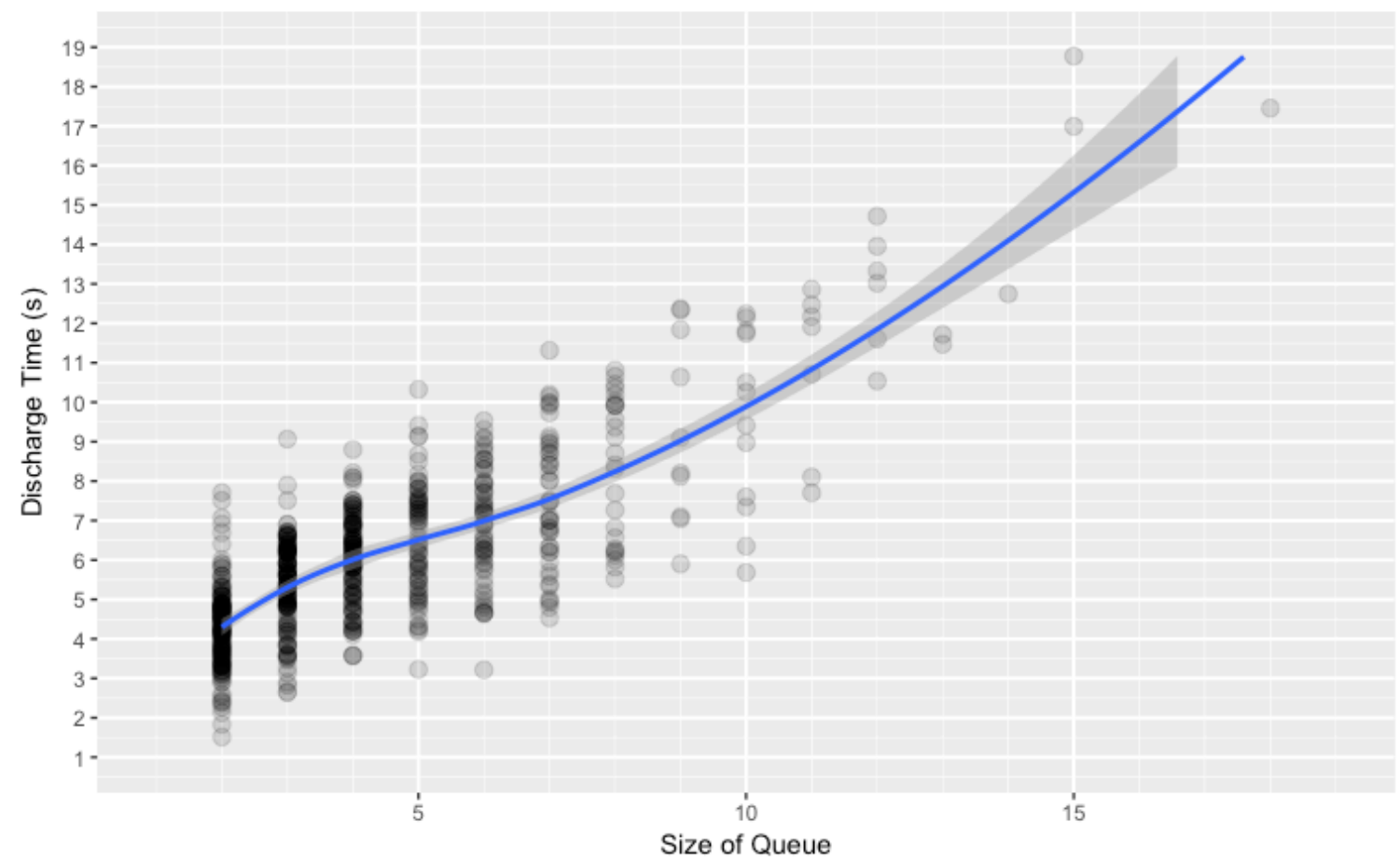

Figure 5-5 Queue Discharge Time for All Observed Queues

The queue characteristics that were analyzed in detail with respect to queue size consist of bikeway approach width, bikeway receiving width, bikeway crossing distance, intersection grade, and whether a bike box was utilized.

\subsubsection{Per Bikeway Approach Width}

The queue discharge times based on the queue size and bikeway approach width are tabulated in Table 9 and displayed in Figure 5-6 as a scatterplot with smoothed lines showing the conditional means associated with the various facility widths. The lines were plotted using R and the "+ stat_smooth(se=F)" option within the ggplot2 package. 


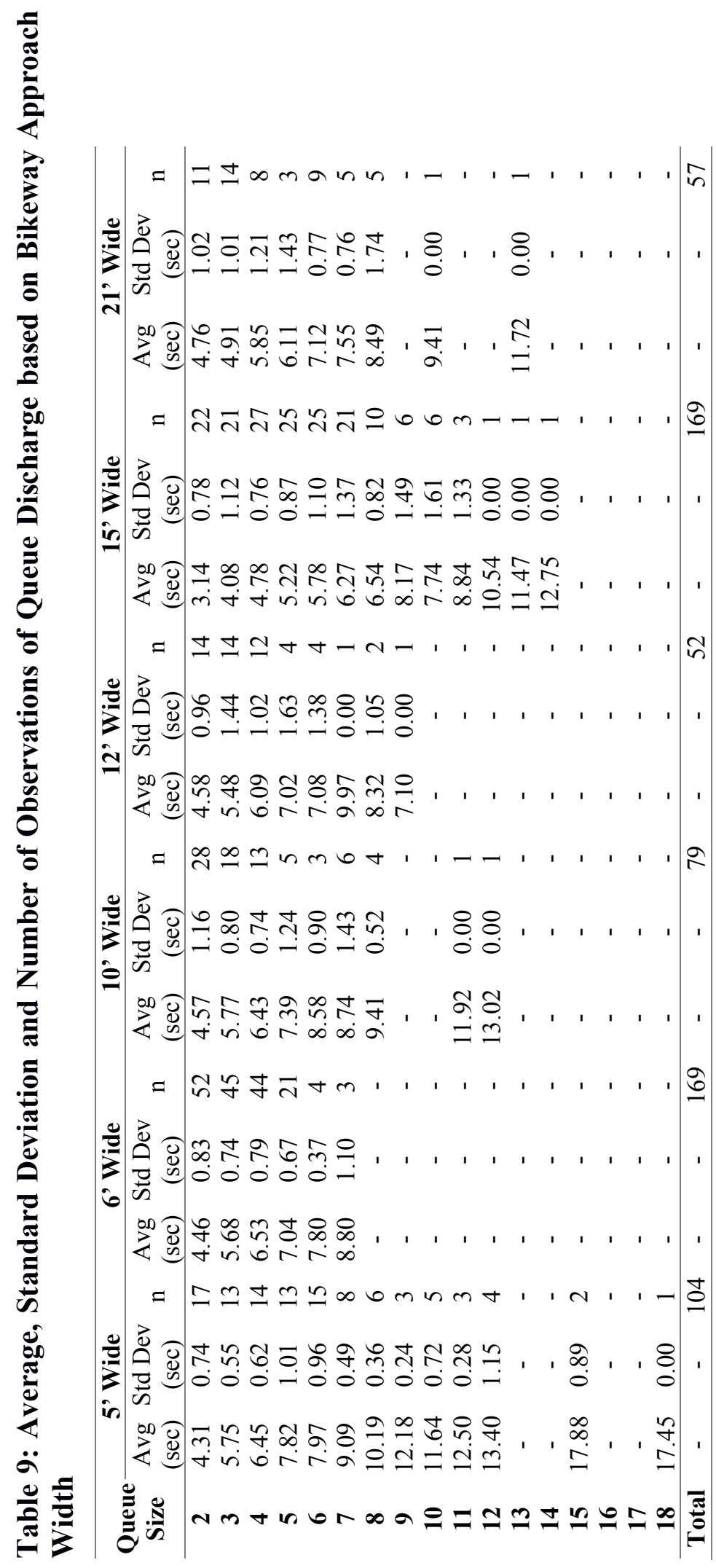




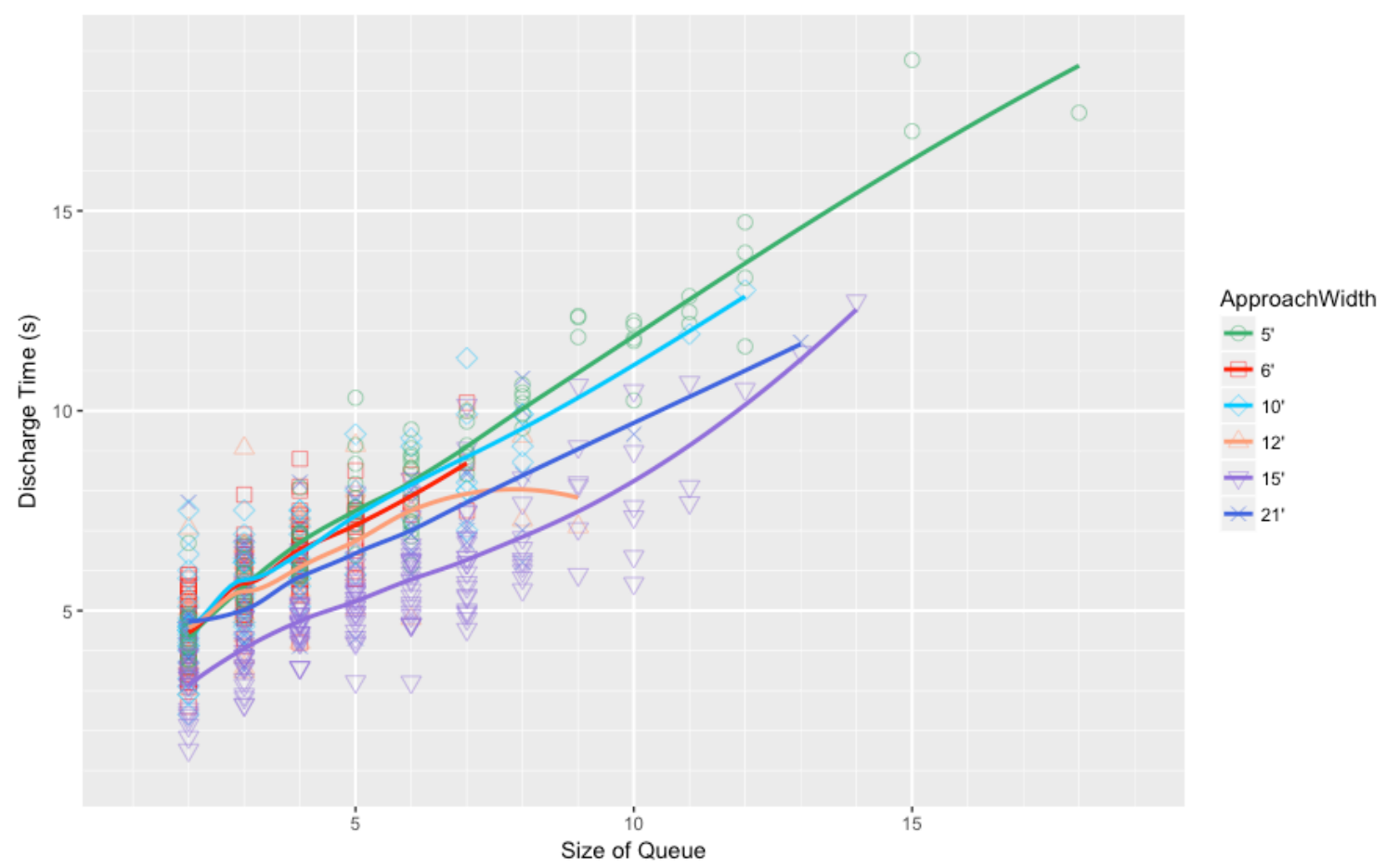

Figure 5-6 Queue Discharge Time based on Bikeway Approach Width

The results appear to indicate that, in general, wider bike facilities approaching an intersection discharge queues of bicyclists into the intersection over a shorter amount of time as compared to narrower approaches.

The installation of the bike box along the Madison approach, which increased the approach width from five to 15 feet, resulted in consistently lower average discharge times for all queue sizes, a reduction of greater than one second for queues of two cyclists to as much as about four seconds for queues of nine cyclists.

Similarly, given that the bike box at the Broadway approach was infrequently utilized, the queues that did not utilize any portion of the bike box were considered to have an approach width of 10 feet ( $7^{\prime}$ bike lane $+3^{\prime}$ buffer) rather than 21 feet that was available for queues that did utilize the bike box. It appears that the queues experienced a reduced discharge 
time when the area of the bike box was utilized, a reduction of as much as approximately two seconds for queues of 10 cyclists.

\subsubsection{Per Bikeway Receiving Width}

The queue discharge times based on the queue size and bikeway receiving width are tabulated in Table 10 and displayed in Figure 5-7 as a scatterplot with smoothed lines showing the conditional means associated with the various facility widths. The lines were plotted using R and the "+ stat_smooth(se=F)" option within the ggplot2 package.

Table 10: Average, Standard Deviation and Number of Observations of Queue Discharge based on Bikeway Receiving Width

\begin{tabular}{cccccccccc}
\hline \multirow{2}{*}{$\begin{array}{c}\text { Queue } \\
\text { Size }\end{array}$} & $\begin{array}{c}\text { 6' Wide } \\
\text { Avg } \\
(\mathrm{sec})\end{array}$ & $\begin{array}{c}\text { Std Dev } \\
(\mathrm{sec})\end{array}$ & $\mathrm{n}$ & $\begin{array}{c}\text { Avg } \\
(\mathrm{sec})\end{array}$ & $\begin{array}{c}\text { Std Dev } \\
(\mathrm{sec})\end{array}$ & $\mathrm{n}$ & $\begin{array}{c}\text { Avg } \\
(\mathrm{sec})\end{array}$ & $\begin{array}{c}\text { Std } \text { Sev } \\
(\mathrm{sec})\end{array}$ & $\mathrm{n}$ \\
\hline $\mathbf{2}$ & 4.46 & 0.83 & 52 & 4.58 & 0.96 & 14 & 4.14 & 1.16 & 78 \\
$\mathbf{3}$ & 5.68 & 0.74 & 45 & 5.48 & 1.44 & 14 & 5.05 & 1.18 & 66 \\
$\mathbf{4}$ & 6.53 & 0.79 & 44 & 6.09 & 1.02 & 12 & 5.64 & 1.12 & 62 \\
$\mathbf{5}$ & 7.04 & 0.67 & 21 & 7.02 & 1.63 & 4 & 6.25 & 1.55 & 46 \\
$\mathbf{6}$ & 7.80 & 0.37 & 4 & 7.08 & 1.38 & 4 & 6.81 & 1.44 & 52 \\
$\mathbf{7}$ & 8.80 & 1.10 & 3 & 9.97 & 0.00 & 1 & 7.37 & 1.71 & 40 \\
$\mathbf{8}$ & - & - & - & 8.32 & 1.05 & 2 & 8.27 & 1.80 & 25 \\
$\mathbf{9}$ & - & - & - & 7.10 & 0.00 & 1 & 9.51 & 2.26 & 9 \\
$\mathbf{1 0}$ & - & - & - & - & - & - & 9.50 & 2.23 & 12 \\
$\mathbf{1 1}$ & - & - & - & - & - & - & 10.85 & 1.97 & 7 \\
$\mathbf{1 2}$ & - & - & - & - & - & - & 12.86 & 1.40 & 6 \\
$\mathbf{1 3}$ & - & - & - & - & - & - & 11.59 & 0.12 & 2 \\
$\mathbf{1 4}$ & - & - & - & - & - & - & 12.75 & 0.00 & 1 \\
$\mathbf{1 5}$ & - & - & - & - & - & - & 17.88 & 0.89 & 2 \\
$\mathbf{1 6}$ & - & - & - & - & - & - & - & - & - \\
$\mathbf{1 7}$ & - & - & - & - & - & - & - & - & - \\
$\mathbf{1 8}$ & - & - & - & - & - & - & 17.45 & 0.00 & 1 \\
\hline Total & - & - & 169 & - & - & 52 & - & - & 409 \\
\hline
\end{tabular}




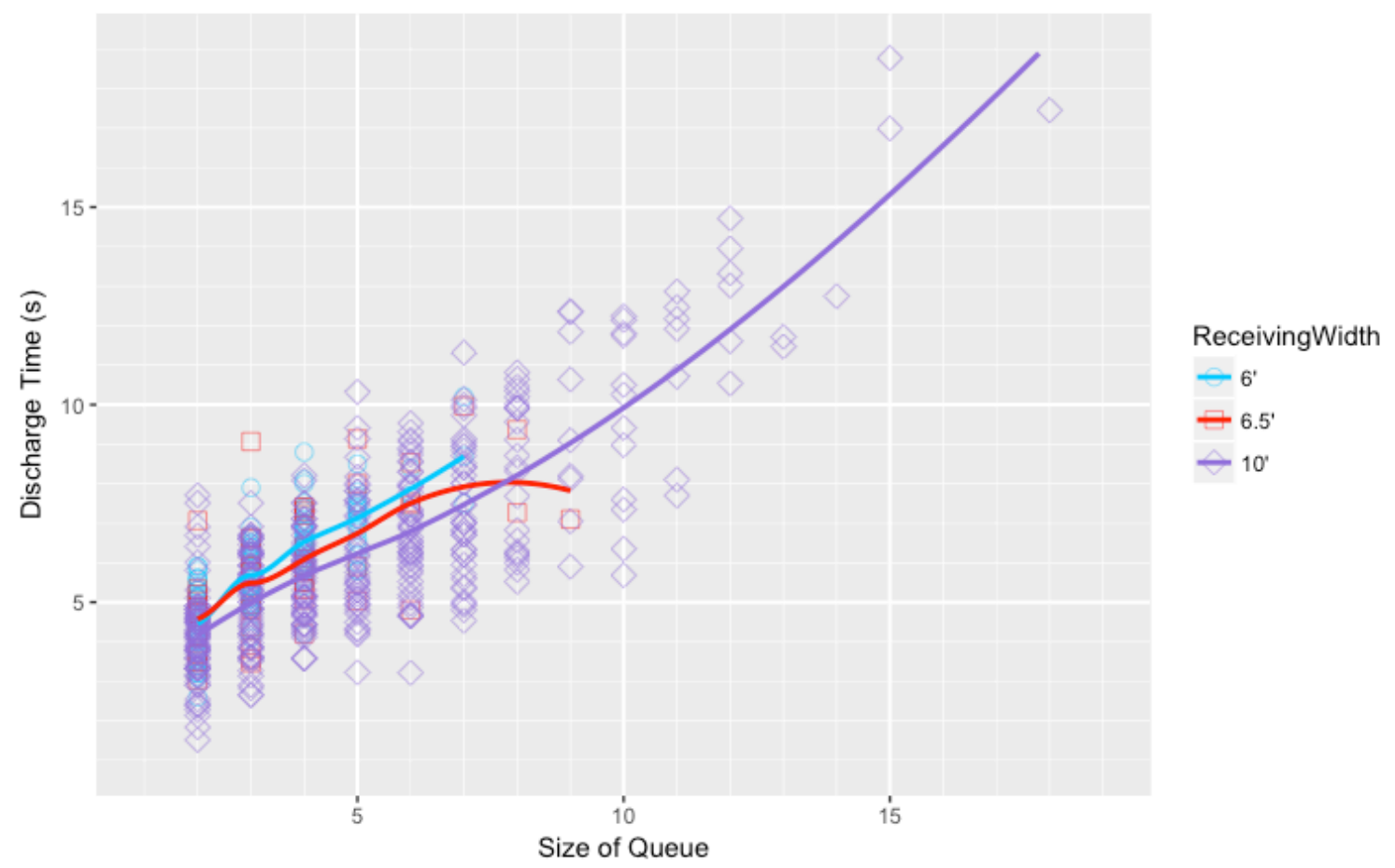

Figure 5-7 Queue Discharge Time based on Bikeway Receiving Width

The results appear to indicate that wider receiving bike facilities generally discharge queues of bicyclists into the intersection over a shorter amount of time as compared to narrower receiving facilities.

\subsubsection{Per Crossing Distance}

The queue discharge times based on the queue size and bikeway crossing distance are tabulated in Table 11 and displayed in Figure 5-8 as a scatterplot with smoothed lines showing the conditional means associated with the various facility distances. The lines were plotted using R and the "+ stat_smooth(se=F)" option within the ggplot2 package. 
Table 11: Average, Standard Deviation and Number of Observations of Queue Discharge based on Crossing Distance

\begin{tabular}{|c|c|c|c|c|c|c|c|c|c|c|c|c|}
\hline \multirow[b]{2}{*}{$\begin{array}{l}\text { Queue } \\
\text { Size }\end{array}$} & \multicolumn{3}{|c|}{ 46' } & \multicolumn{3}{|c|}{ 54' } & \multicolumn{3}{|c|}{56} & \multicolumn{3}{|c|}{ 60' } \\
\hline & $\begin{array}{l}\text { Avg } \\
(\mathrm{sec})\end{array}$ & $\begin{array}{l}\text { Std Dev } \\
(\mathrm{sec})\end{array}$ & $\mathrm{n}$ & $\begin{array}{l}\text { Avg } \\
\text { (sec) }\end{array}$ & $\begin{array}{l}\text { Std Dev } \\
(\mathrm{sec})\end{array}$ & $\mathrm{n}$ & $\begin{array}{l}\text { Avg } \\
(\mathrm{sec})\end{array}$ & $\begin{array}{c}\text { Std Dev } \\
(\mathrm{sec})\end{array}$ & $\mathrm{n}$ & $\begin{array}{l}\text { Avg } \\
\text { (sec) }\end{array}$ & $\begin{array}{c}\text { Std Dev } \\
(\mathrm{sec})\end{array}$ & $\mathrm{n}$ \\
\hline 2 & 4.63 & 1.13 & 39 & 3.65 & 0.96 & 39 & 4.58 & 0.96 & 14 & 4.46 & 0.83 & 52 \\
\hline 3 & 5.39 & 0.99 & 32 & 4.72 & 1.24 & 34 & 5.48 & 1.44 & 14 & 5.68 & 0.74 & 45 \\
\hline 4 & 6.21 & 0.99 & 21 & 5.35 & 1.07 & 41 & 6.09 & 1.02 & 12 & 6.53 & 0.79 & 44 \\
\hline 5 & 6.91 & 1.45 & 8 & 6.11 & 1.54 & 38 & 7.02 & 1.63 & 4 & 7.04 & 0.67 & 21 \\
\hline 6 & 7.48 & 1.02 & 12 & 6.60 & 1.49 & 40 & 7.08 & 1.38 & 4 & 7.80 & 0.37 & 4 \\
\hline 7 & 8.20 & 1.32 & 11 & 7.05 & 1.73 & 29 & 9.97 & 0.00 & 1 & 8.80 & 1.10 & 3 \\
\hline 8 & 8.90 & 1.42 & 9 & 7.91 & 1.90 & 16 & 8.32 & 1.05 & 2 & - & - & - \\
\hline 9 & - & - & - & 9.51 & 2.26 & 9 & 7.10 & 0.00 & 1 & - & - & - \\
\hline 10 & 9.41 & 0.00 & 1 & 9.51 & 2.32 & 11 & - & - & - & - & - & - \\
\hline 11 & 11.92 & 0.00 & 1 & 10.67 & 2.07 & 6 & - & - & - & - & - & - \\
\hline 12 & 13.02 & 0.00 & 1 & 12.83 & 1.54 & 5 & - & - & - & - & - & - \\
\hline 13 & 11.72 & 0.00 & 1 & 11.47 & 0.00 & 1 & - & - & - & - & - & - \\
\hline 14 & - & - & - & 12.75 & 0.00 & 1 & - & - & - & - & - & - \\
\hline 15 & - & - & - & 17.88 & 0.89 & 2 & - & - & - & - & - & - \\
\hline 16 & - & - & - & - & - & - & - & - & - & - & - & - \\
\hline 17 & - & - & - & - & - & - & - & - & - & - & - & - \\
\hline 18 & - & - & - & 17.45 & 0.00 & 1 & - & - & - & - & - & - \\
\hline Total & - & - & 136 & - & - & 273 & - & - & 52 & - & - & 169 \\
\hline
\end{tabular}

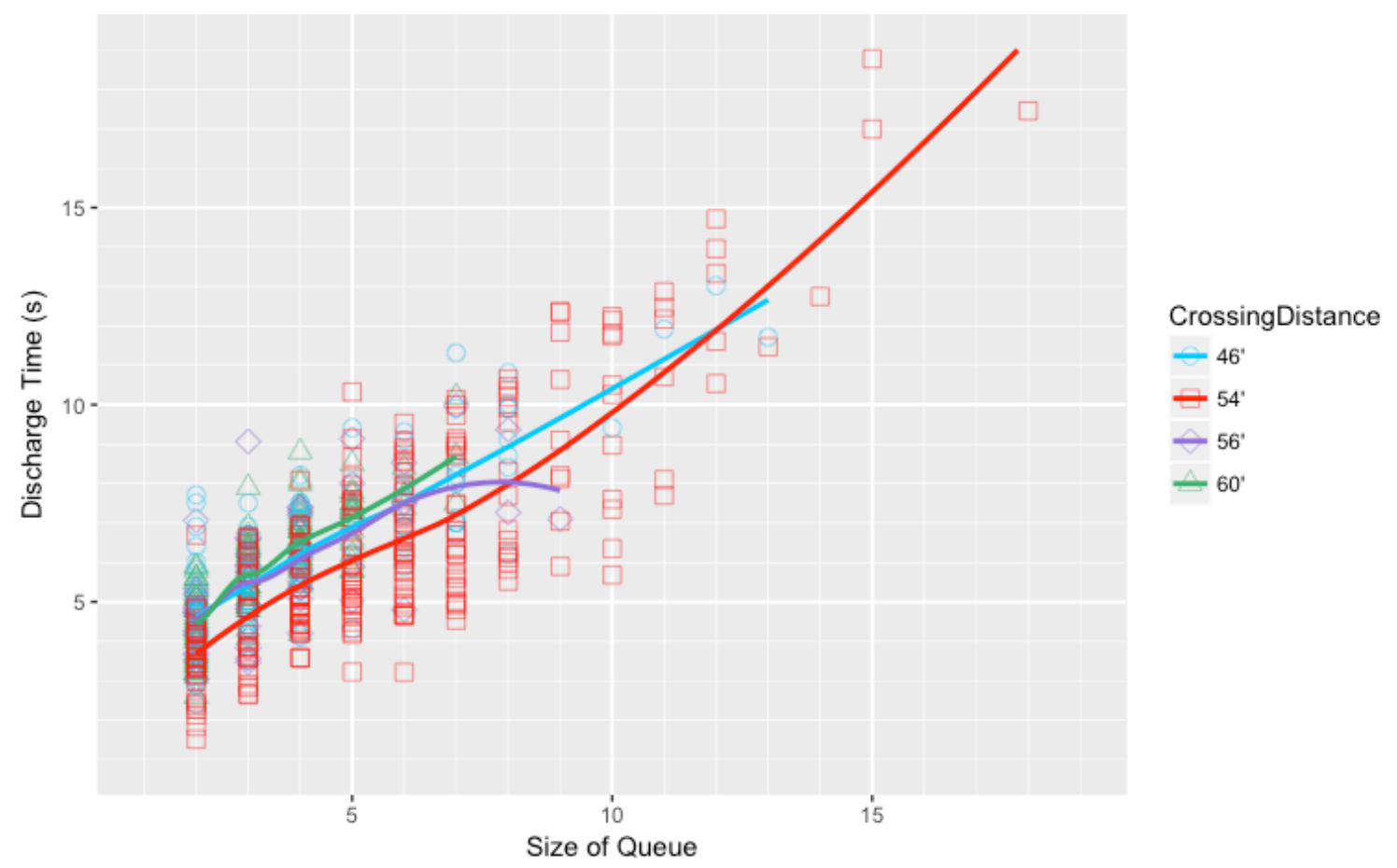

Figure 5-8 Queue Discharge Time based on Bikeway Crossing Distance 
The results do not appear to indicate a relationship between crossing distance and queue discharge rates, given the largest crossing distance experiences a similar discharge rate as the shortest crossing distance.

\subsubsection{Per Approach Grade}

The queue discharge times based on the queue size and approach grade of the bikeway are tabulated in Table 12 and displayed in Figure 5-9 as a scatterplot with smoothed lines showing the conditional means associated with the various grades. The lines were plotted using R and the "+ stat_smooth(se=F)" option within the ggplot2 package.

Table 12: Average, Standard Deviation and Number of Observations of Queue Discharge based on Approach Grade

\begin{tabular}{|c|c|c|c|c|c|c|c|c|c|}
\hline \multirow[b]{2}{*}{$\begin{array}{l}\text { Queue } \\
\text { Size }\end{array}$} & \multicolumn{3}{|c|}{$-4 \%$} & \multicolumn{3}{|c|}{$+1 \%$} & \multicolumn{3}{|c|}{$+2 \%$} \\
\hline & $\begin{array}{l}\text { Avg } \\
(\mathrm{sec})\end{array}$ & $\begin{array}{l}\text { Std Dev } \\
(\mathrm{sec})\end{array}$ & $\mathrm{n}$ & $\begin{array}{l}\text { Avg } \\
\text { (sec) }\end{array}$ & $\begin{array}{l}\text { Std Dev } \\
(\mathrm{sec})\end{array}$ & $\mathrm{n}$ & $\begin{array}{l}\text { Avg } \\
(\mathrm{sec})\end{array}$ & $\begin{array}{c}\text { Std Dev } \\
(\mathrm{sec})\end{array}$ & $\mathrm{n}$ \\
\hline 2 & 4.61 & 1.09 & 53 & 4.46 & 0.83 & 52 & 3.65 & 0.96 & 39 \\
\hline 3 & 5.42 & 1.15 & 46 & 5.68 & 0.74 & 45 & 4.72 & 1.24 & 34 \\
\hline 4 & 6.16 & 1.00 & 33 & 6.53 & 0.79 & 44 & 5.35 & 1.07 & 41 \\
\hline 5 & 6.95 & 1.52 & 12 & 7.04 & 0.67 & 21 & 6.11 & 1.54 & 38 \\
\hline 6 & 7.38 & 1.14 & 16 & 7.80 & 0.37 & 4 & 6.60 & 1.49 & 40 \\
\hline 7 & 8.35 & 1.35 & 12 & 8.80 & 1.10 & 3 & 7.05 & 1.73 & 29 \\
\hline 8 & 8.79 & 1.38 & 11 & - & - & - & 7.91 & 1.90 & 16 \\
\hline 9 & 7.10 & 0.00 & 1 & - & - & - & 9.51 & 2.26 & 9 \\
\hline 10 & 9.41 & 0.00 & 1 & - & - & - & 9.51 & 2.32 & 11 \\
\hline 11 & 11.92 & 0.00 & 1 & - & - & - & 10.67 & 2.07 & 6 \\
\hline 12 & 13.02 & 0.00 & 1 & - & - & - & 12.83 & 1.54 & 5 \\
\hline 13 & 11.72 & 0.00 & 1 & - & - & - & 11.47 & 0.00 & 1 \\
\hline 14 & - & - & - & - & - & - & 12.75 & 0.00 & 1 \\
\hline 15 & - & - & - & - & - & - & 17.88 & 0.89 & 2 \\
\hline 16 & - & - & - & - & - & - & - & - & - \\
\hline 17 & - & - & - & - & - & - & - & - & - \\
\hline 18 & - & - & - & - & - & - & 17.45 & 0.00 & 1 \\
\hline Total & - & - & 188 & - & - & 169 & - & - & 273 \\
\hline
\end{tabular}




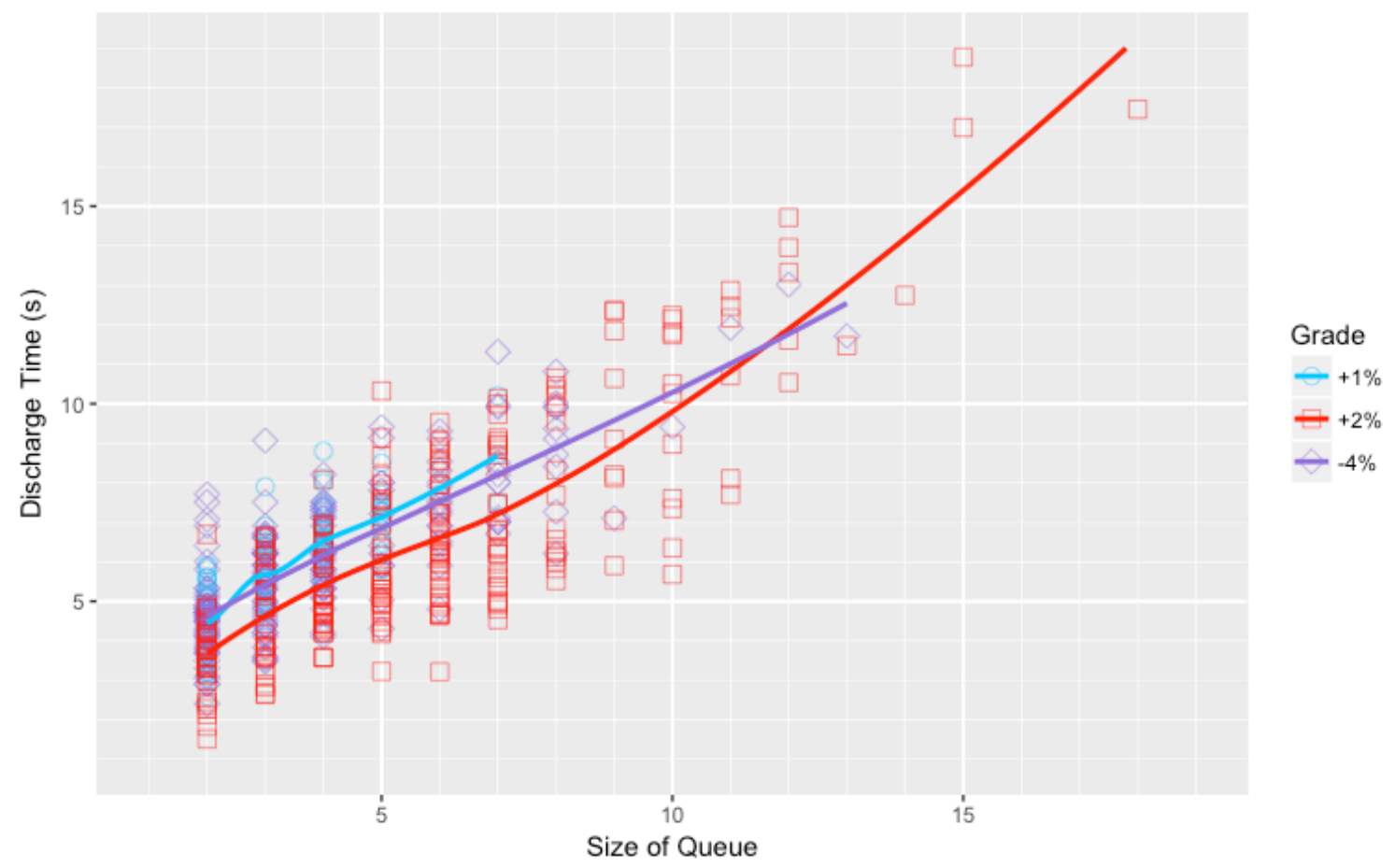

Figure 5-9 Queue Discharge Time based on Approach Grade

The results display very similar discharge rates for the $+1 \%$ approach grade and the $-4 \%$ approach grade, whereas the $+2 \%$ approach grades consistently had lower discharge rates for queues of 10 or fewer cyclists. Therefore, there is no apparent relationship between queue discharge rates and uphill or downhill approaches.

\subsubsection{Per Utilization of the Bike Box}

The queue discharge times based on the queue size and utilization of the bike box at the intersection approach are tabulated in Table 13 and displayed in Figure 5-10 as a scatterplot with smoothed lines showing the conditional means and the 95 percent confidence interval as the shaded area. The lines were plotted using R and the "+ stat_smooth(se=T)" option within the ggplot2 package. 
Table 13: Average, Standard Deviation and Number of Observations of Queue Discharge based on Utilization of Bike Box

\begin{tabular}{ccccccc}
\hline \multirow{2}{*}{$\begin{array}{c}\text { Queue } \\
\text { Size }\end{array}$} & \multicolumn{3}{c}{ Bikg Box Utilized } & \multicolumn{4}{c}{ Bike Box Not Utilized } \\
\hline $\mathbf{2}$ (sec) & $\begin{array}{c}\text { Std Dev } \\
(\mathrm{sec})\end{array}$ & $\mathrm{n}$ & $\begin{array}{c}\text { Avg } \\
(\mathrm{sec})\end{array}$ & $\begin{array}{c}\text { Std Dev } \\
(\mathrm{sec})\end{array}$ & $\mathrm{n}$ \\
\hline $\mathbf{2}$ & 3.68 & 1.16 & 33 & 4.48 & 0.93 & 111 \\
$\mathbf{3}$ & 4.41 & 1.15 & 35 & 5.68 & 0.88 & 90 \\
$\mathbf{4}$ & 5.02 & 0.99 & 35 & 6.43 & 0.81 & 83 \\
$\mathbf{5}$ & 5.32 & 0.99 & 28 & 7.31 & 1.04 & 43 \\
$\mathbf{6}$ & 6.14 & 1.18 & 34 & 7.88 & 1.05 & 26 \\
$\mathbf{7}$ & 6.52 & 1.37 & 26 & 8.98 & 1.04 & 18 \\
$\mathbf{8}$ & 7.19 & 1.52 & 15 & 9.62 & 0.89 & 12 \\
$\mathbf{9}$ & 8.17 & 1.49 & 6 & 10.91 & 2.21 & 4 \\
$\mathbf{1 0}$ & 7.98 & 1.60 & 7 & 11.64 & 0.72 & 5 \\
$\mathbf{1 1}$ & 8.84 & 1.33 & 3 & 12.36 & 0.35 & 4 \\
$\mathbf{1 2}$ & 10.54 & 0.00 & 1 & 13.32 & 1.04 & 5 \\
$\mathbf{1 3}$ & 11.59 & 0.12 & 2 & - & - & - \\
$\mathbf{1 4}$ & 12.75 & 0.00 & 1 & - & - & - \\
$\mathbf{1 5}$ & - & - & - & 17.88 & 0.89 & 2 \\
$\mathbf{1 6}$ & - & - & - & - & - & - \\
$\mathbf{1 7}$ & - & - & - & - & - & - \\
$\mathbf{1 8}$ & - & - & - & 17.45 & 0.00 & 1 \\
\hline Total & - & - & 226 & - & - & 404 \\
\hline
\end{tabular}

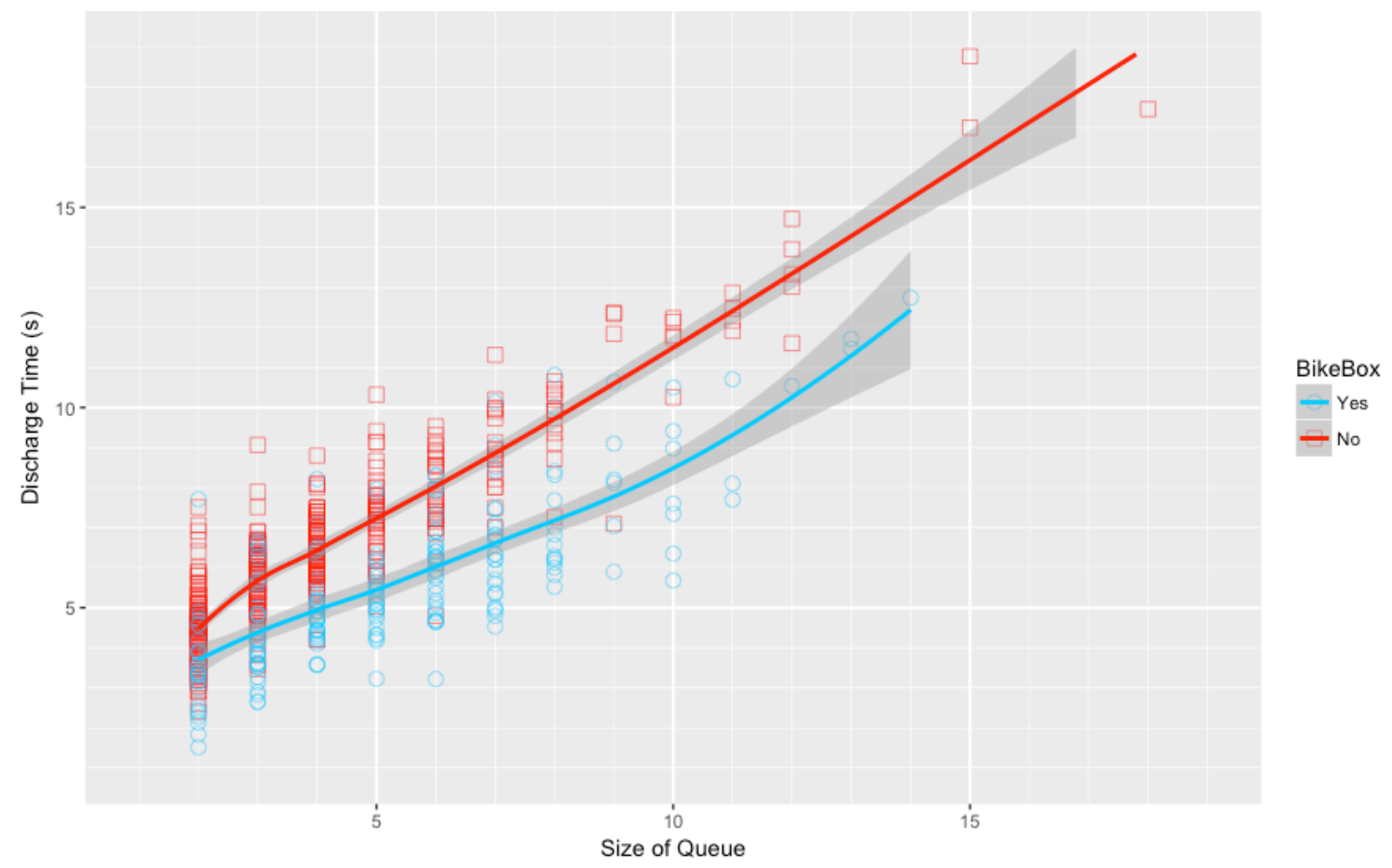

Figure 5-10 Queue Discharge Time based on Utilization of the Bike Box 
The results appear to indicate that utilization of the bike box has a potential relationship with a reduced queue discharge time as compared to queues that do not utilize the bike box. The associated reduction in queue discharge time is greatest for queues of nine cyclists with a reduction of approximately three seconds.

\subsubsection{Findings}

The queue discharge results appear to potentially indicate that wider bike facilities approaching an intersection, wider receiving bike facilities, or utilization of a bike box generally discharge queues of bicyclists into the intersection over a shorter amount of time as compared to narrower features or underutilized facilities.

The installation of the bike box along the Madison approach, which increased the approach width from five to 15 feet, resulted in consistently lower average discharge times for all queue sizes, a reduction of greater than one second for queues of two cyclists to as much as about four seconds for queues of nine cyclists.

\subsection{Intersection Clearance Times}

This section presents detailed analysis of the intersection clearance times for queues of cyclists based on their respective size. All observed queues are tabulated in Table 14 and displayed in Figure 5-11 as a scatterplot with a smoothed line showing the mean and the 95 percent confidence interval as the shaded area. This line was plotted using $\mathrm{R}$ and the "+ stat_smooth(se=T)" option within the ggplot2 package. 
Table 14: Average, Standard Deviation and Number of Observations of Intersection Clearance Time

\begin{tabular}{cccc}
\hline \multirow{2}{*}{ Queue Size } & \multicolumn{3}{c}{ All Observations } \\
\cline { 2 - 4 } & Avg (sec) & Std Dev (sec) & $\mathrm{n}$ \\
\hline $\mathbf{2}$ & 8.63 & 1.26 & 144 \\
$\mathbf{3}$ & 9.62 & 1.31 & 125 \\
$\mathbf{4}$ & 10.12 & 1.14 & 118 \\
$\mathbf{5}$ & 10.65 & 1.37 & 71 \\
$\mathbf{6}$ & 10.73 & 1.41 & 60 \\
$\mathbf{7}$ & 11.31 & 1.48 & 44 \\
$\mathbf{8}$ & 11.85 & 1.53 & 27 \\
$\mathbf{9}$ & 12.77 & 1.99 & 10 \\
$\mathbf{1 0}$ & 13.11 & 1.81 & 12 \\
$\mathbf{1 1}$ & 14.26 & 1.73 & 7 \\
$\mathbf{1 2}$ & 16.04 & 1.47 & 6 \\
$\mathbf{1 3}$ & 14.75 & 0.23 & 2 \\
$\mathbf{1 4}$ & 16.26 & 0.00 & 1 \\
$\mathbf{1 5}$ & 21.02 & 1.02 & 2 \\
$\mathbf{1 6}$ & - & - & - \\
$\mathbf{1 7}$ & - & - & - \\
$\mathbf{1 8}$ & 20.33 & 0.00 & 1 \\
\hline Total & - & - & 630 \\
\hline
\end{tabular}

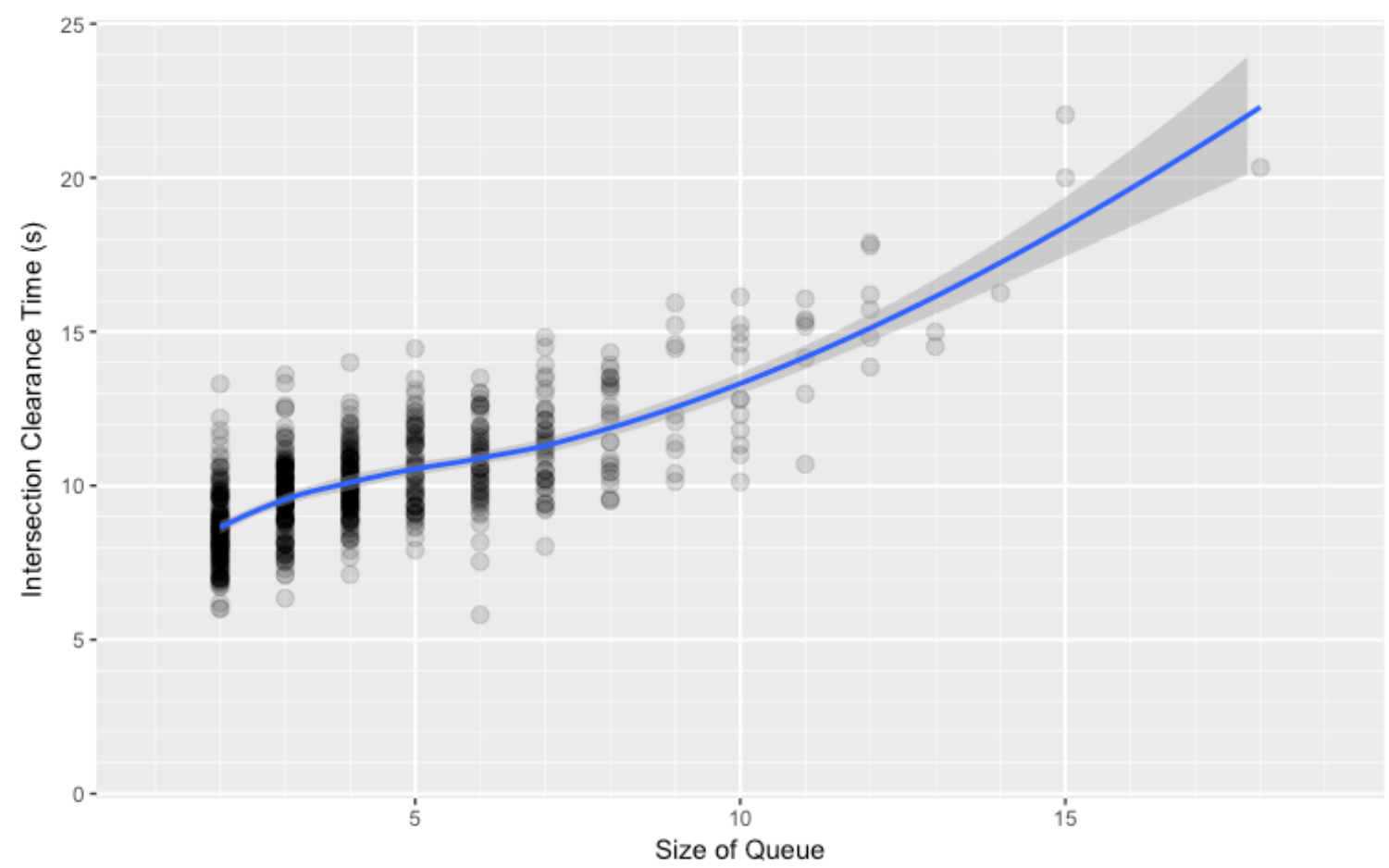

Figure 5-11 Intersection Clearance Time for All Observed Queues 
The queue characteristics that were analyzed in detail with respect to queue size consist of bikeway approach width, bikeway receiving width, bikeway crossing distance, intersection grade, and whether a bike box was utilized.

\subsubsection{Per Bikeway Approach Width}

The intersection clearance times based on the queue size and bikeway approach width are tabulated in Table 15 and displayed in Figure 5-12 as a scatterplot with smoothed lines showing the conditional means associated with the various facility widths. The lines were plotted using R and the "+ stat_smooth(se=F)" option within the ggplot2 package. 


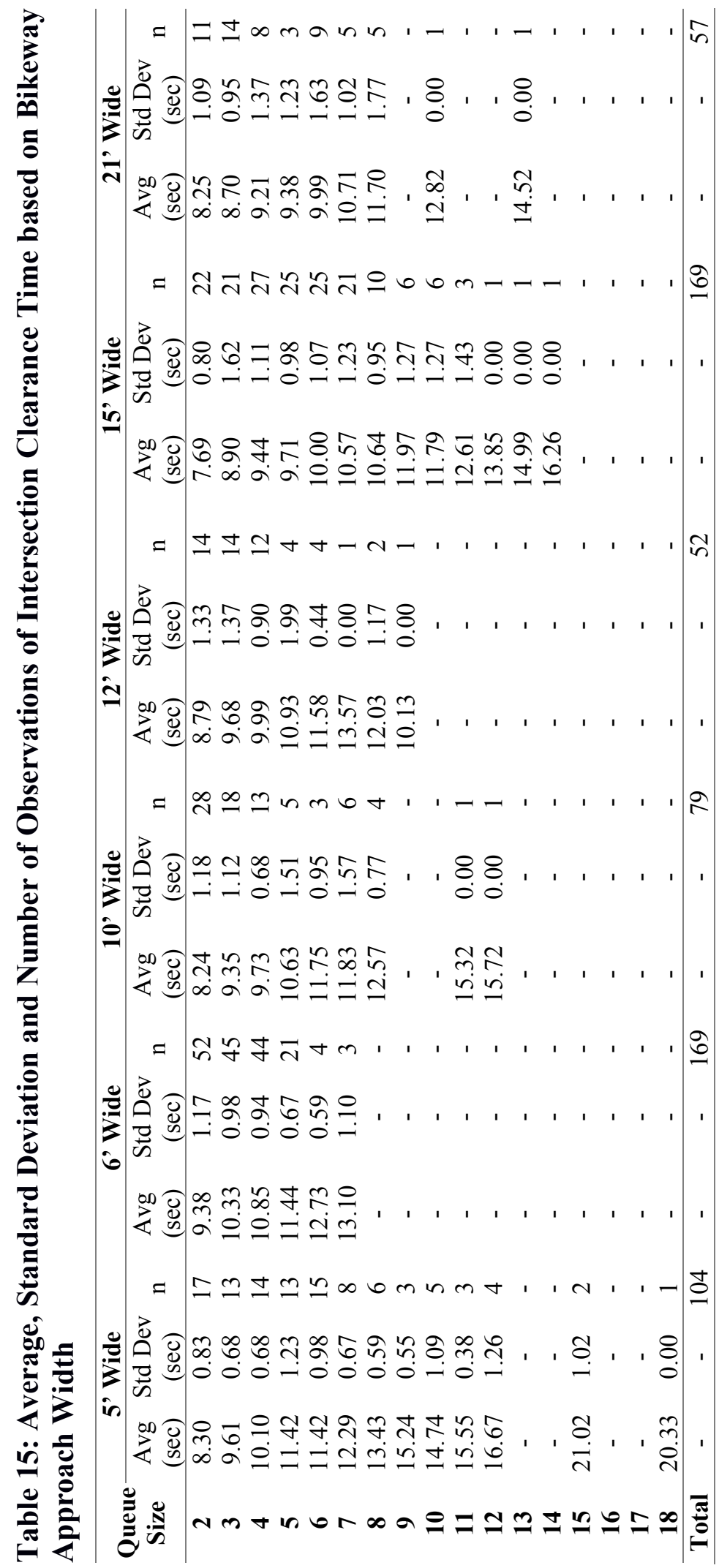




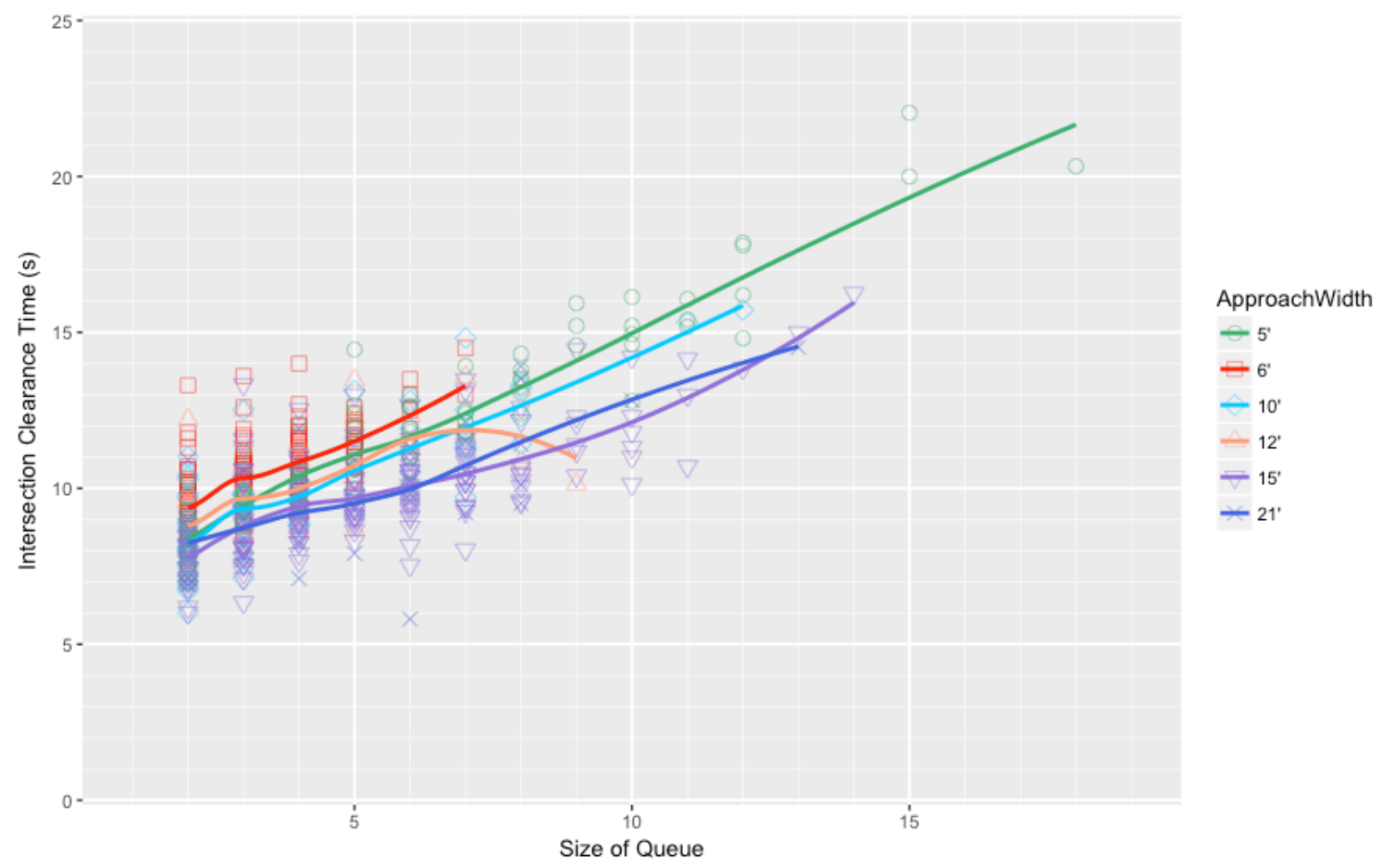

Figure 5-12 Intersection Clearance Time based on Bikeway Approach Width

The results appear to indicate that, in general, wider bike facilities approaching an intersection clear queues of bicyclists through the intersection over a shorter amount of time as compared to narrower approaches.

The installation of the bike box along the Madison approach, which increased the approach width from five to 15 feet, resulted in consistently lower clearance times for all queue sizes. For example, the reduction for queues of 10 cyclists was approximately three seconds.

Similarly, given that the bike box at the Broadway approach was infrequently utilized, the queues that did not utilize any portion of the bike box were considered to have an approach width of 10 feet ( $7^{\prime}$ bike lane $+3^{\prime}$ buffer) rather than 21 feet that was available for queues 
that did utilize the bike box. It appears that the queues experience a reduced clearance time when the area of the bike box was utilized, a reduction of as much as approximately two seconds for queues of 12 cyclists.

\subsubsection{Per Bikeway Receiving Width}

The intersection clearance times based on the queue size and bikeway receiving width are tabulated in Table 16 and displayed in Figure 5-13 as a scatterplot with smoothed lines showing the conditional means associated with the various facility widths. The lines were plotted using R and the “+ stat_smooth(se=F)" option within the ggplot2 package.

Table 16: Average, Standard Deviation and Number of Observations of Intersection Clearance Time based on Bikeway Receiving Width

\begin{tabular}{|c|c|c|c|c|c|c|c|c|c|}
\hline \multirow{2}{*}{$\begin{array}{c}\text { Queue } \\
\text { Size }\end{array}$} & \multicolumn{3}{|c|}{ 6' Wide } & \multicolumn{3}{|c|}{ 6.5' Wide } & \multicolumn{3}{|c|}{ 10' Wide } \\
\hline & $\begin{array}{l}\text { Avg } \\
(\mathrm{sec})\end{array}$ & $\begin{array}{l}\text { Std Dev } \\
(\mathrm{sec})\end{array}$ & $\mathrm{n}$ & $\begin{array}{l}\text { Avg } \\
(\mathrm{sec})\end{array}$ & $\begin{array}{l}\text { Std Dev } \\
(\mathrm{sec})\end{array}$ & $\mathrm{n}$ & $\begin{array}{l}\text { Avg } \\
(\mathrm{sec})\end{array}$ & $\begin{array}{c}\text { Std Dev } \\
(\mathrm{sec})\end{array}$ & $\mathrm{n}$ \\
\hline 2 & 9.38 & 1.17 & 52 & 8.79 & 1.33 & 14 & 8.10 & 1.03 & 78 \\
\hline 3 & 10.33 & 0.98 & 45 & 9.68 & 1.37 & 14 & 9.12 & 1.26 & 66 \\
\hline 4 & 10.85 & 0.94 & 44 & 9.99 & 0.90 & 12 & 9.62 & 1.04 & 62 \\
\hline 5 & 11.44 & 0.67 & 21 & 10.93 & 1.99 & 4 & 10.27 & 1.38 & 46 \\
\hline 6 & 12.73 & 0.59 & 4 & 11.58 & 0.44 & 4 & 10.51 & 1.36 & 52 \\
\hline 7 & 13.10 & 1.10 & 3 & 13.57 & 0.00 & 1 & 11.12 & 1.38 & 40 \\
\hline 8 & - & - & - & 12.03 & 1.17 & 2 & 11.83 & 1.56 & 25 \\
\hline 9 & - & - & - & 10.13 & 0.00 & 1 & 13.06 & 1.89 & 9 \\
\hline 10 & - & - & - & - & - & - & 13.11 & 1.81 & 12 \\
\hline 11 & - & - & - & - & - & - & 14.26 & 1.73 & 7 \\
\hline 12 & - & - & - & - & - & - & 16.04 & 1.47 & 6 \\
\hline 13 & - & - & - & - & - & - & 14.75 & 0.23 & 2 \\
\hline 14 & - & - & - & - & - & - & 16.26 & 0.00 & 1 \\
\hline 15 & - & - & - & - & - & - & 21.02 & 1.02 & 2 \\
\hline 16 & - & - & - & - & - & - & - & - & - \\
\hline 17 & - & - & - & - & - & - & - & - & - \\
\hline 18 & - & - & - & - & - & - & 20.33 & 0.00 & 1 \\
\hline Total & - & - & 169 & - & - & 52 & - & - & 409 \\
\hline
\end{tabular}




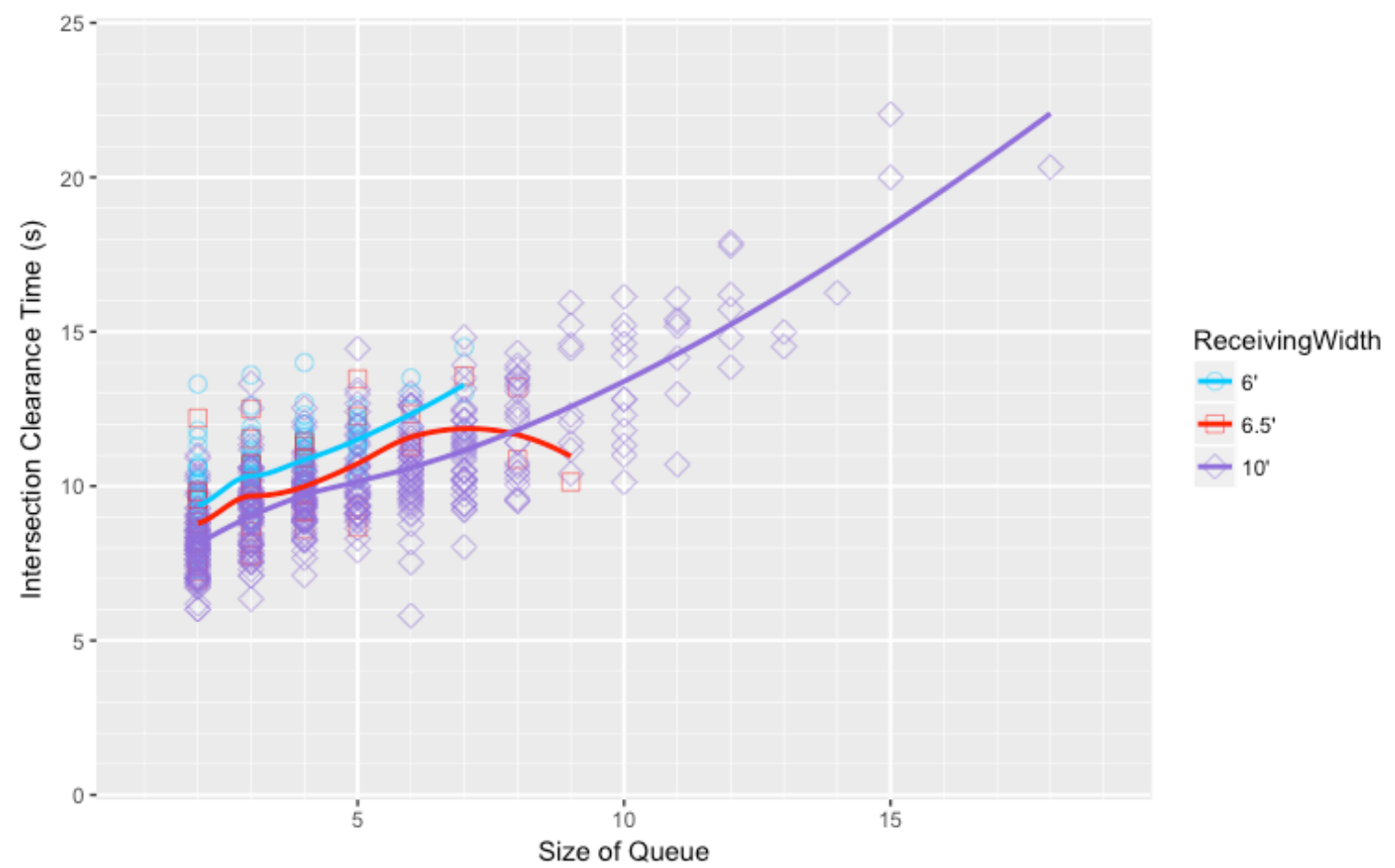

Figure 5-13 Intersection Clearance Time based on Bikeway Receiving Width

The results appear to indicate that wider receiving bike facilities generally clear queues of bicyclists through the intersection over a shorter amount of time as compared to narrower receiving facilities.

\subsubsection{Per Crossing Distance}

The intersection clearance times based on the queue size and bikeway crossing distance are tabulated in Table 17 and displayed in Figure 5-14 as a scatterplot with smoothed lines showing the conditional means associated with the various facility distances. The lines were plotted using R and the "+ stat_smooth(se=F)" option within the ggplot2 package. 
Table 17: Average, Standard Deviation and Number of Observations of Intersection Clearance Time based on Crossing Distance

\begin{tabular}{ccccccccccccc}
\hline $\begin{array}{c}\text { Queue } \\
\text { Size }\end{array}$ & $\begin{array}{c}\text { Avg } \\
\text { (sec) }\end{array}$ & $\begin{array}{c}\text { Std Dev } \\
(\mathrm{sec})\end{array}$ & $\mathrm{n}$ & $\begin{array}{c}\text { Avg } \\
(\mathrm{sec})\end{array}$ & $\begin{array}{c}\text { Std Dev } \\
(\mathrm{sec})\end{array}$ & $\mathrm{n}$ & $\begin{array}{c}\text { Avg } \\
(\mathrm{sec})\end{array}$ & $\begin{array}{c}\text { Std Dev } \\
(\mathrm{sec})\end{array}$ & $\begin{array}{c}\mathrm{n} \\
\text { (td }\end{array}$ & $\begin{array}{c}\text { Avg } \\
(\mathrm{sec})\end{array}$ & $\begin{array}{c}\text { Std Dev } \\
(\mathrm{sec})\end{array}$ & $\mathrm{n}$ \\
\hline $\mathbf{2}$ & 8.24 & 1.16 & 39 & 7.96 & 0.87 & 39 & 8.79 & 1.33 & 14 & 9.38 & 1.17 & 52 \\
$\mathbf{3}$ & 9.07 & 1.10 & 32 & 9.17 & 1.38 & 34 & 9.68 & 1.37 & 14 & 10.33 & 0.98 & 45 \\
$\mathbf{4}$ & 9.53 & 1.03 & 21 & 9.66 & 1.03 & 41 & 9.99 & 0.90 & 12 & 10.85 & 0.94 & 44 \\
$\mathbf{5}$ & 10.16 & 1.54 & 8 & 10.30 & 1.34 & 38 & 10.93 & 1.99 & 4 & 11.44 & 0.67 & 21 \\
$\mathbf{6}$ & 10.43 & 1.67 & 12 & 10.53 & 1.24 & 40 & 11.58 & 0.44 & 4 & 12.73 & 0.59 & 4 \\
$\mathbf{7}$ & 11.32 & 1.45 & 11 & 11.04 & 1.34 & 29 & 13.57 & 0.00 & 1 & 13.10 & 1.10 & 3 \\
$\mathbf{8}$ & 12.08 & 1.48 & 9 & 11.69 & 1.58 & 16 & 12.03 & 1.17 & 2 & - & - & - \\
$\mathbf{9}$ & - & - & - & 13.06 & 1.89 & 9 & 10.13 & 0.00 & 1 & - & - & - \\
$\mathbf{1 0}$ & 12.82 & 0.00 & 1 & 13.13 & 1.89 & 11 & - & - & - & - & - & - \\
$\mathbf{1 1}$ & 15.32 & 0.00 & 1 & 14.08 & 1.80 & 6 & - & - & - & - & - & - \\
$\mathbf{1 2}$ & 15.72 & 0.00 & 1 & 16.11 & 1.60 & 5 & - & - & - & - & - & - \\
$\mathbf{1 3}$ & 14.52 & 0.00 & 1 & 14.99 & 0.00 & 1 & - & - & - & - & - & - \\
$\mathbf{1 4}$ & - & - & - & 16.26 & 0.00 & 1 & - & - & - & - & - & - \\
$\mathbf{1 5}$ & - & - & - & 21.02 & 1.02 & 2 & - & - & - & - & - & - \\
$\mathbf{1 6}$ & - & - & - & - & - & - & - & - & - & - & - & - \\
$\mathbf{1 7}$ & - & - & - & - & - & - & - & - & - & - & - & - \\
$\mathbf{1 8}$ & - & - & - & 20.33 & 0.00 & 1 & - & - & - & - & - & - \\
\hline Total & - & - & - & - & - & 273 & - & - & 52 & - & - & 169 \\
\hline
\end{tabular}

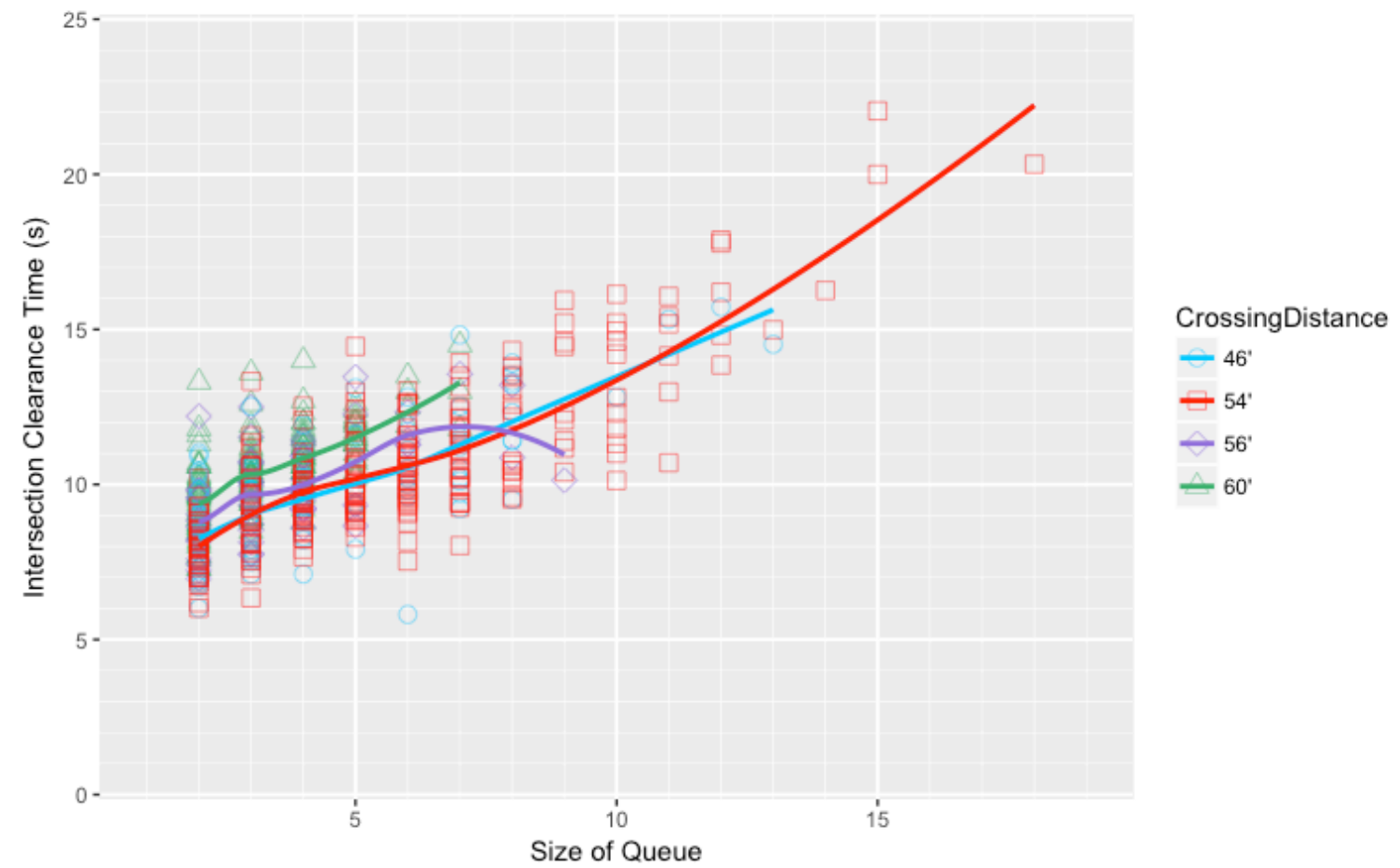

Figure 5-14 Intersection Clearance Time based on Bikeway Crossing Distance 
The results do not appear to indicate a significant relationship between crossing distance and intersection clearance times, given the relative similarities in clearance times as compared to the differences in crossing widths.

\subsubsection{Per Approach Grade}

The intersection clearance times based on the queue size and approach grade of the bikeway are tabulated in Table 18 and displayed in Figure 5-15 as a scatterplot with smoothed lines showing the conditional means associated with the various grades. The lines were plotted using R and the "+ stat_smooth(se=F)" option within the ggplot2 package.

Table 18: Average, Standard Deviation and Number of Observations of Intersection Clearance Time based on Approach Grade

\begin{tabular}{cccccccccc}
\hline $\begin{array}{c}\text { Queue } \\
\text { Size }\end{array}$ & $\begin{array}{c}\text { Avg } \\
(\mathrm{sec})\end{array}$ & $\begin{array}{c}\mathbf{- 4 \%} \\
\text { Std Dev } \\
(\mathrm{sec})\end{array}$ & $\mathrm{n}$ & $\begin{array}{c}\text { Avg } \\
(\mathrm{sec})\end{array}$ & $\begin{array}{c}\mathbf{+ 1 \%} \\
\text { Std Dev } \\
(\mathrm{sec})\end{array}$ & $\mathrm{n}$ & $\begin{array}{c}\text { Avg } \\
(\mathrm{sec})\end{array}$ & $\begin{array}{c}\mathbf{+ 2 \%} \\
\text { Std Dev } \\
(\mathrm{sec})\end{array}$ & $\mathrm{n}$ \\
\hline $\mathbf{2}$ & 8.39 & 1.23 & 53 & 9.38 & 1.17 & 52 & 7.96 & 0.87 & 39 \\
$\mathbf{3}$ & 9.25 & 1.22 & 46 & 10.33 & 0.98 & 45 & 9.17 & 1.38 & 34 \\
$\mathbf{4}$ & 9.70 & 1.01 & 33 & 10.85 & 0.94 & 44 & 9.66 & 1.03 & 41 \\
$\mathbf{5}$ & 10.42 & 1.74 & 12 & 11.44 & 0.67 & 21 & 10.30 & 1.34 & 38 \\
$\mathbf{6}$ & 10.72 & 1.55 & 16 & 12.73 & 0.59 & 4 & 10.53 & 1.24 & 40 \\
$\mathbf{7}$ & 11.51 & 1.52 & 12 & 13.10 & 1.10 & 3 & 11.04 & 1.34 & 29 \\
$\mathbf{8}$ & 12.07 & 1.43 & 11 & - & - & - & 11.69 & 1.58 & 16 \\
$\mathbf{9}$ & 10.13 & 0.00 & 1 & - & - & - & 13.06 & 1.89 & 9 \\
$\mathbf{1 0}$ & 12.82 & 0.00 & 1 & - & - & - & 13.13 & 1.89 & 11 \\
$\mathbf{1 1}$ & 15.32 & 0.00 & 1 & - & - & - & 14.08 & 1.80 & 6 \\
$\mathbf{1 2}$ & 15.72 & 0.00 & 1 & - & - & - & 16.11 & 1.60 & 5 \\
$\mathbf{1 3}$ & 14.52 & 0.00 & 1 & - & - & - & 14.99 & 0.00 & 1 \\
$\mathbf{1 4}$ & - & - & - & - & - & - & 16.26 & 0.00 & 1 \\
$\mathbf{1 5}$ & - & - & - & - & - & - & 21.02 & 1.02 & 2 \\
$\mathbf{1 6}$ & - & - & - & - & - & - & - & - & - \\
$\mathbf{1 7}$ & - & - & - & - & - & - & - & - & - \\
$\mathbf{1 8}$ & - & - & - & - & - & - & 20.33 & 0.00 & 1 \\
\hline Total & - & - & 188 & - & - & 169 & - & - & 273 \\
\hline
\end{tabular}




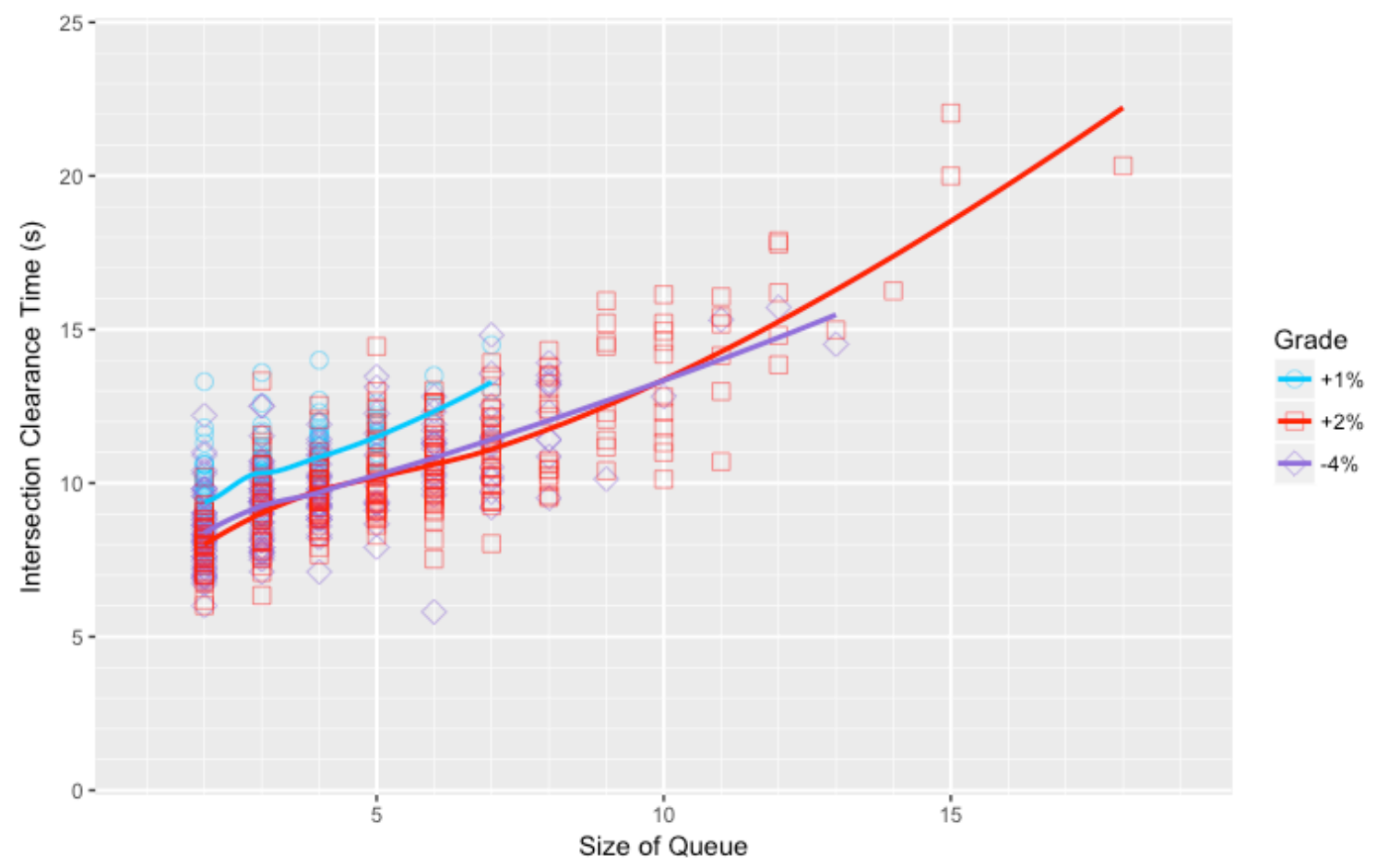

Figure 5-15 Intersection Clearance Time based on Approach Grade

The results display very similar clearance times for the queues along the $+2 \%$ approach grade and the $-4 \%$ approach grade, whereas the queues along the $+1 \%$ approach grades consistently had higher clearance times. Therefore, there does not appear to be a strong relationship between intersection clearance times and uphill or downhill approaches for these short intersection crossing distances.

\subsubsection{Per Utilization of the Bike Box}

The intersection clearance times based on the queue size and utilization of the bike box at the intersection approach are tabulated in Table 19 and displayed in Figure 5-16 as a scatterplot with smoothed lines showing the conditional means and the 95 percent confidence interval as the shaded area. The lines were plotted using $\mathrm{R}$ and the "+ stat_smooth(se=T)" option within the ggplot2 package. 
Table 19: Average, Standard Deviation and Number of Observations of Intersection Clearance Time based on Utilization of Bike Box

\begin{tabular}{ccccccc}
\hline \multirow{2}{*}{$\begin{array}{c}\text { Queue } \\
\text { Size }\end{array}$} & $\begin{array}{c}\text { Avg } \\
\text { Ave Box Utilized }\end{array}$ & $\begin{array}{c}\text { Std Dev } \\
(\mathrm{sec})\end{array}$ & $\mathrm{n}$ & $\begin{array}{c}\text { Avg } \\
(\mathrm{sec})\end{array}$ & $\begin{array}{c}\text { Std Dev } \\
(\mathrm{sec})\end{array}$ & $\mathrm{n}$ \\
\hline $\mathbf{2}$ & 7.87 & 0.95 & 33 & 8.85 & 1.26 & 111 \\
$\mathbf{3}$ & 8.82 & 1.39 & 35 & 9.93 & 1.12 & 90 \\
$\mathbf{4}$ & 9.39 & 1.18 & 35 & 10.42 & 0.98 & 83 \\
$\mathbf{5}$ & 9.68 & 1.01 & 28 & 11.29 & 1.18 & 43 \\
$\mathbf{6}$ & 10.00 & 1.24 & 34 & 11.69 & 0.97 & 26 \\
$\mathbf{7}$ & 10.60 & 1.19 & 26 & 12.34 & 1.22 & 18 \\
$\mathbf{8}$ & 10.99 & 1.37 & 15 & 12.91 & 0.95 & 12 \\
$\mathbf{9}$ & 11.97 & 1.27 & 6 & 13.97 & 2.26 & 4 \\
$\mathbf{1 0}$ & 11.94 & 1.23 & 7 & 14.74 & 1.09 & 5 \\
$\mathbf{1 1}$ & 12.61 & 1.43 & 3 & 15.49 & 0.34 & 4 \\
$\mathbf{1 2}$ & 13.85 & 0.00 & 1 & 16.48 & 1.19 & 5 \\
$\mathbf{1 3}$ & 14.75 & 0.23 & 2 & - & - & - \\
$\mathbf{1 4}$ & 16.26 & 0.00 & 1 & - & - & - \\
$\mathbf{1 5}$ & - & - & - & 21.02 & 1.02 & 2 \\
$\mathbf{1 6}$ & - & - & - & - & - & - \\
$\mathbf{1 7}$ & - & - & - & - & - & - \\
$\mathbf{1 8}$ & - & - & - & 20.33 & 0.00 & 1 \\
\hline Total & - & - & 226 & - & - & 404 \\
\hline
\end{tabular}

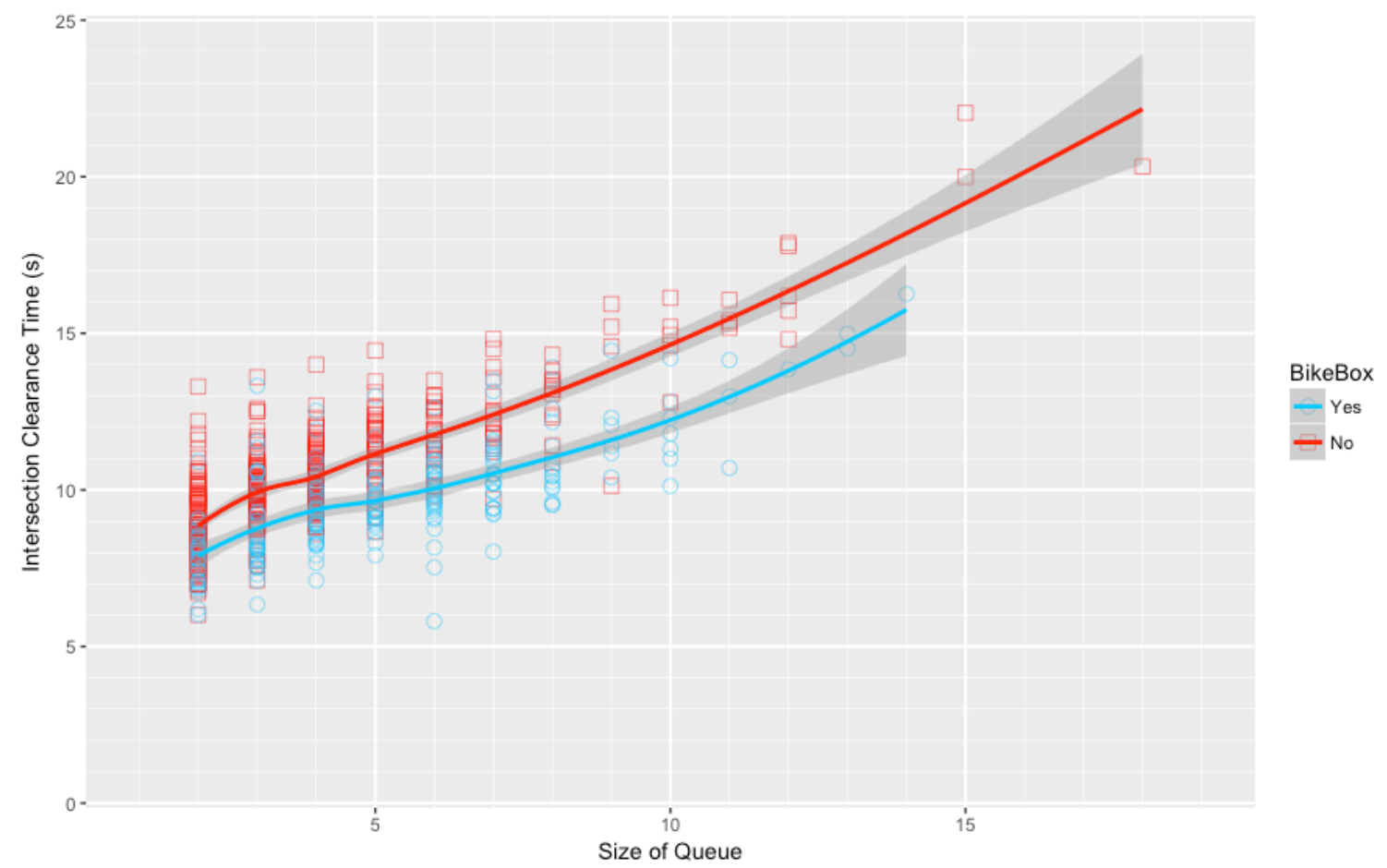

Figure 5-16 Intersection Clearance Time based on Utilization of the Bike Box 
The results appear to indicate that utilization of the bike box has a relationship with a reduced intersection clearance time as compared to queues that do not utilize the bike box. The associated reduction in intersection clearance time is greatest for queues of ten cyclists with a reduction of approximately 2.5 seconds.

\subsubsection{Findings}

The intersection clearance results appear to potentially indicate that wider bike facilities approaching an intersection, wider receiving bike facilities, or utilization of a bike box generally clear queues of bicyclists through the intersection over a shorter amount of time as compared to narrower features or underutilized facilities.

\subsection{Limitations}

Limitations encountered within the results and findings presented above consist of:

- Comparisons intended to analyze performance characteristics of different types of bike facilities relied on study approaches that also had varying degrees of roadway grade.

- The analysis of intersection clearance time is limited by the lack of direct comparisons, as the distance required to clear the intersection was different for each intersection.

- The Williams Avenue approach occasionally had cars parked alongside the bike lane, likely affecting the natural flow of bicycles through the intersection.

- Although this research assists in the greater understanding of performance characteristics associated with groups of cyclists stopped at signalized 
intersections, the precise effect that such revisions to bike facilities would have on overall intersection operations could also be affected by 1) additional bike demand that would be associated with an improved bike facility, 2) a change in the number of motorized vehicles along a revised roadway, and/or 3) different arrival patterns of bicycle platoons.

\subsection{Future Research}

Future research identified from the above analysis consists of:

- The desire to analyze a specific roadway approach that has a bike lane (and single receiving lane) which routinely collects numerous cyclists at a red signal, capturing conditions 'before' and 'after' the introduction of a bike box at the intersection. While the study approach of SE Madison Street at SE Grand Avenue resulted in various time savings associated with the introduction of a bike box, it is unknown how much of a factor the existing second receiving lane had with the resulting improved time efficiencies.

- Adding to this data by performing similar research associated with a variety of other bikeway widths, types of facilities, and/or varying approach grades.

- Identifying typical intersection widths that would provide standardized 'clearance' distances when reducing data from intersection video footage and to allow for direct comparisons with other study intersections.

- Development of a relationship between bikeway revisions and the respective change in traffic demand for both bikes and motorized vehicles, to provide the ability to more accurately analyze 'before' and 'after' intersection operations. 


\section{Chapter 6 - Conclusions}

The first aspect of bicyclist queue discharge characteristics that was analyzed in detail as part of this study was the mean of the average headways associated with each queue size.

For all observations, the lowest mean of the average headway within queues is approximately 0.8 seconds per cyclist and occurs for groups of seven cyclists. For queues larger than seven in size, the mean of the average headway remains stable until queues of 12 in size and starts to slightly increase toward approximately 1.0 seconds for queues larger than 12 cyclists.

Regarding the mean of the average headway based on utilization of a bike box, it appears that utilization of a bike box has a potential relationship with a reduced average headway as compared to queues that do not utilize a bike box. The associated reduction in the mean of the average headway was approximately 0.2 to 0.3 seconds per cyclist for queues of three or more in size.

The second aspect of bicyclist queue discharge characteristics that was analyzed in detail as part of this study was the queue discharge rates associated with the observed queues. The queue discharge results appear to potentially indicate that wider bike facilities approaching an intersection, wider receiving bike facilities, or utilization of a bike box generally discharge queues of bicyclists into the intersection over a shorter amount of time as compared to narrower features or underutilized facilities. The installation of the bike box along the Madison approach, which increased the approach width from five to 15 feet, resulted in consistently lower average discharge times for all queue sizes, a reduction of 
greater than one second for queues of two cyclists to as much as about four seconds for queues of nine cyclists.

The third aspect of bicyclist queue discharge characteristics that was analyzed in detail as part of this study was the intersection clearance time associated with the observed queues. The intersection clearance results appear to potentially indicate that wider bike facilities approaching an intersection, wider receiving bike facilities, or utilization of a bike box generally clear queues of bicyclists through the intersection over a shorter amount of time as compared to narrower features or underutilized facilities.

\subsection{Implications for Design or Operation of Bicycle Facilities}

The information provided within this document in combination with future research could allow for bicycle facility design and/or operational decisions to be made that would allow cyclists to travel more efficiently through a signalized intersection and potentially also improve motor vehicle operations.

Suitable locations for analysis would be intersections with: a relatively high amount of bicycle traffic located to the inside of turning motor vehicles, a significant amount of turning motor vehicles in a shared through/right lane, and/or limited existing intersection capacity.

For example, if an existing intersection routinely fails to clear all of the right-turning motor vehicles during the peak hour signal cycles due to relatively high bicycle traffic, it could be beneficial for motor vehicle operations to widen the bicycle facility to more efficiently accommodate a greater number of cyclists in the same amount of time. 


\section{Chapter 7 - References}

Allen, D. Patrick, Joseph E. Hummer, Nagui M. Rouphail, and Joseph S. Milazzo II. 1998. "Effect of Bicycles on Capacity of Signalized Intersections." Transportation Research Record 87-95.

Chen, Xiaoming, Chunfu Shao, and Hao Yue. 2007. "Influence of Bicycle Traffic on Capacity of Typical Signalized Intersection." Tsinghua Science and Technology 12 (2): 198-203.

Dey, Partha Pratim, Sumit Nandal, and Rahul Kalyan. 2013. "Queue Discharge Characteristics at Signalised Intersections Under Mixed Traffic Conditions." European Transport 1-21.

Guo, Yanming, Quan Yu, Yunlong Zhang, and Jian Rong. 2012. "Effect of Bicycles on the Saturation Flow Rate of Turning Vehicles at Signalized Intersections." Journal of Transportation Engineering 21-30.

Lilan, Li, Zhang Yaping, Lan Xiang, Ye Ruimin, and Wang Yuping. 2009. "Research on the Bicycle Capacity at Signalized Intersection Based on Fluid Diffusion Characteristics." Critical Issues in Transportation Systems Planning, Development, and Management (ASCE) 1306-1311.

Monsere, Christopher, Miguel A. Figliozzi, Sam Thompson, and Kirk Paulsen. 2013. Operational Guidance For Bicycle-Specific Traffic Signals in the United States. No. FHWA-OR-RD-14-06. Prod. Transportation Research and Education Center (TREC). Portland, OR.

Qian, D. L., and Z. Q. Niu. 2010. "Analysis of Capacity and Its Sensitivity of Right-turn Motor Vehicles at Signalized Intersection under Mixed Traffic." China Journal of Highway and Transport 77-83.

Raksuntorn, Winai, and Sarosh I. Khan. 2003. "Saturation Flow Rate, Start-Up Lost Time, and Capacity for Bicycles at Signalized Intersections." Transportation Research Record 1852: 105-113.

Tarko, Andrzej P., and Marian Tracz. 2000. "Uncertainty in Saturation Flow Predictions." Transportation Research Circular E-C018: 4th International Symposium on Highway Capacity 310-321.

Transportation Research Board. 2010. HCM 2010: Highway Capacity Manual. Washington, DC.

Wang, Yong-Gang, Gang Wei, Xu Zhu, and Yu-Long Pei. 2011. "Capacity of Bicycle Platoon Flow at Two-Phase Signalized Intersection: a Case Analysis of Xi-an City." Promet - Traffic\&Transportation 177-186.

Wheeler, Nikki, Ryan Conrad, and Miguel Andres Figliozzi. 2010. "A Statistical Analysis of Bicycle Rider Performance: The impact of gender on riders' performance at signalized intersections." 89th Annual Meeting Transportation Research Board.

Xuan, Yiguang, Vikash Gayah, Carlos Daganzo, and Michael Cassidy. 2009. Multimodal Traffic at Isolated Signalized Intersections: New Management Strategies to Increase Capacity. Working Paper, UC Berkeley Center for Future Urban Transport. 
Chapter 8 - Appendix: Excel Spreadsheet of Video Footage Data

\begin{tabular}{|c|c|c|c|c|c|c|c|c|c|c|c|c|c|c|c|c|c|}
\hline 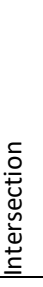 & $\begin{array}{l}\stackrel{ \pm}{\pi} \\
0\end{array}$ & $\begin{array}{l}\bar{z} \\
\text { 오 } \\
\end{array}$ & $\begin{array}{l}\stackrel{0}{J} \\
\stackrel{\Xi}{\Xi} \\
\Sigma\end{array}$ & 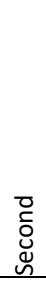 & 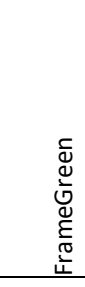 & 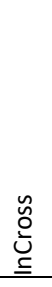 & $\begin{array}{l}\text { Oे } \\
\text { @ } \\
\underline{\underline{D}}\end{array}$ & 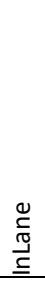 & $\begin{array}{l}\stackrel{d}{J} \\
\stackrel{d}{J} \\
\stackrel{\sigma}{\Xi} \\
\end{array}$ & 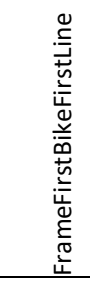 & 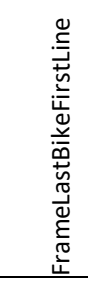 & 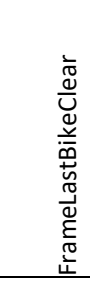 & 足 & $\begin{array}{l}-7 \\
\frac{1}{ \pm} \\
\dot{0} \\
3\end{array}$ & $\begin{array}{l}\tilde{N} \\
\frac{1}{0} \\
\dot{3} \\
3\end{array}$ & 采 & $\begin{array}{l}\frac{0}{0} \\
\frac{\pi}{0} \\
\end{array}$ \\
\hline 1 & 41506 & 17 & 30 & 54 & 535 & 0 & & 2 & 2 & 574 & 584 & 620 & 10.0 & 6 & 6 & 60 & 1 \\
\hline 1 & 41506 & 17 & 32 & 4 & 1233 & 1 & & 6 & 6 & 1279 & 1310 & 1352 & 10.0 & 6 & 6 & 60 & 1 \\
\hline 1 & 41506 & 17 & 33 & 14 & 1931 & 0 & & 5 & 5 & 1963 & 2008 & 2051 & 10.0 & 6 & 6 & 60 & 1 \\
\hline 1 & 41506 & 17 & 34 & 26 & 2650 & 0 & & 7 & 7 & 2686 & 2737 & 2780 & 10.0 & 6 & 6 & 60 & 1 \\
\hline 1 & 41506 & 17 & 35 & 34 & 3327 & 0 & & 5 & 5 & 3345 & 3401 & 3444 & 10.0 & 6 & 6 & 60 & 1 \\
\hline 1 & 41506 & 17 & 36 & 44 & 4025 & 0 & & 4 & 4 & 4045 & 4113 & 4165 & 10.0 & 6 & 6 & 60 & 1 \\
\hline 1 & 41506 & 17 & 37 & 56 & 4744 & 0 & & 2 & 2 & 4784 & 4794 & 4850 & 10.0 & 6 & 6 & 60 & 1 \\
\hline 1 & 41506 & 17 & 40 & 11 & 6093 & 0 & & 2 & 2 & 6133 & 6151 & 6199 & 10.0 & 6 & 6 & 60 & 1 \\
\hline 1 & 41506 & 17 & 41 & 21 & 6791 & 0 & & 4 & 4 & 6821 & 6849 & 6890 & 10.0 & 6 & 6 & 60 & 1 \\
\hline 1 & 41506 & 17 & 42 & 30 & 7489 & 0 & & 4 & 4 & 7522 & 7553 & 7595 & 10.0 & 6 & 6 & 60 & 1 \\
\hline 1 & 41506 & 17 & 43 & 42 & 8208 & 0 & & 4 & 4 & 8236 & 8268 & 8307 & 10.0 & 6 & 6 & 60 & 1 \\
\hline 1 & 41506 & 17 & 46 & 0 & 9582 & 0 & & 3 & 3 & 9647 & 9661 & 9708 & 10.0 & 6 & 6 & 60 & 1 \\
\hline 1 & 41506 & 17 & 47 & 10 & 10280 & 0 & & 5 & 5 & 10309 & 10351 & 10393 & 10.0 & 6 & 6 & 60 & 1 \\
\hline 1 & 41506 & 17 & 48 & 20 & 10978 & 1 & & 4 & 4 & 11017 & 11051 & 11101 & 10.0 & 6 & 6 & 60 & 1 \\
\hline 1 & 41506 & 17 & 49 & 30 & 11676 & 0 & & 3 & 3 & 11705 & 11730 & 11775 & 10.0 & 6 & 6 & 60 & 1 \\
\hline 1 & 41506 & 17 & 50 & 37 & 12350 & 0 & & 2 & 2 & 12388 & 12395 & 12441 & 10.0 & 6 & 6 & 60 & 1 \\
\hline 1 & 41506 & 17 & 54 & 7 & 14443 & 1 & & 4 & 4 & 14483 & 14514 & 14555 & 10.0 & 6 & 6 & 60 & 1 \\
\hline 1 & 41506 & 17 & 55 & 17 & 15141 & 1 & & 6 & 6 & 15173 & 15218 & 15271 & 10.0 & 6 & 6 & 60 & 1 \\
\hline 1 & 41506 & 17 & 56 & 27 & 15839 & 0 & & 3 & 3 & 15868 & 15889 & 15941 & 10.0 & 6 & 6 & 60 & 1 \\
\hline 1 & 41506 & 17 & 57 & 39 & 16558 & 0 & & 2 & 2 & 16578 & 16592 & 16631 & 10.0 & 6 & 6 & 60 & 1 \\
\hline 1 & 41506 & 17 & 58 & 47 & 17235 & 0 & & 5 & 5 & 17264 & 17297 & 17337 & 10.0 & 6 & 6 & 60 & 1 \\
\hline 1 & 41506 & 18 & 1 & 6 & 18630 & 0 & & 3 & 3 & 18666 & 18682 & 18724 & 10.0 & 6 & 6 & 60 & 1 \\
\hline 1 & 41506 & 18 & 2 & 18 & 19349 & 0 & & 2 & 2 & 19377 & 19405 & 19451 & 10.0 & 6 & 6 & 60 & 1 \\
\hline 1 & 41506 & 18 & 4 & 36 & 20724 & 0 & & 5 & 5 & 20761 & 20797 & 20837 & 10.0 & 6 & 6 & 60 & 1 \\
\hline 1 & 41506 & 18 & 8 & 5 & 22815 & 0 & & 5 & 5 & 22860 & 22886 & 22930 & 10.0 & 6 & 6 & 60 & 1 \\
\hline 1 & 41506 & 18 & 11 & 33 & 24888 & 0 & & 2 & 2 & 24910 & 24931 & 24975 & 10.0 & 6 & 6 & 60 & 1 \\
\hline 1 & 41506 & 18 & 17 & 22 & 28377 & 0 & & 3 & 3 & 28404 & 28443 & 28485 & 10.0 & 6 & 6 & 60 & 1 \\
\hline 1 & 41506 & 18 & 18 & 32 & 29076 & 0 & & 3 & 3 & 29111 & 29135 & 29193 & 10.0 & 6 & 6 & 60 & 1 \\
\hline 1 & 41506 & 18 & 19 & 44 & 29795 & 0 & & 2 & 2 & 29829 & 29850 & 29897 & 10.0 & 6 & 6 & 60 & 1 \\
\hline 1 & 41506 & 18 & 22 & 2 & 31170 & 1 & & 2 & 2 & 31203 & 31212 & 31259 & 10.0 & 6 & 6 & 60 & 1 \\
\hline 1 & 41506 & 18 & 23 & 12 & 31867 & 0 & & 2 & 2 & 31899 & 31902 & 31961 & 10.0 & 6 & 6 & 60 & 1 \\
\hline
\end{tabular}




\begin{tabular}{|c|c|c|c|c|c|c|c|c|c|c|c|c|c|c|c|c|c|}
\hline 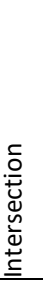 & $\begin{array}{l}\stackrel{ \pm}{ \pm} \\
\stackrel{0}{0}\end{array}$ & $\begin{array}{l}\text { 亏े } \\
\text { 오 }\end{array}$ & 节 & 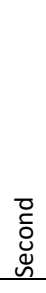 & 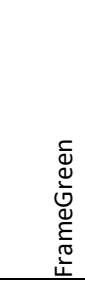 & $\begin{array}{l}\widetilde{O} \\
\text { 이 } \\
\underline{\underline{E}}\end{array}$ & 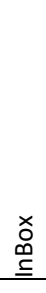 & 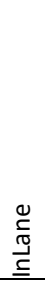 & 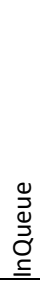 & 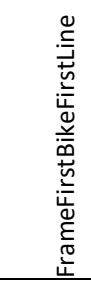 & 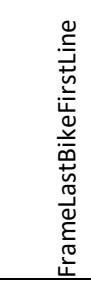 & 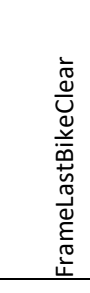 & 足 & $\begin{array}{l}\frac{7}{5} \\
\frac{1}{0} \\
3 \\
3\end{array}$ & $\begin{array}{l}\frac{N}{5} \\
\frac{5}{0} \\
\dot{0}\end{array}$ & 而 & $\begin{array}{l}\frac{\pi}{0} \\
\frac{\pi}{0} \\
\end{array}$ \\
\hline 1 & 41507 & 17 & 32 & 7 & 1269 & 0 & & 4 & 4 & 1296 & 1334 & 1373 & 10.0 & 6 & 6 & 60 & 1 \\
\hline 1 & 41507 & 17 & 34 & 27 & 2665 & 0 & & 7 & 7 & 2729 & 2767 & 2810 & 10.0 & 6 & 6 & 60 & 1 \\
\hline 1 & 41507 & 17 & 35 & 39 & 3383 & 0 & & 3 & 3 & 3403 & 3442 & 3481 & 10.0 & 6 & 6 & 60 & 1 \\
\hline 1 & 41507 & 17 & 36 & 46 & 4060 & 2 & & 4 & 4 & 4082 & 4121 & 4158 & 10.0 & 6 & 6 & 60 & 1 \\
\hline 1 & 41507 & 17 & 37 & 58 & 4779 & 0 & & 3 & 3 & 4800 & 4841 & 4898 & 10.0 & 6 & 6 & 60 & 1 \\
\hline 1 & 41507 & 17 & 40 & 18 & 6175 & 2 & & 5 & 5 & 6198 & 6240 & 6279 & 10.0 & 6 & 6 & 60 & 1 \\
\hline 1 & 41507 & 17 & 41 & 26 & 6852 & 0 & & 4 & 4 & 6884 & 6924 & 6964 & 10.0 & 6 & 6 & 60 & 1 \\
\hline 1 & 41507 & 17 & 42 & 33 & 7549 & 1 & & 2 & 2 & 7592 & 7601 & 7650 & 10.0 & 6 & 6 & 60 & 1 \\
\hline 1 & 41507 & 17 & 43 & 45 & 8268 & 1 & & 5 & 5 & 8317 & 8346 & 8389 & 10.0 & 6 & 6 & 60 & 1 \\
\hline 1 & 41507 & 17 & 44 & 51 & 8922 & 1 & & 2 & 2 & 8954 & 8962 & 9008 & 10.0 & 6 & 6 & 60 & 1 \\
\hline 1 & 41507 & 17 & 46 & 5 & 9641 & 0 & & 3 & 3 & 9684 & 9704 & 9744 & 10.0 & 6 & 6 & 60 & 1 \\
\hline 1 & 41507 & 17 & 48 & 23 & 11016 & 1 & & 4 & 4 & 11056 & 11075 & 11115 & 10.0 & 6 & 6 & 60 & 1 \\
\hline 1 & 41507 & 17 & 49 & 35 & 11735 & 1 & & 3 & 3 & 11773 & 11791 & 11835 & 10.0 & 6 & 6 & 60 & 1 \\
\hline 1 & 41507 & 17 & 50 & 43 & 12412 & 0 & & 5 & 5 & 12456 & 12497 & 12536 & 10.0 & 6 & 6 & 60 & 1 \\
\hline 1 & 41507 & 17 & 51 & 53 & 13110 & 0 & & 6 & 6 & 13141 & 13184 & 13235 & 10.0 & 6 & 6 & 60 & 1 \\
\hline 1 & 41507 & 17 & 53 & 3 & 13808 & 0 & & 5 & 5 & 13835 & 13866 & 13911 & 10.0 & 6 & 6 & 60 & 1 \\
\hline 1 & 41507 & 17 & 56 & 32 & 15901 & 1 & & 6 & 6 & 15947 & 15985 & 16036 & 10.0 & 6 & 6 & 60 & 1 \\
\hline 1 & 41507 & 17 & 57 & 42 & 16599 & 1 & & 4 & 4 & 16640 & 16673 & 16714 & 10.0 & 6 & 6 & 60 & 1 \\
\hline 1 & 41507 & 17 & 58 & 49 & 17271 & 1 & & 3 & 3 & 17293 & 17320 & 17366 & 10.0 & 6 & 6 & 60 & 1 \\
\hline 1 & 41507 & 18 & 0 & 1 & 17990 & 1 & & 4 & 4 & 18030 & 18058 & 18103 & 10.0 & 6 & 6 & 60 & 1 \\
\hline 1 & 41507 & 18 & 3 & 31 & 20083 & 0 & & 2 & 2 & 20113 & 20120 & 20170 & 10.0 & 6 & 6 & 60 & 1 \\
\hline 1 & 41507 & 18 & 8 & 8 & 22853 & 0 & & 4 & 4 & 22876 & 22913 & 22952 & 10.0 & 6 & 6 & 60 & 1 \\
\hline 1 & 41507 & 18 & 10 & 30 & 24270 & 0 & & 4 & 4 & 24302 & 24312 & 24358 & 10.0 & 6 & 6 & 60 & 1 \\
\hline 1 & 41507 & 18 & 12 & 48 & 25645 & 0 & & 2 & 2 & 25689 & 25693 & 25743 & 10.0 & 6 & 6 & 60 & 1 \\
\hline 1 & 41507 & 18 & 15 & 5 & 27016 & 1 & & 4 & 4 & 27045 & 27084 & 27125 & 10.0 & 6 & 6 & 60 & 1 \\
\hline 1 & 41507 & 18 & 20 & 55 & 30506 & 0 & & 2 & 2 & 30540 & 30546 & 30624 & 10.0 & 6 & 6 & 60 & 1 \\
\hline 1 & 41507 & 18 & 22 & 4 & 31204 & 0 & & 4 & 4 & 31245 & 31267 & 31318 & 10.0 & 6 & 6 & 60 & 1 \\
\hline 1 & 41507 & 18 & 23 & 14 & 31901 & 0 & & 2 & 2 & 31940 & 31960 & 32014 & 10.0 & 6 & 6 & 60 & 1 \\
\hline 1 & 41507 & 18 & 25 & 36 & 33318 & 0 & & 4 & 4 & 33348 & 33379 & 33434 & 10.0 & 6 & 6 & 60 & 1 \\
\hline 1 & 41508 & 16 & 32 & 56 & 1734 & 0 & & 2 & 2 & 1770 & 1771 & 1826 & 10.0 & 6 & 6 & 60 & 1 \\
\hline 1 & 41508 & 16 & 36 & 23 & 3803 & 0 & & 3 & 3 & 3844 & 3867 & 3919 & 10.0 & 6 & 6 & 60 & 1 \\
\hline 1 & 41508 & 16 & 44 & 32 & 8688 & 0 & & 2 & 2 & 8721 & 8735 & 8784 & 10.0 & 6 & 6 & 60 & 1 \\
\hline 1 & 41508 & 16 & 45 & 42 & 9386 & 0 & & 3 & 3 & 9432 & 9450 & 9494 & 10.0 & 6 & 6 & 60 & 1 \\
\hline
\end{tabular}




\begin{tabular}{|c|c|c|c|c|c|c|c|c|c|c|c|c|c|c|c|c|c|}
\hline 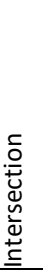 & $\begin{array}{l}\stackrel{\pi}{0} \\
\stackrel{0}{0}\end{array}$ & $\begin{array}{l}\overline{\bar{y}} \\
\text { 오 }\end{array}$ & 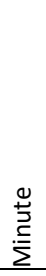 & 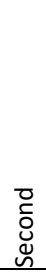 & 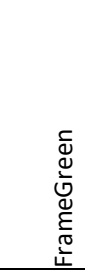 & 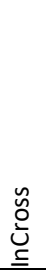 & $\begin{array}{l}\text { Oे } \\
\text { @ } \\
\underline{\underline{0}}\end{array}$ & 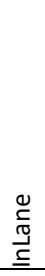 & 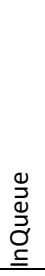 & 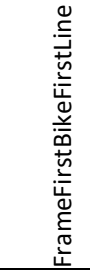 & 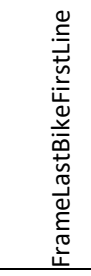 & 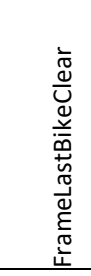 & $\stackrel{\tilde{u}}{u}$ & $\begin{array}{l}\frac{7}{ \pm} \\
\frac{1}{0} \\
3\end{array}$ & 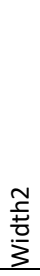 & 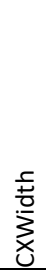 & $\begin{array}{l}\frac{0}{0} \\
\frac{\pi}{0} \\
\end{array}$ \\
\hline 1 & 41508 & 16 & 49 & 12 & 11481 & 0 & & 4 & 4 & 11517 & 11551 & 11597 & 10.0 & 6 & 6 & 60 & 1 \\
\hline 1 & 41508 & 16 & 53 & 51 & 14272 & 0 & & 3 & 3 & 14309 & 14334 & 14384 & 10.0 & 6 & 6 & 60 & 1 \\
\hline 1 & 41508 & 16 & 56 & 11 & 15668 & 0 & & 2 & 2 & 15690 & 15703 & 15745 & 10.0 & 6 & 6 & 60 & 1 \\
\hline 1 & 41508 & 17 & 0 & 48 & 18439 & 0 & & 5 & 5 & 18472 & 18505 & 18547 & 10.0 & 6 & 6 & 60 & 1 \\
\hline 1 & 41508 & 17 & 3 & 8 & 19834 & 0 & & 4 & 4 & 19863 & 19898 & 19944 & 10.0 & 6 & 6 & 60 & 1 \\
\hline 1 & 41508 & 17 & 8 & 55 & 23302 & 0 & & 3 & 3 & 23335 & 23361 & 23409 & 10.0 & 6 & 6 & 60 & 1 \\
\hline 1 & 41508 & 17 & 10 & 5 & 23999 & 0 & & 3 & 3 & 24030 & 24050 & 24096 & 10.0 & 6 & 6 & 60 & 1 \\
\hline 1 & 41508 & 17 & 11 & 17 & 24718 & 0 & & 2 & 2 & 24759 & 24772 & 24818 & 10.0 & 6 & 6 & 60 & 1 \\
\hline 1 & 41508 & 17 & 13 & 35 & 26093 & 0 & & 5 & 5 & 26122 & 26161 & 26200 & 10.0 & 6 & 6 & 60 & 1 \\
\hline 1 & 41508 & 17 & 14 & 45 & 26791 & 0 & & 4 & 4 & 26823 & 26865 & 26911 & 10.0 & 6 & 6 & 60 & 1 \\
\hline 1 & 41508 & 17 & 15 & 54 & 27489 & 0 & & 5 & 5 & 27517 & 27562 & 27611 & 10.0 & 6 & 6 & 60 & 1 \\
\hline 1 & 41508 & 17 & 17 & 6 & 28208 & 0 & & 4 & 4 & 28236 & 28272 & 28310 & 10.0 & 6 & 6 & 60 & 1 \\
\hline 1 & 41508 & 17 & 18 & 14 & 28884 & 0 & & 4 & 4 & 28920 & 28949 & 28992 & 10.0 & 6 & 6 & 60 & 1 \\
\hline 1 & 41508 & 17 & 19 & 24 & 29582 & 1 & & 3 & 3 & 29610 & 29633 & 29680 & 10.0 & 6 & 6 & 60 & 1 \\
\hline 1 & 41508 & 17 & 20 & 34 & 30281 & 0 & & 2 & 2 & 30318 & 30334 & 30378 & 10.0 & 6 & 6 & 60 & 1 \\
\hline 1 & 41508 & 17 & 21 & 44 & 30978 & 0 & & 5 & 5 & 31010 & 31050 & 31094 & 10.0 & 6 & 6 & 60 & 1 \\
\hline 1 & 41508 & 17 & 22 & 54 & 31676 & 0 & & 4 & 4 & 31704 & 31746 & 31788 & 10.0 & 6 & 6 & 60 & 1 \\
\hline 1 & 41508 & 17 & 24 & 4 & 32374 & 0 & & 3 & 3 & 32413 & 32437 & 32478 & 10.0 & 6 & 6 & 60 & 1 \\
\hline 1 & 41508 & 17 & 25 & 11 & 33049 & 0 & & 3 & 3 & 33078 & 33102 & 33149 & 10.0 & 6 & 6 & 60 & 1 \\
\hline 1 & 41508 & 17 & 26 & 23 & 33768 & 1 & & 3 & 3 & 33798 & 33817 & 33857 & 10.0 & 6 & 6 & 60 & 1 \\
\hline 1 & 41508 & 17 & 27 & 31 & 34445 & 0 & & 3 & 3 & 34470 & 34496 & 34539 & 10.0 & 6 & 6 & 60 & 1 \\
\hline 1 & 41508 & 17 & 31 & 1 & 602 & 0 & & 4 & 4 & 630 & 668 & 709 & 10.0 & 6 & 6 & 60 & 1 \\
\hline 1 & 41508 & 17 & 32 & 10 & 1299 & 0 & & 4 & 4 & 1330 & 1379 & 1417 & 10.0 & 6 & 6 & 60 & 1 \\
\hline 1 & 41508 & 17 & 33 & 20 & 1997 & 0 & & 5 & 5 & 2029 & 2072 & 2112 & 10.0 & 6 & 6 & 60 & 1 \\
\hline 1 & 41508 & 17 & 35 & 40 & 3392 & 1 & & 4 & 4 & 3426 & 3454 & 3498 & 10.0 & 6 & 6 & 60 & 1 \\
\hline 1 & 41508 & 17 & 36 & 50 & 4089 & 0 & & 2 & 2 & 4120 & 4137 & 4188 & 10.0 & 6 & 6 & 60 & 1 \\
\hline 1 & 41508 & 17 & 39 & 10 & 5485 & 0 & & 2 & 2 & 5518 & 5538 & 5581 & 10.0 & 6 & 6 & 60 & 1 \\
\hline 1 & 41508 & 17 & 40 & 22 & 6205 & 1 & & 3 & 3 & 6233 & 6269 & 6314 & 10.0 & 6 & 6 & 60 & 1 \\
\hline 1 & 41508 & 17 & 43 & 49 & 8276 & 0 & & 4 & 4 & 8309 & 8344 & 8382 & 10.0 & 6 & 6 & 60 & 1 \\
\hline 1 & 41508 & 17 & 46 & 7 & 9651 & 0 & & 3 & 3 & 9682 & 9705 & 9757 & 10.0 & 6 & 6 & 60 & 1 \\
\hline 1 & 41508 & 17 & 47 & 17 & 10350 & 0 & & 5 & 5 & 10380 & 10425 & 10476 & 10.0 & 6 & 6 & 60 & 1 \\
\hline 1 & 41508 & 17 & 48 & 29 & 11069 & 1 & & 2 & 2 & 11092 & 11101 & 11145 & 10.0 & 6 & 6 & 60 & 1 \\
\hline 1 & 41508 & 17 & 49 & 37 & 11746 & 0 & & 7 & 7 & 11768 & 11821 & 11864 & 10.0 & 6 & 6 & 60 & 1 \\
\hline
\end{tabular}




\begin{tabular}{|c|c|c|c|c|c|c|c|c|c|c|c|c|c|c|c|c|c|}
\hline 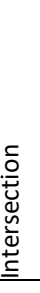 & $\begin{array}{l}\text { ग̃ } \\
\text { D̃ }\end{array}$ & $\begin{array}{l}\overline{\bar{y}} \\
\text { 오 }\end{array}$ & 苞 & 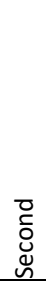 & 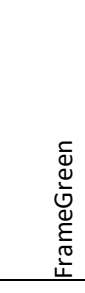 & 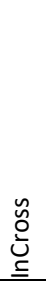 & $\begin{array}{l}\text { ○े } \\
\text { @ } \\
\end{array}$ & 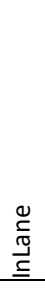 & 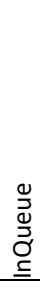 & 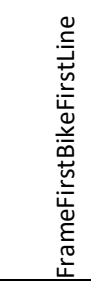 & 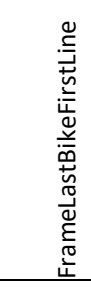 & 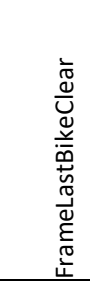 & 足 & $\begin{array}{l}-1 \\
\frac{1}{ \pm} \\
.0 \\
3 \\
3\end{array}$ & $\begin{array}{l}\frac{N}{5} \\
\frac{5}{0} \\
3 \\
3\end{array}$ & 而 & $\begin{array}{l}\frac{0}{0} \\
\frac{\pi}{0} \\
\end{array}$ \\
\hline 1 & 41508 & 17 & 50 & 46 & 12444 & 1 & & 4 & 4 & 12479 & 12508 & 12554 & 10.0 & 6 & 6 & 60 & 1 \\
\hline 1 & 41508 & 17 & 51 & 56 & 13142 & 0 & & 2 & 2 & 13175 & 13188 & 13231 & 10.0 & 6 & 6 & 60 & 1 \\
\hline 1 & 41508 & 17 & 54 & 16 & 14538 & 0 & & 3 & 3 & 14574 & 14596 & 14641 & 10.0 & 6 & 6 & 60 & 1 \\
\hline 1 & 41508 & 17 & 55 & 26 & 15236 & 0 & & 3 & 3 & 15274 & 15290 & 15338 & 10.0 & 6 & 6 & 60 & 1 \\
\hline 1 & 41508 & 17 & 57 & 43 & 16608 & 0 & & 2 & 2 & 16639 & 16650 & 16696 & 10.0 & 6 & 6 & 60 & 1 \\
\hline 1 & 41508 & 17 & 58 & 55 & 17327 & 0 & & 2 & 2 & 17363 & 17375 & 17424 & 10.0 & 6 & 6 & 60 & 1 \\
\hline 1 & 41508 & 18 & 0 & 3 & 18003 & 1 & & 3 & 3 & 18037 & 18052 & 18109 & 10.0 & 6 & 6 & 60 & 1 \\
\hline 1 & 41508 & 18 & 1 & 13 & 18702 & 0 & & 4 & 4 & 18728 & 18760 & 18803 & 10.0 & 6 & 6 & 60 & 1 \\
\hline 1 & 41508 & 18 & 2 & 23 & 19400 & 1 & & 3 & 3 & 19437 & 19469 & 19511 & 10.0 & 6 & 6 & 60 & 1 \\
\hline 1 & 41508 & 18 & 3 & 35 & 20118 & 1 & & 2 & 2 & 20150 & 20163 & 20215 & 10.0 & 6 & 6 & 60 & 1 \\
\hline 1 & 41508 & 18 & 5 & 55 & 21514 & 0 & & 4 & 4 & 21537 & 21579 & 21620 & 10.0 & 6 & 6 & 60 & 1 \\
\hline 1 & 41508 & 18 & 10 & 34 & 24306 & 1 & & 3 & 3 & 24334 & 24367 & 24405 & 10.0 & 6 & 6 & 60 & 1 \\
\hline 1 & 41508 & 18 & 11 & 42 & 24984 & 0 & & 3 & 3 & 25016 & 25040 & 25088 & 10.0 & 6 & 6 & 60 & 1 \\
\hline 1 & 41508 & 18 & 12 & 50 & 25660 & 0 & & 2 & 2 & 25673 & 25696 & 25741 & 10.0 & 6 & 6 & 60 & 1 \\
\hline 1 & 41508 & 18 & 14 & 0 & 26358 & 1 & & 2 & 2 & 26388 & 26407 & 26448 & 10.0 & 6 & 6 & 60 & 1 \\
\hline 1 & 41508 & 18 & 15 & 9 & 27056 & 0 & & 3 & 3 & 27073 & 27097 & 27141 & 10.0 & 6 & 6 & 60 & 1 \\
\hline 1 & 41508 & 18 & 17 & 29 & 28452 & 1 & & 2 & 2 & 28492 & 28503 & 28553 & 10.0 & 6 & 6 & 60 & 1 \\
\hline 1 & 41508 & 18 & 18 & 39 & 29150 & 1 & & 2 & 2 & 29178 & 29191 & 29239 & 10.0 & 6 & 6 & 60 & 1 \\
\hline 1 & 41508 & 18 & 20 & 59 & 30546 & 0 & & 5 & 5 & 30592 & 30620 & 30665 & 10.0 & 6 & 6 & 60 & 1 \\
\hline 1 & 41508 & 18 & 22 & 9 & 31244 & 0 & & 2 & 2 & 31274 & 31275 & 31340 & 10.0 & 6 & 6 & 60 & 1 \\
\hline 1 & 41508 & 18 & 24 & 29 & 32641 & 0 & & 3 & 3 & 32658 & 32689 & 32730 & 10.0 & 6 & 6 & 60 & 1 \\
\hline 1 & 41508 & 18 & 25 & 39 & 33339 & 0 & & 5 & 5 & 33364 & 33397 & 33453 & 10.0 & 6 & 6 & 60 & 1 \\
\hline 1 & 41509 & 16 & 31 & 38 & 958 & 1 & & 2 & 2 & 1000 & 1014 & 1061 & 10.0 & 6 & 6 & 60 & 1 \\
\hline 1 & 41509 & 16 & 36 & 15 & 3723 & 0 & & 2 & 2 & 3773 & 3782 & 3856 & 10.0 & 6 & 6 & 60 & 1 \\
\hline 1 & 41509 & 16 & 37 & 25 & 4421 & 0 & & 4 & 4 & 4441 & 4476 & 4521 & 10.0 & 6 & 6 & 60 & 1 \\
\hline 1 & 41509 & 16 & 42 & 4 & 7211 & 0 & & 2 & 2 & 7237 & 7254 & 7302 & 10.0 & 6 & 6 & 60 & 1 \\
\hline 1 & 41509 & 16 & 46 & 44 & 10002 & 0 & & 2 & 2 & 10034 & 10035 & 10084 & 10.0 & 6 & 6 & 60 & 1 \\
\hline 1 & 41509 & 16 & 47 & 54 & 10700 & 0 & & 3 & 3 & 10727 & 10767 & 10809 & 10.0 & 6 & 6 & 60 & 1 \\
\hline 1 & 41509 & 16 & 49 & 6 & 11419 & 1 & & 2 & 2 & 11468 & 11470 & 11518 & 10.0 & 6 & 6 & 60 & 1 \\
\hline 1 & 41509 & 16 & 51 & 24 & 12795 & 0 & & 2 & 2 & 12829 & 12843 & 12890 & 10.0 & 6 & 6 & 60 & 1 \\
\hline 1 & 41509 & 16 & 53 & 41 & 14170 & 0 & & 2 & 2 & 14192 & 14206 & 14247 & 10.0 & 6 & 6 & 60 & 1 \\
\hline 1 & 41509 & 16 & 54 & 53 & 14889 & 0 & & 3 & 3 & 14921 & 14950 & 14995 & 10.0 & 6 & 6 & 60 & 1 \\
\hline 1 & 41509 & 16 & 57 & 11 & 16265 & 1 & & 3 & 3 & 16296 & 16308 & 16354 & 10.0 & 6 & 6 & 60 & 1 \\
\hline
\end{tabular}




\begin{tabular}{|c|c|c|c|c|c|c|c|c|c|c|c|c|c|c|c|c|c|}
\hline 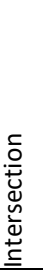 & $\begin{array}{l}\stackrel{\pi}{0} \\
\stackrel{0}{0}\end{array}$ & $\begin{array}{l}\overline{\bar{y}} \\
\text { 오 }\end{array}$ & 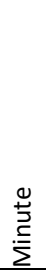 & $\begin{array}{l}0 \\
0 \\
0 \\
\mathcal{U} \\
\end{array}$ & 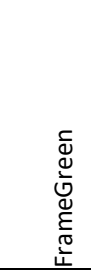 & 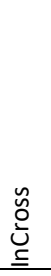 & $\begin{array}{l}\text { ○े } \\
\text { ఏ } \\
\underline{\underline{D}}\end{array}$ & 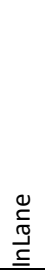 & 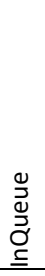 & 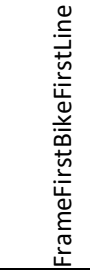 & 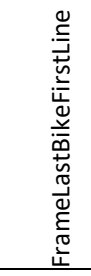 & 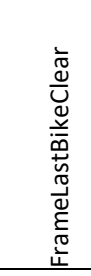 & $\stackrel{\tilde{u}}{u}$ & $\begin{array}{l}\frac{7}{ \pm} \\
\frac{1}{0} \\
3\end{array}$ & 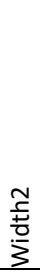 & 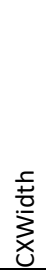 & $\begin{array}{l}\frac{0}{0} \\
\frac{\pi}{0} \\
\end{array}$ \\
\hline 1 & 41509 & 16 & 58 & 21 & 16963 & 0 & & 3 & 3 & 16990 & 17013 & 17070 & 10.0 & 6 & 6 & 60 & 1 \\
\hline 1 & 41509 & 17 & 0 & 41 & 18359 & 0 & & 3 & 3 & 18394 & 18415 & 18460 & 10.0 & 6 & 6 & 60 & 1 \\
\hline 1 & 41509 & 17 & 1 & 50 & 19057 & 0 & & 4 & 4 & 19092 & 19138 & 19184 & 10.0 & 6 & 6 & 60 & 1 \\
\hline 1 & 41509 & 17 & 4 & 10 & 20453 & 0 & & 3 & 3 & 20487 & 20518 & 20561 & 10.0 & 6 & 6 & 60 & 1 \\
\hline 1 & 41509 & 17 & 7 & 40 & 22546 & 0 & & 5 & 5 & 22581 & 22616 & 22659 & 10.0 & 6 & 6 & 60 & 1 \\
\hline 1 & 41509 & 17 & 11 & 7 & 24619 & 0 & & 4 & 4 & 24651 & 24678 & 24720 & 10.0 & 6 & 6 & 60 & 1 \\
\hline 1 & 41509 & 17 & 12 & 17 & 25317 & 0 & & 3 & 3 & 25335 & 25366 & 25405 & 10.0 & 6 & 6 & 60 & 1 \\
\hline 1 & 41509 & 17 & 13 & 29 & 26036 & 0 & & 3 & 3 & 26065 & 26101 & 26172 & 10.0 & 6 & 6 & 60 & 1 \\
\hline 1 & 41509 & 17 & 14 & 37 & 26712 & 0 & & 2 & 2 & 26742 & 26755 & 26799 & 10.0 & 6 & 6 & 60 & 1 \\
\hline 1 & 41509 & 17 & 15 & 47 & 27410 & 0 & & 4 & 4 & 27429 & 27465 & 27514 & 10.0 & 6 & 6 & 60 & 1 \\
\hline 1 & 41509 & 17 & 16 & 57 & 28109 & 0 & & 4 & 4 & 28136 & 28165 & 28205 & 10.0 & 6 & 6 & 60 & 1 \\
\hline 1 & 41509 & 17 & 18 & 7 & 28806 & 0 & & 2 & 2 & 28834 & 28840 & 28890 & 10.0 & 6 & 6 & 60 & 1 \\
\hline 1 & 41509 & 17 & 22 & 44 & 31576 & 0 & & 4 & 4 & 31605 & 31637 & 31680 & 10.0 & 6 & 6 & 60 & 1 \\
\hline 1 & 41509 & 17 & 23 & 54 & 32275 & 0 & & 4 & 4 & 32303 & 32341 & 32384 & 10.0 & 6 & 6 & 60 & 1 \\
\hline 1 & 41509 & 17 & 25 & 6 & 32994 & 0 & & 4 & 4 & 33027 & 33057 & 33098 & 10.0 & 6 & 6 & 60 & 1 \\
\hline 1 & 41509 & 17 & 26 & 14 & 33671 & 0 & & 4 & 4 & 33696 & 33725 & 33763 & 10.0 & 6 & 6 & 60 & 1 \\
\hline 1 & 41509 & 17 & 29 & 44 & 35765 & 0 & & 4 & 4 & 35795 & 35831 & 35873 & 10.0 & 6 & 6 & 60 & 1 \\
\hline 1 & 41509 & 17 & 30 & 53 & 527 & 0 & & 2 & 2 & 555 & 568 & 611 & 10.0 & 6 & 6 & 60 & 1 \\
\hline 1 & 41509 & 17 & 33 & 15 & 1944 & 1 & & 3 & 3 & 1981 & 2007 & 2047 & 10.0 & 6 & 6 & 60 & 1 \\
\hline 1 & 41509 & 17 & 34 & 23 & 2621 & 1 & & 4 & 4 & 2654 & 2690 & 2736 & 10.0 & 6 & 6 & 60 & 1 \\
\hline 1 & 41509 & 17 & 35 & 33 & 3319 & 0 & & 3 & 3 & 3348 & 3367 & 3410 & 10.0 & 6 & 6 & 60 & 1 \\
\hline 1 & 41509 & 17 & 37 & 53 & 4715 & 0 & & 5 & 5 & 4738 & 4788 & 4835 & 10.0 & 6 & 6 & 60 & 1 \\
\hline 1 & 41509 & 17 & 41 & 20 & 6786 & 0 & & 4 & 4 & 6816 & 6851 & 6895 & 10.0 & 6 & 6 & 60 & 1 \\
\hline 1 & 41509 & 17 & 43 & 40 & 8182 & 0 & & 3 & 3 & 8216 & 8242 & 8292 & 10.0 & 6 & 6 & 60 & 1 \\
\hline 1 & 41509 & 17 & 47 & 10 & 10276 & 0 & & 3 & 3 & 10299 & 10330 & 10379 & 10.0 & 6 & 6 & 60 & 1 \\
\hline 1 & 41509 & 17 & 49 & 29 & 11672 & 1 & & 2 & 2 & 11713 & 11723 & 11779 & 10.0 & 6 & 6 & 60 & 1 \\
\hline 1 & 41509 & 17 & 51 & 49 & 13068 & 1 & & 2 & 2 & 13102 & 13112 & 13153 & 10.0 & 6 & 6 & 60 & 1 \\
\hline 1 & 41509 & 17 & 52 & 59 & 13766 & 1 & & 4 & 4 & 13809 & 13841 & 13883 & 10.0 & 6 & 6 & 60 & 1 \\
\hline 1 & 41509 & 17 & 54 & 11 & 14485 & 0 & & 4 & 4 & 14510 & 14554 & 14605 & 10.0 & 6 & 6 & 60 & 1 \\
\hline 1 & 41509 & 17 & 57 & 39 & 16558 & 0 & & 3 & 3 & 16595 & 16611 & 16661 & 10.0 & 6 & 6 & 60 & 1 \\
\hline 1 & 41509 & 18 & 2 & 18 & 19349 & 0 & & 3 & 3 & 19378 & 19403 & 19444 & 10.0 & 6 & 6 & 60 & 1 \\
\hline 1 & 41509 & 18 & 4 & 36 & 20724 & 0 & & 2 & 2 & 20765 & 20775 & 20820 & 10.0 & 6 & 6 & 60 & 1 \\
\hline 1 & 41509 & 18 & 6 & 58 & 22141 & 0 & & 2 & 2 & 22169 & 22173 & 22221 & 10.0 & 6 & 6 & 60 & 1 \\
\hline
\end{tabular}




\begin{tabular}{|c|c|c|c|c|c|c|c|c|c|c|c|c|c|c|c|c|c|}
\hline 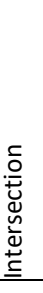 & $\begin{array}{l}\stackrel{0}{ \pm} \\
\text { D̃ }\end{array}$ & 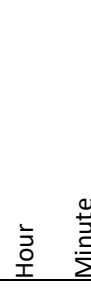 & 莣 & 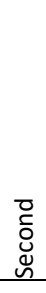 & 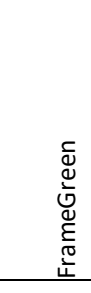 & $\begin{array}{l}\tilde{u} \\
\stackrel{0}{\underline{U}} \\
\underline{\underline{E}}\end{array}$ & 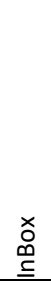 & 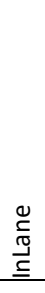 & 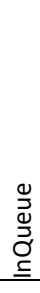 & 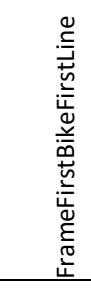 & 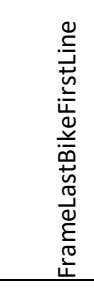 & 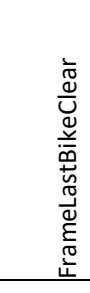 & 气ัน & $\begin{array}{l}-1 \\
\frac{1}{1} \\
.0 \\
3 \\
3\end{array}$ & $\begin{array}{l}\frac{N}{5} \\
\frac{1}{0} \\
\frac{1}{3}\end{array}$ & \begin{tabular}{l}
5 \\
\multirow{2}{*}{0} \\
0 \\
0
\end{tabular} & $\begin{array}{l}\frac{0}{0} \\
\frac{\pi}{0} \\
\end{array}$ \\
\hline 1 & 41509 & $18 \quad 10$ & 10 & 25 & 24214 & 0 & & 2 & 2 & 24247 & 24258 & 24300 & 10.0 & 6 & 6 & 60 & 1 \\
\hline 1 & 41509 & $18 \quad 1$ & 16 & 13 & 27683 & 0 & & 5 & 5 & 27713 & 27743 & 27793 & 10.0 & 6 & 6 & 60 & 1 \\
\hline 1 & 41509 & 181 & 17 & 25 & 28402 & 0 & & 2 & 2 & 28446 & 28448 & 28508 & 10.0 & 6 & 6 & 60 & 1 \\
\hline 1 & 41509 & $18 \quad 18$ & 18 & 33 & 29079 & 0 & & 2 & 2 & 29100 & 29111 & 29152 & 10.0 & 6 & 6 & 60 & 1 \\
\hline 1 & 41509 & $18 \quad 2$ & 20 & 52 & 30475 & 1 & & 2 & 2 & 30498 & 30501 & 30568 & 10.0 & 6 & 6 & 60 & 1 \\
\hline 1 & 41509 & $18 \quad 2$ & 26 & 44 & 33988 & 0 & & 2 & 2 & 34030 & 34044 & 34104 & 10.0 & 6 & 6 & 60 & 1 \\
\hline 2 & 41925 & $16<15$ & 5 ? & & 7139 & 1 & & 2 & 2 & 7233 & 7280 & 7386 & 30.0 & 12 & 6.5 & 56 & -4 \\
\hline 2 & 41925 & $16<18$ & 8 ? & & 2397 & 0 & & 2 & 2 & 2508 & 2522 & 2656 & 30.0 & 12 & 6.5 & 56 & -4 \\
\hline 2 & 41925 & $16<45$ & 5 ? & & -12 & 0 & & 3 & 3 & 103 & 174 & 287 & 30.0 & 12 & 6.5 & 56 & -4 \\
\hline 2 & 41925 & $16<45$ & 5 ? & & 2086 & 0 & & 4 & 4 & 2177 & 2260 & 2344 & 30.0 & 12 & 6.5 & 56 & -4 \\
\hline 2 & 41925 & $16<45$ & 5 ? & & 4185 & 1 & & 2 & 2 & 4325 & 4341 & 4480 & 30.0 & 12 & 6.5 & 56 & -4 \\
\hline 2 & 41925 & $16<45$ & 5 ? & & 6284 & 0 & & 3 & 3 & 6351 & 6453 & 6574 & 30.0 & 12 & 6.5 & 56 & -4 \\
\hline 2 & 41925 & $16<45$ & 5 ? & & 12581 & 0 & & 2 & 2 & 12657 & 12723 & 12875 & 30.0 & 12 & 6.5 & 56 & -4 \\
\hline 2 & 41925 & $16<45$ & 5 ? & & 18849 & 0 & & 4 & 4 & 18908 & 18975 & 19126 & 30.0 & 12 & 6.5 & 56 & -4 \\
\hline 2 & 41925 & $16<45$ & 5 ? & & 27240 & 0 & & 2 & 2 & 27353 & 27400 & 27527 & 30.0 & 12 & 6.5 & 56 & -4 \\
\hline 2 & 41925 & $16<45$ & 5 ? & & 29338 & 0 & & 2 & 2 & 29450 & 29482 & 29609 & 30.0 & 12 & 6.5 & 56 & -4 \\
\hline 2 & 41925 & $16<45$ & 5 ? & & 31437 & 0 & & 2 & 2 & 31541 & 31583 & 31702 & 30.0 & 12 & 6.5 & 56 & -4 \\
\hline 2 & 41925 & $16<45$ & 5 ? & & 33539 & 0 & & 6 & 6 & 33641 & 33765 & 33877 & 30.0 & 12 & 6.5 & 56 & -4 \\
\hline 2 & 41925 & $16<45$ & 5 ? & & 37734 & 0 & & 3 & 3 & 37782 & 37849 & 37967 & 30.0 & 12 & 6.5 & 56 & -4 \\
\hline 2 & 41925 & $16<45$ & 5 ? & & 39833 & 0 & & 2 & 2 & 39870 & 39924 & 40042 & 30.0 & 12 & 6.5 & 56 & -4 \\
\hline 2 & 41925 & $16<45$ & 5 ? & & 41932 & 1 & & 5 & 5 & 41983 & 42083 & 42192 & 30.0 & 12 & 6.5 & 56 & -4 \\
\hline 2 & 41925 & $16<45$ & 5 ? & & 44031 & 1 & & 2 & 2 & 44103 & 44136 & 44254 & 30.0 & 12 & 6.5 & 56 & -4 \\
\hline 2 & 41925 & $16<45$ & 5 ? & & 46130 & 0 & & 3 & 3 & 46171 & 46328 & 46451 & 30.0 & 12 & 6.5 & 56 & -4 \\
\hline 2 & 41925 & $17<12$ & 2 ? & & 3437 & 0 & & 3 & 3 & 3551 & 3610 & 3739 & 30.0 & 12 & 6.5 & 56 & -4 \\
\hline 2 & 41925 & $17<12$ & 2 ? & & 5536 & 1 & & 6 & 6 & 5585 & 5680 & 5879 & 30.0 & 12 & 6.5 & 56 & -4 \\
\hline 2 & 41925 & $17<12$ & 2 ? & & 11833 & 0 & & 2 & 2 & 11917 & 11961 & 12078 & 30.0 & 12 & 6.5 & 56 & -4 \\
\hline 2 & 41925 & $17<12$ & 2 ? & & 16030 & 0 & & 2 & 2 & 16124 & 16181 & 16317 & 30.0 & 12 & 6.5 & 56 & -4 \\
\hline 2 & 41925 & $17<12$ & 2 ? & & 18129 & 0 & & 3 & 3 & 18236 & 18307 & 18432 & 30.0 & 12 & 6.5 & 56 & -4 \\
\hline 2 & 41925 & $17<12$ & 2 ? & & 24424 & 0 & & 5 & 5 & 24502 & 24601 & 24704 & 30.0 & 12 & 6.5 & 56 & -4 \\
\hline 2 & 41925 & $17<12$ & 2 ? & & 26523 & 1 & & 2 & 2 & 26588 & 26634 & 26740 & 30.0 & 12 & 6.5 & 56 & -4 \\
\hline 2 & 41925 & $17<12$ & 2 ? & & 28620 & 0 & & 4 & 4 & 28709 & 28836 & 28963 & 30.0 & 12 & 6.5 & 56 & -4 \\
\hline 2 & 41925 & $17<12$ & 2 ? & & 30718 & 0 & & 6 & 6 & 30812 & 30942 & 31057 & 30.0 & 12 & 6.5 & 56 & -4 \\
\hline 2 & 41925 & $17<12$ & 2 ? & & 32817 & 0 & & 4 & 4 & 32888 & 32977 & 33092 & 30.0 & 12 & 6.5 & 56 & -4 \\
\hline
\end{tabular}




\begin{tabular}{|c|c|c|c|c|c|c|c|c|c|c|c|c|c|c|c|c|c|}
\hline 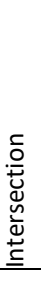 & $\begin{array}{l}\underset{ \pm}{ \pm} \\
\stackrel{0}{0} \\
\end{array}$ & $\begin{array}{l}\text { 亏े } \\
\text { 온 }\end{array}$ & $\begin{array}{l}\stackrel{0}{ \pm} \\
\stackrel{\Xi}{\Xi} \\
\end{array}$ & 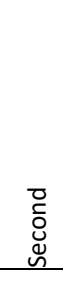 & 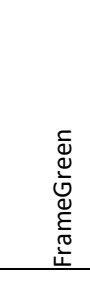 & 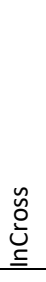 & $\begin{array}{l}\text { ò } \\
\text { 足 } \\
\end{array}$ & 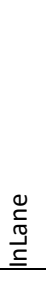 & $\begin{array}{l}\stackrel{0}{\partial} \\
\stackrel{\Delta}{\sigma} \\
\underline{\underline{\sigma}}\end{array}$ & 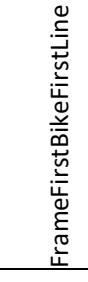 & 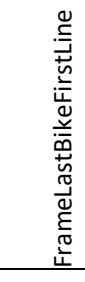 & 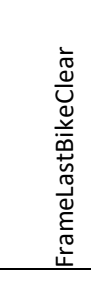 & 气ू & $\begin{array}{l}\frac{1}{5} \\
\stackrel{+}{ \pm} \\
\stackrel{0}{0} \\
3\end{array}$ & $\begin{array}{l}N \\
\frac{N}{7} \\
\frac{0}{3} \\
3\end{array}$ & 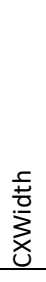 & $\begin{array}{l}\frac{\pi}{0} \\
\frac{\pi}{0} \\
\end{array}$ \\
\hline 2 & 41925 & $17<1$ & $12 ?$ & ? & 34915 & 0 & & 2 & 2 & 34990 & 35025 & 35143 & 30.0 & 12 & 6.5 & 56 & -4 \\
\hline 2 & 41925 & $17<1$ & $12 ?$ & ? & 37014 & 0 & & 4 & 4 & 37090 & 37197 & 37306 & 30.0 & 12 & 6.5 & 56 & -4 \\
\hline 2 & 41925 & $17<1$ & 12 ? & ? & 39112 & 0 & & 5 & 5 & 39208 & 39386 & 39516 & 30.0 & 12 & 6.5 & 56 & -4 \\
\hline 2 & 41925 & $17<1$ & 12 ? & ? & 41211 & 0 & & 8 & 8 & 41279 & 41492 & 41607 & 30.0 & 12 & 6.5 & 56 & -4 \\
\hline 2 & 41925 & $17<1$ & 12 ? & ? & 43310 & 0 & & 3 & 3 & 43507 & 43582 & 43685 & 30.0 & 12 & 6.5 & 56 & -4 \\
\hline 2 & 41925 & $17<1$ & 12 ? & ? & 45408 & 0 & & 3 & 3 & 45470 & 45553 & 45688 & 30.0 & 12 & 6.5 & 56 & -4 \\
\hline 2 & 41925 & $17<3$ & 36 ? & ? & 2719 & 0 & & 6 & 6 & 2824 & 2975 & 3089 & 30.0 & 12 & 6.5 & 56 & -4 \\
\hline 2 & 41925 & $17<3$ & 36 ? & ? & 4818 & 2 & & 3 & 3 & 4890 & 4949 & 5074 & 30.0 & 12 & 6.5 & 56 & -4 \\
\hline 2 & 41925 & $17<3$ & 36 ? & ? & 6914 & 0 & & 3 & 3 & 6979 & 7021 & 7158 & 30.0 & 12 & 6.5 & 56 & -4 \\
\hline 2 & 41925 & $17<3$ & 36 ? & ? & 9012 & 1 & & 4 & 4 & 9076 & 9177 & 9303 & 30.0 & 12 & 6.5 & 56 & -4 \\
\hline 2 & 41925 & $17<3$ & 36 ? & ? & 11111 & 0 & & 4 & 4 & 11221 & 11333 & 11439 & 30.0 & 12 & 6.5 & 56 & -4 \\
\hline 2 & 41925 & $17<3$ & 36 ? & ? & 13210 & 0 & & 5 & 5 & 13293 & 13450 & 13578 & 30.0 & 12 & 6.5 & 56 & -4 \\
\hline 2 & 41925 & $17<3$ & 36 ? & ? & 15309 & 0 & & 7 & 7 & 15420 & 15608 & 15716 & 30.0 & 12 & 6.5 & 56 & -4 \\
\hline 2 & 41925 & $17<3$ & 36 ? & ? & 17408 & 0 & & 4 & 4 & 17479 & 17627 & 17747 & 30.0 & 12 & 6.5 & 56 & -4 \\
\hline 2 & 41925 & $17<3$ & 36 ? & ? & 19510 & 0 & & 9 & 9 & 19572 & 19723 & 19814 & 30.0 & 12 & 6.5 & 56 & -4 \\
\hline 2 & 41925 & $17<3$ & 36 ? & ? & 23708 & 1 & & 4 & 4 & 23776 & 23868 & 23993 & 30.0 & 12 & 6.5 & 56 & -4 \\
\hline 2 & 41925 & $17<3$ & 36 ? & ? & 25804 & 1 & & 3 & 3 & 25892 & 25981 & 26126 & 30.0 & 12 & 6.5 & 56 & -4 \\
\hline 2 & 41925 & $17<3$ & $36 ?$ & ? & 27861 & 0 & & 2 & 2 & 27973 & 28073 & 28227 & 30.0 & 12 & 6.5 & 56 & -4 \\
\hline 2 & 41925 & $17<3$ & 36 ? & ? & 29957 & 0 & & 4 & 4 & 30087 & 30179 & 30284 & 30.0 & 12 & 6.5 & 56 & -4 \\
\hline 2 & 41925 & $17<3$ & 36 ? & ? & 32056 & 1 & & 4 & 4 & 32155 & 32248 & 32361 & 30.0 & 12 & 6.5 & 56 & -4 \\
\hline 2 & 41925 & $17<3$ & 36 ? & ? & 34156 & 0 & & 8 & 8 & 34226 & 34374 & 34482 & 30.0 & 12 & 6.5 & 56 & -4 \\
\hline 2 & 41925 & $17<3$ & 36 ? & ? & 36255 & 1 & & 3 & 3 & 36313 & 36359 & 36487 & 30.0 & 12 & 6.5 & 56 & -4 \\
\hline 2 & 41925 & $17<3$ & 36 ? & ? & 38353 & 1 & & 3 & 3 & 38441 & 38501 & 38615 & 30.0 & 12 & 6.5 & 56 & -4 \\
\hline 2 & 41925 & $17<3$ & 36 ? & ? & 40455 & 1 & & 3 & 3 & 40507 & 40654 & 40801 & 30.0 & 12 & 6.5 & 56 & -4 \\
\hline 2 & 41925 & $17<3$ & $36 ?$ & ? & 42554 & 0 & & 4 & 4 & 42647 & 42706 & 42831 & 30.0 & 12 & 6.5 & 56 & -4 \\
\hline 3 & 41499 & 6 & 36 & 46 & 4036 & 0 & 0 & 2 & 2 & 4065 & 4077 & 4116 & 10.0 & 10 & 10 & 46 & -4 \\
\hline 3 & 41499 & 6 & 40 & 46 & 6433 & 0 & 0 & 2 & 2 & 6477 & 6493 & 6530 & 10.0 & 10 & 10 & 46 & -4 \\
\hline 3 & 41499 & 6 & 45 & 46 & 9430 & 1 & 0 & 2 & 2 & 9452 & 9477 & 9510 & 10.0 & 10 & 10 & 46 & -4 \\
\hline 3 & 41499 & 6 & 50 & 47 & 12426 & 0 & 0 & 2 & 2 & 12464 & 12484 & 12524 & 10.0 & 10 & 10 & 46 & -4 \\
\hline 3 & 41499 & 7 & 17 & 46 & 28601 & 0 & 0 & 2 & 2 & 28622 & 28642 & 28679 & 10.0 & 10 & 10 & 46 & -4 \\
\hline 3 & 41499 & 7 & 19 & 46 & 29800 & 0 & 0 & 4 & 4 & 29831 & 29851 & 29888 & 10.0 & 10 & 10 & 46 & -4 \\
\hline 3 & 41499 & 7 & 31 & 46 & 1057 & 0 & 0 & 2 & 2 & 1094 & 1100 & 1136 & 10.0 & 10 & 10 & 46 & -4 \\
\hline 3 & 41499 & 7 & 38 & 47 & 5252 & 0 & 0 & 4 & 4 & 5291 & 5321 & 5354 & 10.0 & 10 & 10 & 46 & -4 \\
\hline
\end{tabular}




\begin{tabular}{|c|c|c|c|c|c|c|c|c|c|c|c|c|c|c|c|c|c|}
\hline 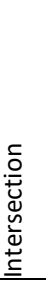 & $\begin{array}{l}\stackrel{0}{0} \\
0\end{array}$ & $\begin{array}{l}\grave{亏} \\
\text { 온 }\end{array}$ & $\begin{array}{l}\stackrel{\Xi}{J} \\
\stackrel{\Xi}{\Sigma}\end{array}$ & 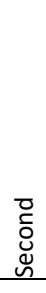 & 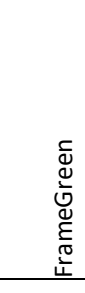 & 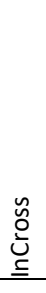 & 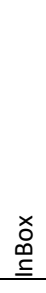 & 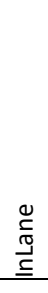 & 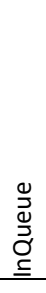 & 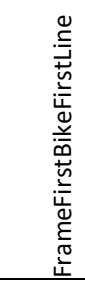 & 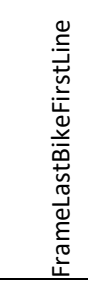 & 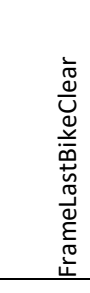 & 足 & $\begin{array}{l}-1 \\
\frac{1}{ \pm} \\
\frac{0}{3} \\
3\end{array}$ & $\begin{array}{l}\frac{N}{5} \\
\frac{5}{3} \\
3\end{array}$ & \begin{tabular}{l}
5 \\
\multirow{2}{*}{0} \\
0 \\
0 \\
0
\end{tabular} & $\begin{array}{l}\frac{\pi}{0} \\
\frac{\pi}{0} \\
\end{array}$ \\
\hline 3 & 41499 & 7 & 44 & 47 & 8847 & 1 & 1 & 2 & 3 & 8889 & 8913 & 8953 & 10.0 & 21 & 10 & 46 & -4 \\
\hline 3 & 41499 & 7 & 45 & 46 & 9446 & 0 & 2 & 8 & 10 & 9462 & 9540 & 9574 & 10.0 & 21 & 10 & 46 & -4 \\
\hline 3 & 41499 & 7 & 46 & 46 & 10045 & 0 & 0 & 3 & 3 & 10063 & 10101 & 10135 & 10.0 & 10 & 10 & 46 & -4 \\
\hline 3 & 41499 & 7 & 47 & 46 & 10644 & 0 & 1 & 1 & 2 & 10664 & 10691 & 10722 & 10.0 & 21 & 10 & 46 & -4 \\
\hline 3 & 41499 & 7 & 48 & 46 & 11243 & 1 & 2 & 2 & 4 & 11264 & 11284 & 11314 & 10.0 & 21 & 10 & 46 & -4 \\
\hline 3 & 41499 & 7 & 49 & 46 & 11842 & 0 & 0 & 3 & 3 & 11879 & 11904 & 11940 & 10.0 & 10 & 10 & 46 & -4 \\
\hline 3 & 41499 & 7 & 58 & 46 & 17233 & 0 & 0 & 2 & 2 & 17267 & 17279 & 17314 & 10.0 & 10 & 10 & 46 & -4 \\
\hline 3 & 41499 & 8 & 2 & 46 & 19629 & 0 & 1 & 3 & 4 & 19648 & 19677 & 19711 & 10.0 & 21 & 10 & 46 & -4 \\
\hline 3 & 41499 & 8 & 3 & 46 & 20228 & 0 & 1 & 3 & 4 & 20245 & 20285 & 20311 & 10.0 & 21 & 10 & 46 & -4 \\
\hline 3 & 41499 & 8 & 6 & 46 & 22026 & 0 & 0 & 2 & 2 & 22052 & 22059 & 22093 & 10.0 & 10 & 10 & 46 & -4 \\
\hline 3 & 41499 & 8 & 11 & 46 & 25024 & 0 & 0 & 5 & 5 & 25051 & 25083 & 25115 & 10.0 & 10 & 10 & 46 & -4 \\
\hline 3 & 41499 & 8 & 12 & 46 & 25620 & 1 & 0 & 3 & 3 & 25637 & 25676 & 25714 & 10.0 & 10 & 10 & 46 & -4 \\
\hline 3 & 41499 & 8 & 15 & 46 & 27417 & 0 & 0 & 12 & 12 & 27450 & 27547 & 27574 & 10.0 & 10 & 10 & 46 & -4 \\
\hline 3 & 41499 & 8 & 16 & 46 & 28016 & 0 & 0 & 4 & 4 & 28045 & 28078 & 28111 & 10.0 & 10 & 10 & 46 & -4 \\
\hline 3 & 41499 & 8 & 25 & 46 & 33410 & 0 & 0 & 3 & 3 & 33444 & 33460 & 33505 & 10.0 & 10 & 10 & 46 & -4 \\
\hline 3 & 41499 & 8 & 29 & 46 & 35807 & 0 & 1 & 3 & 4 & 35839 & 35889 & 35926 & 10.0 & 21 & 10 & 46 & -4 \\
\hline 3 & 41499 & 8 & 32 & 46 & 1652 & 0 & 0 & 8 & 8 & 1679 & 1743 & 1775 & 10.0 & 10 & 10 & 46 & -4 \\
\hline 3 & 41499 & 8 & 35 & 46 & 3450 & 1 & 0 & 8 & 8 & 3487 & 3549 & 3582 & 10.0 & 10 & 10 & 46 & -4 \\
\hline 3 & 41499 & 8 & 36 & 46 & 4050 & 0 & 1 & 1 & 2 & 4076 & 4099 & 4133 & 10.0 & 21 & 10 & 46 & -4 \\
\hline 3 & 41499 & 8 & 37 & 46 & 4649 & 0 & 0 & 4 & 4 & 4683 & 4722 & 4755 & 10.0 & 10 & 10 & 46 & -4 \\
\hline 3 & 41499 & 8 & 41 & 46 & 7046 & 0 & 0 & 3 & 3 & 7076 & 7099 & 7144 & 10.0 & 10 & 10 & 46 & -4 \\
\hline 3 & 41499 & 8 & 42 & 46 & 7645 & 0 & 0 & 6 & 6 & 7688 & 7736 & 7764 & 10.0 & 10 & 10 & 46 & -4 \\
\hline 3 & 41499 & 8 & 50 & 46 & 12440 & 0 & 0 & 8 & 8 & 12477 & 12539 & 12573 & 10.0 & 10 & 10 & 46 & -4 \\
\hline 3 & 41499 & 8 & 51 & 46 & 13039 & 0 & 1 & 2 & 3 & 13068 & 13089 & 13129 & 10.0 & 21 & 10 & 46 & -4 \\
\hline 3 & 41499 & 8 & 55 & 46 & 15437 & 0 & 0 & 11 & 11 & 15474 & 15556 & 15590 & 10.0 & 10 & 10 & 46 & -4 \\
\hline 3 & 41499 & 8 & 56 & 46 & 16036 & 0 & 1 & 2 & 3 & 16059 & 16071 & 16114 & 10.0 & 21 & 10 & 46 & -4 \\
\hline 3 & 41499 & 8 & 59 & 46 & 17834 & 0 & 0 & 2 & 2 & 17869 & 17885 & 17922 & 10.0 & 10 & 10 & 46 & -4 \\
\hline 3 & 41500 & 6 & 41 & 48 & 7064 & 1 & 0 & 3 & 3 & 7090 & 7111 & 7143 & 10.0 & 10 & 10 & 46 & -4 \\
\hline 3 & 41500 & 6 & 50 & 48 & 12459 & 0 & 0 & 2 & 2 & 12479 & 12483 & 12529 & 10.0 & 10 & 10 & 46 & -4 \\
\hline 3 & 41500 & 6 & 51 & 48 & 13058 & 0 & 0 & 2 & 2 & 13083 & 13100 & 13134 & 10.0 & 10 & 10 & 46 & -4 \\
\hline 3 & 41500 & 7 & 4 & 47 & 20845 & 0 & 0 & 2 & 2 & 20875 & 20890 & 20928 & 10.0 & 10 & 10 & 46 & -4 \\
\hline 3 & 41500 & 7 & 10 & 48 & 24440 & 0 & 0 & 2 & 2 & 24467 & 24487 & 24526 & 10.0 & 10 & 10 & 46 & -4 \\
\hline 3 & 41500 & 7 & 21 & 47 & 31031 & 0 & 1 & 7 & 8 & 31050 & 31115 & 31145 & 10.0 & 21 & 10 & 46 & -4 \\
\hline
\end{tabular}




\begin{tabular}{|c|c|c|c|c|c|c|c|c|c|c|c|c|c|c|c|c|c|}
\hline 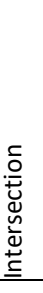 & $\begin{array}{l}\text { ग̃ } \\
\text { D̃ }\end{array}$ & $\begin{array}{l}\text { 亏े } \\
\text { 오 }\end{array}$ & $\stackrel{\stackrel{D}{J}}{\stackrel{ \pm}{\Xi}}$ & 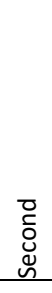 & 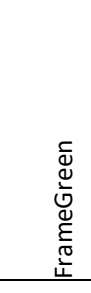 & 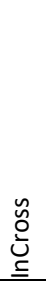 & $\begin{array}{l}\text { ○े } \\
\text { @ } \\
\end{array}$ & 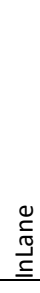 & 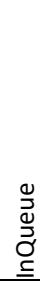 & 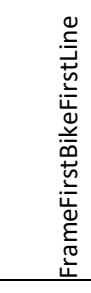 & 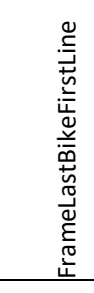 & 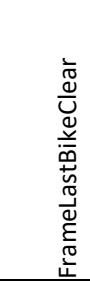 & 足 & 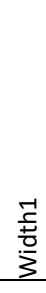 & $\begin{array}{l}\frac{N}{5} \\
\frac{5}{0} \\
3\end{array}$ & \begin{tabular}{l}
5 \\
\multirow{2}{*}{0} \\
0 \\
0
\end{tabular} & $\begin{array}{l}\frac{\pi}{0} \\
\frac{\pi}{0} \\
\end{array}$ \\
\hline 3 & 41500 & 7 & 24 & 47 & 32828 & 0 & 0 & 5 & 5 & 32870 & 32908 & 32944 & 10.0 & 10 & 10 & 46 & -4 \\
\hline 3 & 41500 & 7 & 28 & 48 & 35225 & 0 & 0 & 2 & 2 & 35269 & 35278 & 35314 & 10.0 & 10 & 10 & 46 & -4 \\
\hline 3 & 41500 & 7 & 38 & 47 & 5264 & 0 & 1 & 4 & 5 & 5284 & 5326 & 5357 & 10.0 & 21 & 10 & 46 & -4 \\
\hline 3 & 41500 & 7 & 43 & 47 & 8259 & 0 & 0 & 4 & 4 & 8298 & 8321 & 8361 & 10.0 & 10 & 10 & 46 & -4 \\
\hline 3 & 41500 & 7 & 44 & 47 & 8859 & 0 & 0 & 7 & 7 & 8900 & 8958 & 8984 & 10.0 & 10 & 10 & 46 & -4 \\
\hline 3 & 41500 & 7 & 52 & 47 & 13652 & 2 & 1 & 6 & 7 & 13684 & 13722 & 13754 & 10.0 & 21 & 10 & 46 & -4 \\
\hline 3 & 41500 & 8 & 1 & 47 & 19043 & 0 & 1 & 1 & 2 & 19073 & 19088 & 19133 & 10.0 & 21 & 10 & 46 & -4 \\
\hline 3 & 41500 & 8 & 13 & 47 & 26232 & 0 & 0 & 2 & 2 & 26282 & 26296 & 26335 & 10.0 & 10 & 10 & 46 & -4 \\
\hline 3 & 41500 & 8 & 14 & 47 & 26831 & 0 & 1 & 2 & 3 & 26863 & 26887 & 26925 & 10.0 & 21 & 10 & 46 & -4 \\
\hline 3 & 41500 & 8 & 15 & 47 & 27430 & 0 & 1 & 3 & 4 & 27460 & 27501 & 27533 & 10.0 & 21 & 10 & 46 & -4 \\
\hline 3 & 41500 & 8 & 21 & 47 & 31025 & 0 & 0 & 4 & 4 & 31051 & 31083 & 31113 & 10.0 & 10 & 10 & 46 & -4 \\
\hline 3 & 41500 & 8 & 25 & 47 & 33421 & 0 & 0 & 6 & 6 & 33462 & 33514 & 33549 & 10.0 & 10 & 10 & 46 & -4 \\
\hline 3 & 41500 & 8 & 26 & 47 & 34021 & 0 & 1 & 12 & 13 & 34052 & 34138 & 34166 & 10.0 & 21 & 10 & 46 & -4 \\
\hline 3 & 41500 & 8 & 30 & 47 & 468 & 0 & 0 & 7 & 7 & 507 & 548 & 580 & 10.0 & 10 & 10 & 46 & -4 \\
\hline 3 & 41500 & 8 & 38 & 47 & 5261 & 0 & 0 & 6 & 6 & 5285 & 5334 & 5366 & 10.0 & 10 & 10 & 46 & -4 \\
\hline 3 & 41500 & 8 & 43 & 47 & 8257 & 1 & 1 & 5 & 6 & 8280 & 8337 & 8370 & 10.0 & 21 & 10 & 46 & -4 \\
\hline 3 & 41500 & 8 & 45 & 47 & 9456 & 0 & 0 & 2 & 2 & 9483 & 9485 & 9524 & 10.0 & 10 & 10 & 46 & -4 \\
\hline 3 & 41500 & 8 & 49 & 47 & 11853 & 0 & 1 & 2 & 3 & 11877 & 11889 & 11930 & 10.0 & 21 & 10 & 46 & -4 \\
\hline 3 & 41500 & 8 & 52 & 47 & 13650 & 0 & 0 & 7 & 7 & 13679 & 13730 & 13764 & 10.0 & 10 & 10 & 46 & -4 \\
\hline 3 & 41500 & 8 & 55 & 47 & 15448 & 0 & 2 & 6 & 8 & 15478 & 15518 & 15549 & 10.0 & 21 & 10 & 46 & -4 \\
\hline 3 & 41500 & 8 & 59 & 47 & 17844 & 1 & 1 & 2 & 3 & 17887 & 17906 & 17937 & 10.0 & 21 & 10 & 46 & -4 \\
\hline 3 & 41500 & 9 & 5 & 50 & 21469 & 0 & 1 & 1 & 2 & 21499 & 21517 & 21553 & 10.0 & 21 & 10 & 46 & -4 \\
\hline 3 & 41500 & 9 & 14 & 50 & 26861 & 0 & 1 & 7 & 8 & 26883 & 26969 & 27000 & 10.0 & 21 & 10 & 46 & -4 \\
\hline 3 & 41501 & 7 & 15 & 49 & 27388 & 0 & 1 & 6 & 7 & 27416 & 27455 & 27480 & 10.0 & 21 & 10 & 46 & -4 \\
\hline 3 & 41501 & 7 & 20 & 49 & 30385 & 0 & 1 & 3 & 4 & 30410 & 30440 & 30474 & 10.0 & 21 & 10 & 46 & -4 \\
\hline 3 & 41501 & 7 & 23 & 49 & 32184 & 0 & 0 & 3 & 3 & 32209 & 32247 & 32281 & 10.0 & 10 & 10 & 46 & -4 \\
\hline 3 & 41501 & 7 & 26 & 49 & 33982 & 0 & 0 & 4 & 4 & 34005 & 34045 & 34075 & 10.0 & 10 & 10 & 46 & -4 \\
\hline 3 & 41501 & 7 & 30 & 48 & 483 & 0 & 0 & 7 & 7 & 531 & 596 & 631 & 10.0 & 10 & 10 & 46 & -4 \\
\hline 3 & 41501 & 7 & 34 & 48 & 2881 & 2 & 1 & 5 & 6 & 2909 & 2950 & 2977 & 10.0 & 21 & 10 & 46 & -4 \\
\hline 3 & 41501 & 7 & 39 & 49 & 5879 & 0 & 1 & 5 & 6 & 5913 & 5938 & 5937 & 10.0 & 21 & 10 & 46 & -4 \\
\hline 3 & 41501 & 7 & 40 & 49 & 6479 & 0 & 1 & 5 & 6 & 6505 & 6551 & 6582 & 10.0 & 21 & 10 & 46 & -4 \\
\hline 3 & 41501 & 7 & 43 & 49 & 8277 & 0 & 0 & 3 & 3 & 8305 & 8352 & 8402 & 10.0 & 10 & 10 & 46 & -4 \\
\hline 3 & 01 & 7 & 44 & 49 & 377 & 0 & 0 & 3 & 3 & 909 & 8939 & 8971 & 10.0 & 10 & 10 & 16 & -4 \\
\hline
\end{tabular}




\begin{tabular}{|c|c|c|c|c|c|c|c|c|c|c|c|c|c|c|c|c|c|}
\hline 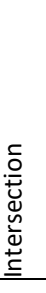 & $\begin{array}{l}\stackrel{0}{0} \\
0\end{array}$ & $\begin{array}{l}\text { 亏े } \\
\text { 오 }\end{array}$ & $\begin{array}{l}\stackrel{D}{J} \\
\stackrel{\leftrightarrows}{\Sigma} \\
\end{array}$ & $\begin{array}{l}\bar{D} \\
\overline{0} \\
\tilde{U} \\
\sim\end{array}$ & 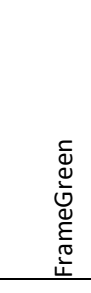 & 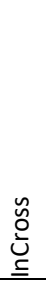 & 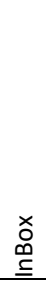 & 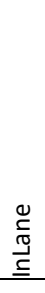 & 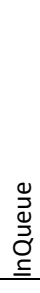 & 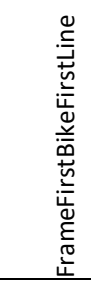 & 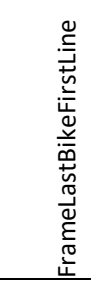 & 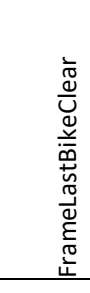 & 足 & $\begin{array}{l}-1 \\
\frac{1}{1} \\
\dot{0} \\
3\end{array}$ & $\begin{array}{l}\frac{N}{5} \\
\frac{5}{3} \\
3\end{array}$ & \begin{tabular}{l}
5 \\
\multirow{2}{*}{0} \\
0 \\
0 \\
0
\end{tabular} & $\begin{array}{l}\frac{\pi}{\pi} \\
\frac{\pi}{0} \\
\end{array}$ \\
\hline 3 & 41501 & 7 & 51 & 49 & 13073 & 0 & 0 & 5 & 5 & 13122 & 13167 & 13204 & 10.0 & 10 & 10 & 46 & -4 \\
\hline 3 & 41501 & 7 & 52 & 49 & 13672 & 0 & 2 & 1 & 3 & 13697 & 13714 & 13747 & 10.0 & 21 & 10 & 46 & -4 \\
\hline 3 & 41501 & 7 & 55 & 49 & 15469 & 1 & 2 & 0 & 2 & 15509 & 15518 & 15550 & 10.0 & 21 & 10 & 46 & -4 \\
\hline 3 & 41501 & 7 & 56 & 49 & 16068 & 0 & 2 & 1 & 3 & 16092 & 16116 & 16152 & 10.0 & 21 & 10 & 46 & -4 \\
\hline 3 & 41501 & 7 & 59 & 49 & 17866 & 1 & 3 & 5 & 8 & 17880 & 17928 & 17961 & 10.0 & 21 & 10 & 46 & -4 \\
\hline 3 & 41501 & 8 & 0 & 49 & 18465 & 1 & 0 & 3 & 3 & 18501 & 18527 & 18560 & 10.0 & 10 & 10 & 46 & -4 \\
\hline 3 & 41501 & 8 & 1 & 49 & 19063 & 1 & 0 & 3 & 3 & 19084 & 19118 & 19150 & 10.0 & 10 & 10 & 46 & -4 \\
\hline 3 & 41501 & 8 & 7 & 49 & 22658 & 0 & 1 & 2 & 3 & 22695 & 22711 & 22741 & 10.0 & 21 & 10 & 46 & -4 \\
\hline 3 & 41501 & 8 & 8 & 49 & 23258 & 0 & 0 & 7 & 7 & 23284 & 23340 & 23371 & 10.0 & 10 & 10 & 46 & -4 \\
\hline 3 & 41501 & 8 & 9 & 49 & 23858 & 0 & 0 & 4 & 4 & 23907 & 23933 & 23958 & 10.0 & 10 & 10 & 46 & -4 \\
\hline 3 & 41501 & 8 & 10 & 49 & 24457 & 0 & 0 & 5 & 5 & 24477 & 24521 & 24551 & 10.0 & 10 & 10 & 46 & -4 \\
\hline 3 & 41501 & 8 & 11 & 49 & 25057 & 0 & 1 & 5 & 6 & 25079 & 25136 & 25174 & 10.0 & 21 & 10 & 46 & -4 \\
\hline 3 & 41501 & 8 & 15 & 49 & 27455 & 1 & 0 & 2 & 2 & 27492 & 27500 & 27531 & 10.0 & 10 & 10 & 46 & -4 \\
\hline 3 & 41501 & 8 & 16 & 49 & 28054 & 0 & 1 & 6 & 7 & 28077 & 28139 & 28169 & 10.0 & 21 & 10 & 46 & -4 \\
\hline 3 & 41501 & 8 & 17 & 49 & 28654 & 0 & 2 & 0 & 2 & 28683 & 28700 & 28739 & 10.0 & 21 & 10 & 46 & -4 \\
\hline 3 & 41501 & 8 & 28 & 48 & 35233 & 0 & 0 & 2 & 2 & 35277 & 35302 & 35337 & 10.0 & 10 & 10 & 46 & -4 \\
\hline 3 & 41501 & 8 & 32 & 48 & 1678 & 0 & 0 & 8 & 8 & 1693 & 1765 & 1792 & 10.0 & 10 & 10 & 46 & -4 \\
\hline 3 & 41501 & 8 & 33 & 48 & 2277 & 0 & 0 & 3 & 3 & 2312 & 2336 & 2371 & 10.0 & 10 & 10 & 46 & -4 \\
\hline 3 & 41501 & 8 & 34 & 48 & 2876 & 1 & 0 & 4 & 4 & 2908 & 2951 & 2987 & 10.0 & 10 & 10 & 46 & -4 \\
\hline 3 & 41501 & 8 & 35 & 48 & 3475 & 0 & 0 & 3 & 3 & 3493 & 3521 & 3546 & 10.0 & 10 & 10 & 46 & -4 \\
\hline 3 & 41501 & 8 & 36 & 48 & 4074 & 0 & 1 & 1 & 2 & 4104 & 4113 & 4143 & 10.0 & 21 & 10 & 46 & -4 \\
\hline 3 & 41501 & 8 & 41 & 48 & 7071 & 1 & 0 & 2 & 2 & 7100 & 7115 & 7146 & 10.0 & 10 & 10 & 46 & -4 \\
\hline 3 & 41501 & 8 & 42 & 48 & 7670 & 1 & 0 & 4 & 4 & 7707 & 7726 & 7763 & 10.0 & 10 & 10 & 46 & -4 \\
\hline 3 & 41501 & 8 & 43 & 48 & 8269 & 1 & 1 & 7 & 8 & 8300 & 8369 & 8404 & 10.0 & 21 & 10 & 46 & -4 \\
\hline 3 & 41501 & 8 & 44 & 48 & 8869 & 0 & 0 & 2 & 2 & 8887 & 8906 & 8942 & 10.0 & 10 & 10 & 46 & -4 \\
\hline 3 & 41501 & 8 & 46 & 48 & 10068 & 2 & 0 & 2 & 2 & 10090 & 10108 & 10140 & 10.0 & 10 & 10 & 46 & -4 \\
\hline 3 & 41501 & 8 & 52 & 48 & 13664 & 0 & 1 & 2 & 3 & 13689 & 13705 & 13746 & 10.0 & 21 & 10 & 46 & -4 \\
\hline 3 & 41501 & 8 & 56 & 48 & 16061 & 0 & 0 & 3 & 3 & 16107 & 16130 & 16165 & 10.0 & 10 & 10 & 46 & -4 \\
\hline 3 & 41501 & 8 & 58 & 48 & 17259 & 1 & 1 & 1 & 2 & 17286 & 17297 & 17328 & 10.0 & 21 & 10 & 46 & -4 \\
\hline 3 & 41501 & 9 & 10 & 51 & 24479 & 0 & 1 & 4 & 5 & 24522 & 24557 & 24588 & 10.0 & 21 & 10 & 46 & -4 \\
\hline 3 & 41501 & 9 & 11 & 51 & 25079 & 1 & 2 & 4 & 6 & 25107 & 25144 & 25179 & 10.0 & 21 & 10 & 46 & -4 \\
\hline 3 & 41501 & 9 & 15 & 51 & 27477 & 0 & 1 & 1 & 2 & 27515 & 27554 & 27586 & 10.0 & 21 & 10 & 46 & -4 \\
\hline 3 & 41501 & 9 & 21 & 51 & 31074 & 0 & 1 & 1 & 2 & 31104 & 31112 & 31145 & 10.0 & 21 & 10 & 46 & -4 \\
\hline
\end{tabular}




\begin{tabular}{|c|c|c|c|c|c|c|c|c|c|c|c|c|c|c|c|c|c|}
\hline 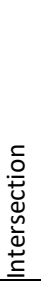 & 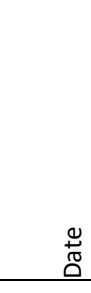 & $\begin{array}{l}\text { 亏े } \\
\text { 오 }\end{array}$ & $\stackrel{\stackrel{D}{J}}{\stackrel{ \pm}{\Xi}}$ & 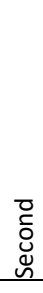 & 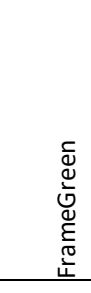 & 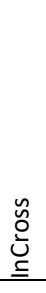 & $\begin{array}{l}\text { ○े } \\
\text { @ } \\
\end{array}$ & 竞 & 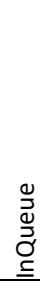 & 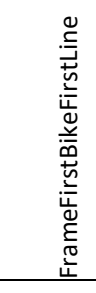 & 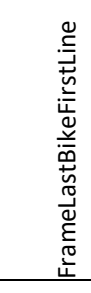 & 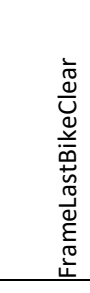 & 足 & $\begin{array}{l}-1 \\
\frac{1}{ \pm} \\
.0 \\
3 \\
3\end{array}$ & $\begin{array}{l}\frac{N}{5} \\
\frac{5}{0} \\
3 \\
3\end{array}$ & \begin{tabular}{l}
5 \\
\multirow{2}{*}{0} \\
0 \\
0
\end{tabular} & $\begin{array}{l}\frac{0}{0} \\
\frac{\pi}{0} \\
\end{array}$ \\
\hline 3 & 41501 & 9 & 28 & 51 & 35262 & 1 & 0 & 2 & 2 & 35279 & 35291 & 35322 & 10.0 & 10 & 10 & 46 & -4 \\
\hline 3 & 41502 & 6 & 41 & 52 & 7055 & 0 & 0 & 3 & 3 & 7081 & 7099 & 7131 & 10.0 & 10 & 10 & 46 & -4 \\
\hline 3 & 41502 & 6 & 56 & 52 & 16045 & 0 & 0 & 2 & 2 & 16075 & 16076 & 16115 & 10.0 & 10 & 10 & 46 & -4 \\
\hline 3 & 41502 & 7 & 7 & 52 & 22637 & 0 & 0 & 2 & 2 & 22677 & 22683 & 22723 & 10.0 & 10 & 10 & 46 & -4 \\
\hline 3 & 41502 & 7 & 23 & 52 & 32227 & 0 & 2 & 4 & 6 & 32250 & 32291 & 32325 & 10.0 & 21 & 10 & 46 & -4 \\
\hline 3 & 41502 & 7 & 37 & 51 & 4705 & 0 & 1 & 3 & 4 & 4724 & 4765 & 4798 & 10.0 & 21 & 10 & 46 & -4 \\
\hline 3 & 41502 & 7 & 45 & 52 & 9500 & 1 & 0 & 2 & 2 & 9527 & 9545 & 9581 & 10.0 & 10 & 10 & 46 & -4 \\
\hline 3 & 41502 & 7 & 46 & 52 & 10100 & 0 & 0 & 3 & 3 & 10126 & 10154 & 10194 & 10.0 & 10 & 10 & 46 & -4 \\
\hline 3 & 41502 & 7 & 51 & 52 & 13096 & 0 & 0 & 4 & 4 & 13126 & 13154 & 13185 & 10.0 & 10 & 10 & 46 & -4 \\
\hline 3 & 41502 & 7 & 53 & 52 & 14295 & 0 & 3 & 0 & 3 & 14320 & 14337 & 14374 & 10.0 & 21 & 10 & 46 & -4 \\
\hline 3 & 41502 & 7 & 54 & 52 & 14894 & 0 & 0 & 3 & 3 & 14919 & 14951 & 14986 & 10.0 & 10 & 10 & 46 & -4 \\
\hline 3 & 41502 & 7 & 55 & 52 & 15493 & 0 & 2 & 1 & 3 & 15519 & 15537 & 15574 & 10.0 & 21 & 10 & 46 & -4 \\
\hline 3 & 41502 & 7 & 57 & 52 & 16691 & 0 & 0 & 4 & 4 & 16717 & 16762 & 16789 & 10.0 & 10 & 10 & 46 & -4 \\
\hline 3 & 41502 & 8 & 0 & 52 & 18489 & 0 & 4 & 2 & 6 & 18510 & 18558 & 18591 & 10.0 & 21 & 10 & 46 & -4 \\
\hline 3 & 41502 & 8 & 2 & 52 & 19687 & 0 & 2 & 3 & 5 & 19706 & 19730 & 19766 & 10.0 & 21 & 10 & 46 & -4 \\
\hline 3 & 41502 & 8 & 5 & 52 & 21485 & 0 & 1 & 1 & 2 & 21515 & 21532 & 21572 & 10.0 & 21 & 10 & 46 & -4 \\
\hline 3 & 41502 & 8 & 6 & 52 & 22085 & 1 & 0 & 2 & 2 & 22149 & 22160 & 22195 & 10.0 & 10 & 10 & 46 & -4 \\
\hline 3 & 41502 & 8 & 11 & 52 & 25080 & 0 & 0 & 4 & 4 & 25102 & 25142 & 25178 & 10.0 & 10 & 10 & 46 & -4 \\
\hline 3 & 41502 & 8 & 13 & 52 & 26279 & 0 & 0 & 5 & 5 & 26315 & 26351 & 26378 & 10.0 & 10 & 10 & 46 & -4 \\
\hline 3 & 41502 & 8 & 27 & 52 & 34666 & 0 & 2 & 5 & 7 & 34694 & 34737 & 34771 & 10.0 & 21 & 10 & 46 & -4 \\
\hline 3 & 41502 & 8 & 28 & 52 & 35266 & 0 & 0 & 2 & 2 & 35298 & 35312 & 35356 & 10.0 & 10 & 10 & 46 & -4 \\
\hline 3 & 41502 & 8 & 30 & 51 & 508 & 0 & 0 & 7 & 7 & 540 & 578 & 605 & 10.0 & 10 & 10 & 46 & -4 \\
\hline 3 & 41502 & 8 & 31 & 51 & 1108 & 0 & 1 & 5 & 6 & 1140 & 1191 & 1219 & 10.0 & 21 & 10 & 46 & -4 \\
\hline 3 & 41502 & 8 & 36 & 51 & 4105 & 1 & 1 & 6 & 7 & 4135 & 4189 & 4226 & 10.0 & 21 & 10 & 46 & -4 \\
\hline 3 & 41502 & 8 & 49 & 52 & 11899 & 1 & 2 & 1 & 3 & 11944 & 11966 & 12004 & 10.0 & 21 & 10 & 46 & -4 \\
\hline 3 & 41502 & 8 & 51 & 52 & 13098 & 0 & 0 & 2 & 2 & 13139 & 13146 & 13181 & 10.0 & 10 & 10 & 46 & -4 \\
\hline 3 & 41502 & 8 & 54 & 52 & 14895 & 2 & 2 & 2 & 4 & 14917 & 14948 & 14991 & 10.0 & 21 & 10 & 46 & -4 \\
\hline 3 & 41502 & 9 & 11 & 52 & 25083 & 0 & 1 & 2 & 3 & 25123 & 25128 & 25173 & 10.0 & 21 & 10 & 46 & -4 \\
\hline 3 & 41502 & 9 & 12 & 52 & 25682 & 0 & 0 & 3 & 3 & 25703 & 25749 & 25780 & 10.0 & 10 & 10 & 46 & -4 \\
\hline 4 & 40444 & 8 & 0 & 7 & 140 & 0 & & 5 & 5 & 247 & 418 & 533 & 30.3 & 5 & 10 & 54 & 2 \\
\hline 4 & 40444 & 8 & 1 & 17 & 138 & 0 & & 3 & 3 & 270 & 348 & 461 & 30.3 & 5 & 10 & 54 & 2 \\
\hline 4 & 40444 & 8 & 2 & 27 & 168 & 0 & & 6 & 6 & 261 & 473 & 593 & 30.3 & 5 & 10 & 54 & 2 \\
\hline 4 & 40444 & 8 & 3 & 37 & 134 & 0 & & 6 & 6 & 236 & 383 & 498 & 30.3 & 5 & 10 & 54 & . \\
\hline
\end{tabular}




\begin{tabular}{|c|c|c|c|c|c|c|c|c|c|c|c|c|c|c|c|c|c|}
\hline 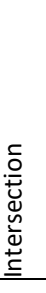 & $\begin{array}{l}\stackrel{ \pm}{ \pm} \\
\stackrel{0}{0}\end{array}$ & $\begin{array}{l}\bar{y} \\
\text { 오 }\end{array}$ & $\begin{array}{l}\stackrel{\Xi}{J} \\
\stackrel{\Xi}{\Sigma}\end{array}$ & 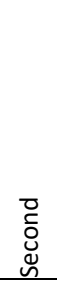 & 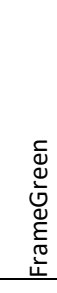 & 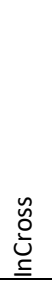 & $\begin{array}{l}\text { Oे } \\
\stackrel{\infty}{\underline{\Phi}}\end{array}$ & 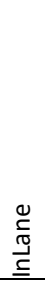 & $\begin{array}{l}\stackrel{d}{\partial} \\
\stackrel{d}{\partial} \\
\underline{\Xi}\end{array}$ & 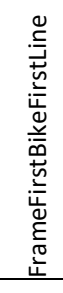 & 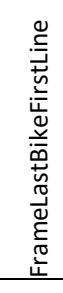 & 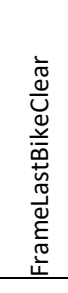 & 气ัน & $\begin{array}{l}\frac{7}{5} \\
\frac{1}{0} \\
3 \\
3\end{array}$ & $\begin{array}{l}\frac{N}{5} \\
\frac{5}{3} \\
3\end{array}$ & $\sum_{0}^{\frac{1}{0}}$ & $\begin{array}{l}\frac{8}{\pi} \\
\frac{\pi}{0} \\
\end{array}$ \\
\hline 4 & 40444 & 8 & 4 & 47 & 162 & 0 & & 7 & 7 & 275 & 469 & 560 & 30.3 & 5 & 10 & 54 & 2 \\
\hline 4 & 40444 & 8 & 5 & 57 & 160 & 0 & & 8 & 8 & 251 & 480 & 566 & 30.3 & 5 & 10 & 54 & 2 \\
\hline 4 & 40444 & 8 & 7 & 6 & 128 & 1 & & 2 & 2 & 249 & 293 & 439 & 30.3 & 5 & 10 & 54 & 2 \\
\hline 4 & 40444 & 8 & 8 & 16 & 126 & 0 & & 6 & 6 & 204 & 375 & 463 & 30.3 & 5 & 10 & 54 & 2 \\
\hline 4 & 40444 & 8 & 9 & 26 & 124 & 0 & & 4 & 4 & 227 & 331 & 441 & 30.3 & 5 & 10 & 54 & 2 \\
\hline 4 & 40444 & 8 & 10 & 37 & 170 & 0 & & 2 & 2 & 275 & 309 & 430 & 30.3 & 5 & 10 & 54 & 2 \\
\hline 4 & 40444 & 8 & 12 & 56 & 166 & 0 & & 2 & 2 & 259 & 311 & 439 & 30.3 & 5 & 10 & 54 & 2 \\
\hline 4 & 40444 & 8 & 14 & 6 & 162 & 0 & & 3 & 3 & 275 & 366 & 487 & 30.3 & 5 & 10 & 54 & 2 \\
\hline 4 & 40444 & 8 & 15 & 16 & 160 & 0 & & 3 & 3 & 309 & 381 & 483 & 30.3 & 5 & 10 & 54 & 2 \\
\hline 4 & 40444 & 8 & 17 & 36 & 124 & 0 & & 7 & 7 & 261 & 457 & 576 & 30.3 & 5 & 10 & 54 & 2 \\
\hline 4 & 40444 & 8 & 18 & 46 & 150 & 0 & & 3 & 3 & 282 & 327 & 463 & 30.3 & 5 & 10 & 54 & 2 \\
\hline 4 & 40444 & 8 & 19 & 56 & 118 & 0 & & 2 & 2 & 229 & 277 & 408 & 30.3 & 5 & 10 & 54 & 2 \\
\hline 4 & 40444 & 8 & 21 & 5 & 174 & 0 & & 12 & 12 & 263 & 608 & 695 & 30.3 & 5 & 10 & 54 & 2 \\
\hline 4 & 40444 & 8 & 24 & 35 & 136 & 0 & & 4 & 4 & 265 & 374 & 485 & 30.3 & 5 & 10 & 54 & 2 \\
\hline 4 & 40444 & 8 & 25 & 45 & 164 & 0 & & 4 & 4 & 253 & 378 & 501 & 30.3 & 5 & 10 & 54 & 2 \\
\hline 4 & 40444 & 8 & 26 & 55 & 160 & 0 & & 8 & 8 & 291 & 504 & 600 & 30.3 & 5 & 10 & 54 & 2 \\
\hline 4 & 40444 & 8 & 28 & 5 & 156 & 1 & & 10 & 10 & 239 & 497 & 574 & 30.3 & 5 & 10 & 54 & 2 \\
\hline 4 & 40444 & 8 & 29 & 15 & 124 & 1 & & 6 & 6 & 236 & 419 & 535 & 30.3 & 5 & 10 & 54 & 2 \\
\hline 4 & 40444 & 8 & 30 & 25 & 120 & 0 & & 3 & 3 & 257 & 330 & 451 & 30.3 & 5 & 10 & 54 & 2 \\
\hline 4 & 40444 & 8 & 31 & 35 & 118 & 0 & & 4 & 4 & 261 & 358 & 465 & 30.3 & 5 & 10 & 54 & 2 \\
\hline 4 & 40444 & 8 & 32 & 44 & 176 & 0 & & 8 & 8 & 309 & 507 & 614 & 30.3 & 5 & 10 & 54 & 2 \\
\hline 4 & 40444 & 8 & 35 & 4 & 140 & 0 & & 5 & 5 & 273 & 483 & 608 & 30.3 & 5 & 10 & 54 & 2 \\
\hline 4 & 40444 & 8 & 36 & 14 & 138 & 1 & & 4 & 4 & 269 & 358 & 457 & 30.3 & 5 & 10 & 54 & 2 \\
\hline 4 & 40444 & 8 & 37 & 24 & 134 & 0 & & 5 & 5 & 237 & 374 & 467 & 30.3 & 5 & 10 & 54 & 2 \\
\hline 4 & 40444 & 8 & 38 & 34 & 162 & 0 & & 3 & 3 & 289 & 350 & 461 & 30.3 & 5 & 10 & 54 & 2 \\
\hline 4 & 40444 & 8 & 39 & 44 & 128 & 0 & & 2 & 2 & 239 & 295 & 398 & 30.3 & 5 & 10 & 54 & 2 \\
\hline 4 & 40444 & 8 & 40 & 53 & 154 & 0 & & 6 & 6 & 265 & 443 & 542 & 30.3 & 5 & 10 & 54 & 2 \\
\hline 4 & 40444 & 8 & 43 & 43 & 148 & 0 & & 11 & 11 & 275 & 568 & 665 & 30.3 & 5 & 10 & 54 & 2 \\
\hline 4 & 40444 & 8 & 44 & 23 & 146 & 0 & & 3 & 3 & 282 & 336 & 447 & 30.3 & 5 & 10 & 54 & 2 \\
\hline 4 & 40444 & 8 & 45 & 33 & 174 & 0 & & 4 & 4 & 316 & 449 & 570 & 30.3 & 5 & 10 & 54 & 2 \\
\hline 4 & 40444 & 8 & 47 & 52 & 140 & 0 & & 2 & 2 & 251 & 285 & 394 & 30.3 & 5 & 10 & 54 & 2 \\
\hline 4 & 40444 & 8 & 49 & 2 & 107 & 0 & & 6 & 6 & 190 & 354 & 469 & 30.3 & 5 & 10 & 54 & 2 \\
\hline 4 & 40444 & 8 & 52 & 32 & 192 & 0 & & 2 & 2 & 315 & 371 & 489 & 30.3 & 5 & 10 & 54 & 2 \\
\hline
\end{tabular}




\begin{tabular}{|c|c|c|c|c|c|c|c|c|c|c|c|c|c|c|c|c|c|}
\hline 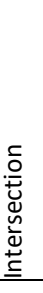 & $\begin{array}{l}\text { ग̃ } \\
\text { D̃ }\end{array}$ & $\begin{array}{l}\text { 亏े } \\
\text { 오 } \\
\end{array}$ & $\begin{array}{l}\stackrel{0}{J} \\
\stackrel{S}{S}\end{array}$ & 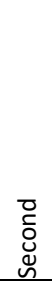 & 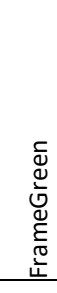 & $\begin{array}{l}\tilde{O} \\
\text { 이 } \\
\underline{\underline{\underline{S}}}\end{array}$ & 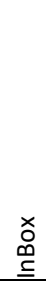 & 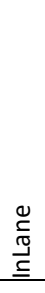 & $\begin{array}{l}\stackrel{d}{\partial} \\
\stackrel{d}{\partial} \\
\underline{\sigma} \\
\underline{\underline{c}}\end{array}$ & 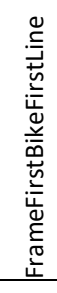 & 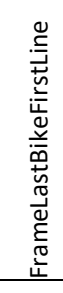 & 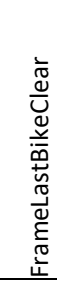 & 号 & $\begin{array}{l}-1 \\
\frac{1}{ \pm} \\
.0 \\
3 \\
3\end{array}$ & $\begin{array}{l}\frac{N}{5} \\
\frac{5}{0} \\
3 \\
3\end{array}$ & \begin{tabular}{l}
5 \\
\multirow{2}{*}{0} \\
0 \\
0
\end{tabular} & $\begin{array}{l}\frac{0}{0} \\
\frac{\pi}{0} \\
\end{array}$ \\
\hline 4 & 40444 & 8 & 53 & 42 & 160 & 0 & & 2 & 2 & 261 & 307 & 402 & 30.3 & 5 & 10 & 54 & 2 \\
\hline 4 & 40444 & 8 & 58 & 22 & 124 & 0 & & 2 & 2 & 234 & 300 & 406 & 30.3 & 5 & 10 & 54 & 2 \\
\hline 4 & 40444 & 8 & 59 & 31 & 119 & 0 & & 2 & 2 & 243 & 296 & 431 & 30.3 & 5 & 10 & 54 & 2 \\
\hline 4 & 40444 & 9 & 0 & 48 & 178 & 0 & & 2 & 2 & 279 & 322 & 420 & 30.3 & 5 & 10 & 54 & 2 \\
\hline 4 & 40444 & 9 & 4 & 17 & 140 & 0 & & 2 & 2 & 257 & 297 & 429 & 30.3 & 5 & 10 & 54 & 2 \\
\hline 4 & 40444 & 9 & 7 & 47 & 164 & 0 & & 3 & 3 & 293 & 396 & 533 & 30.3 & 5 & 10 & 54 & 2 \\
\hline 4 & 40444 & 9 & 10 & 7 & 99 & 0 & & 4 & 4 & 225 & 340 & 453 & 30.3 & 5 & 10 & 54 & 2 \\
\hline 4 & 40444 & 9 & 12 & 27 & 146 & 0 & & 2 & 2 & 279 & 379 & 485 & 30.3 & 5 & 10 & 54 & 2 \\
\hline 4 & 40444 & 9 & 13 & 37 & 144 & 1 & & 3 & 3 & 243 & 335 & 441 & 30.3 & 5 & 10 & 54 & 2 \\
\hline 4 & 40444 & 9 & 14 & 47 & 142 & 0 & & 2 & 2 & 258 & 302 & 425 & 30.3 & 5 & 10 & 54 & 2 \\
\hline 4 & 40444 & 9 & 17 & 7 & 168 & 0 & & 3 & 3 & 331 & 398 & 519 & 30.3 & 5 & 10 & 54 & 2 \\
\hline 4 & 40444 & 9 & 18 & 17 & 136 & 0 & & 3 & 3 & 277 & 338 & 453 & 30.3 & 5 & 10 & 54 & 2 \\
\hline 4 & 40444 & 9 & 28 & 46 & 146 & 0 & & 2 & 2 & 275 & 300 & 416 & 30.3 & 5 & 10 & 54 & 2 \\
\hline 4 & 40444 & 9 & 29 & 55 & 174 & 0 & & 2 & 2 & 257 & 305 & 445 & 30.3 & 5 & 10 & 54 & 2 \\
\hline 4 & 40445 & 8 & 1 & 16 & 126 & 0 & & 10 & 10 & 249 & 527 & 645 & 30.3 & 5 & 10 & 54 & 2 \\
\hline 4 & 40445 & 8 & 2 & 26 & 122 & 1 & & 7 & 7 & 227 & 420 & 509 & 30.3 & 5 & 10 & 54 & 2 \\
\hline 4 & 40445 & 8 & 5 & 55 & 146 & 0 & & 4 & 4 & 263 & 360 & 467 & 30.3 & 5 & 10 & 54 & 2 \\
\hline 4 & 40445 & 8 & 8 & 15 & 142 & 0 & & 4 & 4 & 263 & 351 & 479 & 30.3 & 5 & 10 & 54 & 2 \\
\hline 4 & 40445 & 8 & 9 & 25 & 140 & 0 & & 2 & 2 & 239 & 297 & 445 & 30.3 & 5 & 10 & 54 & 2 \\
\hline 4 & 40445 & 8 & 10 & 35 & 136 & 0 & & 7 & 7 & 233 & 430 & 525 & 30.3 & 5 & 10 & 54 & 2 \\
\hline 4 & 40445 & 8 & 12 & 55 & 132 & 0 & & 5 & 5 & 231 & 425 & 538 & 30.3 & 5 & 10 & 54 & 2 \\
\hline 4 & 40445 & 8 & 14 & 5 & 136 & 0 & & 5 & 5 & 241 & 378 & 487 & 30.3 & 5 & 10 & 54 & 2 \\
\hline 4 & 40445 & 8 & 15 & 15 & 134 & 0 & & 5 & 5 & 239 & 392 & 493 & 30.3 & 5 & 10 & 54 & 2 \\
\hline 4 & 40445 & 8 & 16 & 25 & 132 & 1 & & 8 & 8 & 243 & 485 & 596 & 30.3 & 5 & 10 & 54 & 2 \\
\hline 4 & 40445 & 8 & 18 & 44 & 126 & 0 & & 6 & 6 & 260 & 392 & 507 & 30.3 & 5 & 10 & 54 & 2 \\
\hline 4 & 40445 & 8 & 19 & 54 & 124 & 0 & & 5 & 5 & 268 & 384 & 515 & 30.3 & 5 & 10 & 54 & 2 \\
\hline 4 & 40445 & 8 & 22 & 14 & 118 & 0 & & 5 & 5 & 229 & 342 & 441 & 30.3 & 5 & 10 & 54 & 2 \\
\hline 4 & 40445 & 8 & 23 & 23 & 146 & 1 & & 4 & 4 & 274 & 379 & 483 & 30.3 & 5 & 10 & 54 & 2 \\
\hline 4 & 40445 & 8 & 24 & 34 & 174 & 0 & & 9 & 9 & 289 & 578 & 665 & 30.3 & 5 & 10 & 54 & 2 \\
\hline 4 & 40445 & 8 & 25 & 43 & 170 & 0 & & 6 & 6 & 301 & 470 & 562 & 30.3 & 5 & 10 & 54 & 2 \\
\hline 4 & 40445 & 8 & 26 & 56 & 138 & 0 & & 5 & 5 & 216 & 398 & 511 & 30.3 & 5 & 10 & 54 & 2 \\
\hline 4 & 40445 & 8 & 29 & 13 & 132 & 0 & & 5 & 5 & 257 & 439 & 546 & 30.3 & 5 & 10 & 54 & 2 \\
\hline 4 & 40445 & 8 & 30 & 23 & 132 & 1 & & 3 & 3 & 263 & 318 & 429 & 30.3 & 5 & 10 & 54 & 2 \\
\hline
\end{tabular}




\begin{tabular}{|c|c|c|c|c|c|c|c|c|c|c|c|c|c|c|c|c|c|}
\hline 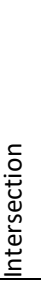 & $\begin{array}{l}\stackrel{ \pm}{ \pm} \\
\stackrel{0}{0}\end{array}$ & $\begin{array}{l}\grave{亏} \\
\text { 온 }\end{array}$ & $\begin{array}{l}\stackrel{\Xi}{J} \\
\stackrel{\Xi}{\Sigma}\end{array}$ & 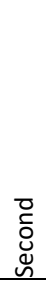 & 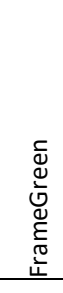 & 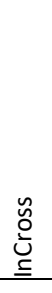 & $\begin{array}{l}\text { 㐅⿸ } \\
\text { ఏ } \\
\underline{\underline{\Xi}}\end{array}$ & 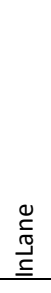 & $\begin{array}{l}\stackrel{d}{\partial} \\
\stackrel{d}{\partial} \\
\underline{\Xi}\end{array}$ & 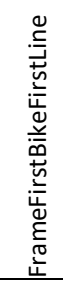 & 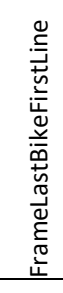 & 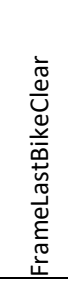 & 足 & $\begin{array}{l}\frac{7}{5} \\
\frac{1}{0} \\
3 \\
3\end{array}$ & $\begin{array}{l}\frac{N}{5} \\
\frac{5}{3} \\
3\end{array}$ & $\sum_{0}^{\frac{1}{0}}$ & $\begin{array}{l}\frac{8}{\pi} \\
\frac{\pi}{0} \\
\end{array}$ \\
\hline 4 & 40445 & 8 & 32 & 42 & 128 & 0 & & 6 & 6 & 202 & 370 & 479 & 30.3 & 5 & 10 & 54 & 2 \\
\hline 4 & 40445 & 8 & 33 & 52 & 126 & 0 & & 15 & 15 & 265 & 671 & 762 & 30.3 & 5 & 10 & 54 & 2 \\
\hline 4 & 40445 & 8 & 35 & 2 & 124 & 0 & & 9 & 9 & 249 & 513 & 596 & 30.3 & 5 & 10 & 54 & 2 \\
\hline 4 & 40445 & 8 & 37 & 22 & 118 & 1 & & 11 & 11 & 227 & 517 & 608 & 30.3 & 5 & 10 & 54 & 2 \\
\hline 4 & 40445 & 8 & 38 & 32 & 146 & 0 & & 5 & 5 & 273 & 402 & 499 & 30.3 & 5 & 10 & 54 & 2 \\
\hline 4 & 40445 & 8 & 40 & 52 & 140 & 0 & & 4 & 4 & 253 & 352 & 467 & 30.3 & 5 & 10 & 54 & 2 \\
\hline 4 & 40445 & 8 & 42 & 1 & 168 & 0 & & 4 & 4 & 263 & 376 & 487 & 30.3 & 5 & 10 & 54 & 2 \\
\hline 4 & 40445 & 8 & 47 & 51 & 126 & 0 & & 4 & 4 & 243 & 336 & 441 & 30.3 & 5 & 10 & 54 & 2 \\
\hline 4 & 40445 & 8 & 52 & 30 & 120 & 0 & & 6 & 6 & 214 & 418 & 533 & 30.3 & 5 & 10 & 54 & 2 \\
\hline 4 & 40445 & 8 & 53 & 40 & 178 & 0 & & 4 & 4 & 322 & 418 & 511 & 30.3 & 5 & 10 & 54 & 2 \\
\hline 4 & 40445 & 8 & 58 & 20 & 140 & 0 & & 6 & 6 & 269 & 378 & 467 & 30.3 & 5 & 10 & 54 & 2 \\
\hline 4 & 40445 & 9 & 4 & 15 & 95 & 0 & & 5 & 5 & 208 & 342 & 447 & 30.3 & 5 & 10 & 54 & 2 \\
\hline 4 & 40445 & 9 & 28 & 43 & 144 & 1 & & 3 & 3 & 295 & 360 & 475 & 30.3 & 5 & 10 & 54 & 2 \\
\hline 4 & 40449 & 7 & 6 & 18 & 148 & 0 & & 7 & 7 & 281 & 433 & 531 & 30.3 & 5 & 10 & 54 & 2 \\
\hline 4 & 40449 & 7 & 8 & 37 & 176 & 0 & & 8 & 8 & 309 & 523 & 624 & 30.3 & 5 & 10 & 54 & 2 \\
\hline 4 & 40449 & 7 & 9 & 47 & 53 & 0 & & 7 & 7 & 158 & 354 & 451 & 30.3 & 5 & 10 & 54 & 2 \\
\hline 4 & 40449 & 7 & 20 & 15 & 91 & 0 & & 10 & 10 & 238 & 479 & 564 & 30.3 & 5 & 10 & 54 & 2 \\
\hline 4 & 40449 & 7 & 23 & 44 & 85 & 1 & & 6 & 6 & 235 & 404 & 497 & 30.3 & 5 & 10 & 54 & 2 \\
\hline 4 & 40449 & 7 & 24 & 54 & 83 & 0 & & 6 & 6 & 184 & 354 & 451 & 30.3 & 5 & 10 & 54 & 2 \\
\hline 4 & 40449 & 7 & 27 & 14 & 77 & 0 & & 11 & 11 & 202 & 485 & 574 & 30.3 & 5 & 10 & 54 & 2 \\
\hline 4 & 40449 & 7 & 28 & 24 & 47 & 0 & & 18 & 18 & 170 & 606 & 693 & 30.3 & 5 & 10 & 54 & 2 \\
\hline 4 & 40449 & 7 & 31 & 54 & 132 & 0 & & 12 & 12 & 269 & 608 & 701 & 30.3 & 5 & 10 & 54 & 2 \\
\hline 4 & 40449 & 7 & 33 & 4 & 130 & 0 & & 15 & 15 & 265 & 729 & 828 & 30.3 & 5 & 10 & 54 & 2 \\
\hline 4 & 40449 & 7 & 34 & 14 & 67 & 0 & & 12 & 12 & 186 & 520 & 639 & 30.3 & 5 & 10 & 54 & 2 \\
\hline 4 & 40449 & 7 & 35 & 23 & 93 & 0 & & 7 & 7 & 263 & 418 & 501 & 30.3 & 5 & 10 & 54 & 2 \\
\hline 4 & 40449 & 7 & 36 & 33 & 61 & 1 & & 8 & 8 & 198 & 400 & 487 & 30.3 & 5 & 10 & 54 & 2 \\
\hline 4 & 40449 & 7 & 37 & 43 & 120 & 0 & & 6 & 6 & 234 & 410 & 497 & 30.3 & 5 & 10 & 54 & 2 \\
\hline 4 & 40449 & 7 & 38 & 53 & 176 & 0 & & 10 & 10 & 283 & 562 & 659 & 30.3 & 5 & 10 & 54 & 2 \\
\hline 4 & 40449 & 7 & 41 & 13 & 114 & 0 & & 7 & 7 & 229 & 416 & 520 & 30.3 & 5 & 10 & 54 & 2 \\
\hline 4 & 40449 & 7 & 47 & 2 & 73 & 0 & & 10 & 10 & 176 & 471 & 564 & 30.3 & 5 & 10 & 54 & 2 \\
\hline 4 & 40449 & 7 & 48 & 12 & 69 & 0 & & 5 & 5 & 188 & 336 & 445 & 30.3 & 5 & 10 & 54 & 2 \\
\hline 4 & 40449 & 7 & 52 & 52 & 122 & 0 & & 6 & 6 & 200 & 338 & 459 & 30.3 & 5 & 10 & 54 & 2 \\
\hline 4 & 40449 & 7 & 57 & 31 & 85 & 0 & & 9 & 9 & 198 & 490 & 598 & 30.3 & 5 & 10 & 54 & 2 \\
\hline
\end{tabular}




\begin{tabular}{|c|c|c|c|c|c|c|c|c|c|c|c|c|c|c|c|c|c|}
\hline 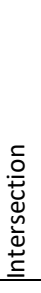 & 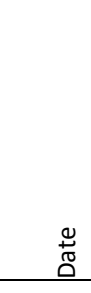 & $\begin{array}{l}\text { 亏े } \\
\text { 오 } \\
\end{array}$ & $\begin{array}{l}\stackrel{0}{J} \\
\stackrel{S}{S}\end{array}$ & 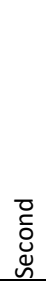 & 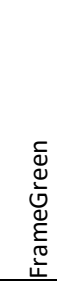 & 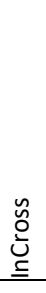 & $\begin{array}{l}\text { ○े } \\
\text { @ } \\
\end{array}$ & 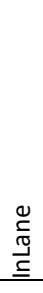 & $\begin{array}{l}\stackrel{0}{\partial} \\
\stackrel{d}{\partial} \\
\stackrel{0}{\Xi}\end{array}$ & 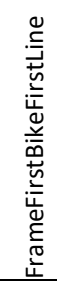 & 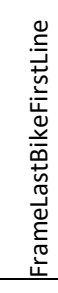 & 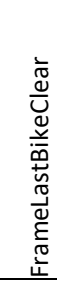 & 号 & $\begin{array}{l}-1 \\
\frac{1}{ \pm} \\
.0 \\
3 \\
3\end{array}$ & $\begin{array}{l}\frac{N}{5} \\
\frac{5}{0} \\
3 \\
3\end{array}$ & \begin{tabular}{l}
5 \\
\multirow{2}{*}{0} \\
0 \\
0
\end{tabular} & $\begin{array}{l}\frac{0}{0} \\
\frac{\pi}{0} \\
\end{array}$ \\
\hline 4 & 40449 & 8 & 2 & 16 & 77 & 0 & & 12 & 12 & 186 & 459 & 556 & 30.3 & 5 & 10 & 54 & 2 \\
\hline 5 & 40948 & 6 & 29 & 26 & 83 & 0 & 1 & 1 & 2 & 158 & 214 & 330 & 30.4 & 15 & 10 & 54 & 2 \\
\hline 5 & 40948 & 6 & 31 & 46 & 138 & 0 & 2 & 1 & 3 & 255 & 364 & 572 & 30.3 & 15 & 10 & 54 & 2 \\
\hline 5 & 40948 & 6 & 34 & 6 & 166 & 0 & 4 & 0 & 4 & 280 & 353 & 481 & 30.4 & 15 & 10 & 54 & 2 \\
\hline 5 & 40948 & 6 & 37 & 35 & 101 & 0 & 2 & 1 & 3 & 196 & 241 & 346 & 30.3 & 15 & 10 & 54 & 2 \\
\hline 5 & 40948 & 6 & 38 & 45 & 132 & 0 & 1 & 1 & 2 & 225 & 227 & 370 & 30.3 & 15 & 10 & 54 & 2 \\
\hline 5 & 40948 & 6 & 43 & 25 & 126 & 0 & 1 & 2 & 3 & 261 & 277 & 426 & 30.3 & 15 & 10 & 54 & 2 \\
\hline 5 & 40948 & 6 & 44 & 35 & 124 & 0 & 2 & 2 & 4 & 240 & 310 & 461 & 30.3 & 15 & 10 & 54 & 2 \\
\hline 5 & 40948 & 6 & 45 & 45 & 122 & 0 & 2 & 0 & 2 & 166 & 208 & 340 & 30.3 & 15 & 10 & 54 & 2 \\
\hline 5 & 40948 & 6 & 52 & 44 & 114 & 0 & 2 & 0 & 2 & 217 & 263 & 377 & 30.3 & 15 & 10 & 54 & 2 \\
\hline 5 & 40948 & 6 & 58 & 34 & 132 & 0 & 3 & 2 & 5 & 233 & 311 & 457 & 30.3 & 15 & 10 & 54 & 2 \\
\hline 5 & 40948 & 7 & 0 & 59 & 95 & 0 & 2 & 1 & 3 & 182 & 233 & 370 & 30.3 & 15 & 10 & 54 & 2 \\
\hline 5 & 40948 & 7 & 4 & 29 & 122 & 0 & 1 & 1 & 2 & 237 & 291 & 420 & 30.3 & 15 & 10 & 54 & 2 \\
\hline 5 & 40948 & 7 & 9 & 9 & 146 & 0 & 2 & 0 & 2 & 174 & 279 & 402 & 30.3 & 15 & 10 & 54 & 2 \\
\hline 5 & 40948 & 7 & 11 & 29 & 112 & 0 & 1 & 2 & 3 & 217 & 223 & 422 & 30.3 & 15 & 10 & 54 & 2 \\
\hline 5 & 40948 & 7 & 12 & 39 & 170 & 0 & 2 & 0 & 2 & 278 & 327 & 457 & 30.3 & 15 & 10 & 54 & 2 \\
\hline 5 & 40948 & 7 & 14 & 58 & 138 & 0 & 2 & 2 & 4 & 237 & 303 & 437 & 30.3 & 15 & 10 & 54 & 2 \\
\hline 5 & 40948 & 7 & 16 & 8 & 136 & 0 & 1 & 5 & 6 & 188 & 389 & 481 & 30.3 & 15 & 10 & 54 & 2 \\
\hline 5 & 40948 & 7 & 17 & 18 & 134 & 0 & 2 & 1 & 3 & 258 & 281 & 437 & 30.3 & 15 & 10 & 54 & 2 \\
\hline 5 & 40948 & 7 & 19 & 38 & 130 & 0 & 2 & 0 & 2 & 221 & 264 & 420 & 30.3 & 15 & 10 & 54 & 2 \\
\hline 5 & 40948 & 7 & 20 & 48 & 99 & 0 & 2 & 1 & 3 & 220 & 276 & 437 & 30.3 & 15 & 10 & 54 & 2 \\
\hline 5 & 40948 & 7 & 21 & 58 & 128 & 0 & 2 & 1 & 3 & 250 & 305 & 479 & 30.3 & 15 & 10 & 54 & 2 \\
\hline 5 & 40948 & 7 & 23 & 8 & 126 & 0 & 2 & 1 & 3 & 215 & 242 & 392 & 30.3 & 15 & 10 & 54 & 2 \\
\hline 5 & 40948 & 7 & 25 & 27 & 122 & 0 & 4 & 1 & 5 & 188 & 279 & 420 & 30.3 & 15 & 10 & 54 & 2 \\
\hline 5 & 40948 & 7 & 26 & 37 & 120 & 0 & 1 & 1 & 2 & 194 & 251 & 386 & 30.3 & 15 & 10 & 54 & 2 \\
\hline 5 & 40948 & 7 & 27 & 47 & 118 & 0 & 1 & 1 & 2 & 264 & 275 & 424 & 30.3 & 15 & 10 & 54 & 2 \\
\hline 5 & 40948 & 7 & 28 & 57 & 116 & 0 & 2 & 2 & 4 & 228 & 295 & 418 & 30.3 & 15 & 10 & 54 & 2 \\
\hline 5 & 40948 & 7 & 35 & 56 & 130 & 0 & 2 & 0 & 2 & 236 & 278 & 402 & 30.3 & 15 & 10 & 54 & 2 \\
\hline 5 & 40948 & 7 & 37 & 6 & 128 & 1 & 4 & 0 & 4 & 248 & 292 & 443 & 30.3 & 15 & 10 & 54 & 2 \\
\hline 5 & 40948 & 7 & 38 & 16 & 126 & 0 & 4 & 1 & 5 & 206 & 348 & 481 & 30.3 & 15 & 10 & 54 & 2 \\
\hline 5 & 40948 & 7 & 39 & 26 & 124 & 0 & 2 & 0 & 2 & 215 & 262 & 403 & 30.3 & 15 & 10 & 54 & 2 \\
\hline 5 & 40948 & 7 & 41 & 46 & 118 & 0 & 2 & 0 & 2 & 215 & 239 & 374 & 30.3 & 15 & 10 & 54 & 2 \\
\hline 5 & 40948 & 7 & 44 & 5 & 142 & 0 & 5 & 3 & 8 & 247 & 363 & 477 & 30.3 & 15 & 10 & 54 & 2 \\
\hline
\end{tabular}




\begin{tabular}{|c|c|c|c|c|c|c|c|c|c|c|c|c|c|c|c|c|c|}
\hline 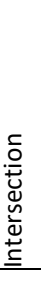 & $\begin{array}{l}\stackrel{ \pm}{0} \\
\stackrel{0}{0}\end{array}$ & $\begin{array}{l}\text { 亏े } \\
\text { 오 }\end{array}$ & 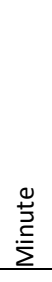 & 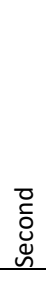 & 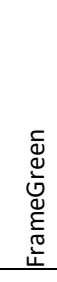 & 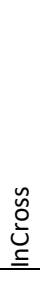 & $\begin{array}{l}\text { ox } \\
\stackrel{\infty}{\underline{0}} \\
\end{array}$ & 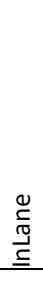 & $\begin{array}{l}\stackrel{d}{\partial} \\
\stackrel{d}{\partial} \\
\underline{\sigma} \\
\underline{\underline{c}}\end{array}$ & 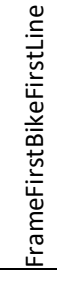 & 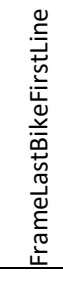 & 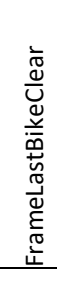 & $\stackrel{\check{u}}{\mathbf{u}}$ & 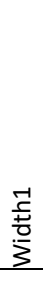 & $\begin{array}{l}\frac{N}{ \pm} \\
\frac{1}{0} \\
\sum \\
3\end{array}$ & $\begin{array}{l}\frac{1}{5} \\
\text { 竞 } \\
0 \\
0\end{array}$ & $\begin{array}{l}\frac{0}{0} \\
\frac{\pi}{0} \\
\end{array}$ \\
\hline 5 & 40948 & 7 & 48 & 45 & 132 & 1 & 2 & 2 & 4 & 183 & 297 & 464 & 30.3 & 15 & 10 & 54 & 2 \\
\hline 5 & 40948 & 7 & 49 & 55 & 130 & 1 & 7 & 4 & 11 & 231 & 406 & 554 & 30.3 & 15 & 10 & 54 & 2 \\
\hline 5 & 40948 & 7 & 51 & 5 & 128 & 0 & 2 & 4 & 6 & 208 & 309 & 424 & 30.3 & 15 & 10 & 54 & 2 \\
\hline 5 & 40948 & 7 & 55 & 44 & 120 & 0 & 5 & 0 & 5 & 220 & 317 & 447 & 30.3 & 15 & 10 & 54 & 2 \\
\hline 5 & 40948 & 8 & 0 & 29 & 110 & 0 & 2 & 0 & 2 & 214 & 214 & 388 & 30.2 & 15 & 10 & 54 & 2 \\
\hline 5 & 40948 & 8 & 1 & 39 & 138 & 0 & 2 & 1 & 3 & 238 & 285 & 396 & 30.2 & 15 & 10 & 54 & 2 \\
\hline 5 & 40948 & 8 & 2 & 49 & 138 & 0 & 3 & 2 & 5 & 210 & 318 & 471 & 30.2 & 15 & 10 & 54 & 2 \\
\hline 5 & 40948 & 8 & 3 & 59 & 136 & 0 & 3 & 1 & 4 & 241 & 315 & 545 & 30.2 & 15 & 10 & 54 & 2 \\
\hline 5 & 40948 & 8 & 5 & 9 & 134 & 0 & 3 & 0 & 3 & 203 & 259 & 385 & 30.2 & 15 & 10 & 54 & 2 \\
\hline 5 & 40948 & 8 & 6 & 19 & 132 & 0 & 4 & 1 & 5 & 220 & 330 & 475 & 30.2 & 15 & 10 & 54 & 2 \\
\hline 5 & 40948 & 8 & 7 & 29 & 130 & 0 & 2 & 1 & 3 & 180 & 248 & 389 & 30.2 & 15 & 10 & 54 & 2 \\
\hline 5 & 40948 & 8 & 8 & 39 & 130 & 0 & 4 & 2 & 6 & 233 & 301 & 498 & 30.2 & 15 & 10 & 54 & 2 \\
\hline 5 & 40948 & 8 & 9 & 49 & 128 & 0 & 2 & 1 & 3 & 235 & 275 & 407 & 30.2 & 15 & 10 & 54 & 2 \\
\hline 5 & 40948 & 8 & 12 & 8 & 124 & 1 & 1 & 2 & 3 & 233 & 324 & 435 & 30.2 & 15 & 10 & 54 & 2 \\
\hline 5 & 40948 & 8 & 13 & 18 & 124 & 1 & 2 & 2 & 4 & 169 & 281 & 427 & 30.2 & 15 & 10 & 54 & 2 \\
\hline 5 & 40948 & 8 & 14 & 28 & 122 & 0 & 2 & 2 & 4 & 226 & 294 & 402 & 30.2 & 15 & 10 & 54 & 2 \\
\hline 5 & 40948 & 8 & 15 & 38 & 118 & 0 & 3 & 2 & 5 & 214 & 291 & 423 & 30.3 & 15 & 10 & 54 & 2 \\
\hline 5 & 40948 & 8 & 16 & 48 & 118 & 0 & 1 & 1 & 2 & 206 & 244 & 392 & 30.2 & 15 & 10 & 54 & 2 \\
\hline 5 & 40948 & 8 & 17 & 58 & 116 & 0 & 3 & 2 & 5 & 199 & 282 & 422 & 30.2 & 15 & 10 & 54 & 2 \\
\hline 5 & 40948 & 8 & 19 & 8 & 113 & 0 & 3 & 1 & 4 & 205 & 271 & 398 & 30.2 & 15 & 10 & 54 & 2 \\
\hline 5 & 40948 & 8 & 20 & 18 & 142 & 0 & 3 & 1 & 4 & 236 & 329 & 469 & 30.2 & 15 & 10 & 54 & 2 \\
\hline 5 & 40948 & 8 & 21 & 27 & 140 & 0 & 1 & 1 & 2 & 256 & 265 & 417 & 30.2 & 15 & 10 & 54 & 2 \\
\hline 5 & 40948 & 8 & 23 & 47 & 134 & 0 & 1 & 1 & 2 & 192 & 233 & 376 & 30.2 & 15 & 10 & 54 & 2 \\
\hline 5 & 40948 & 8 & 24 & 57 & 132 & 0 & 3 & 0 & 3 & 229 & 352 & 505 & 30.2 & 15 & 10 & 54 & 2 \\
\hline 5 & 40948 & 8 & 26 & 7 & 130 & 0 & 2 & 1 & 3 & 242 & 291 & 469 & 30.2 & 15 & 10 & 54 & 2 \\
\hline 5 & 40948 & 8 & 27 & 17 & 128 & 0 & 4 & 3 & 7 & 203 & 350 & 495 & 30.2 & 15 & 10 & 54 & 2 \\
\hline 5 & 40948 & 8 & 28 & 27 & 126 & 0 & 2 & 2 & 4 & 184 & 286 & 406 & 30.2 & 15 & 10 & 54 & 2 \\
\hline 5 & 40948 & 8 & 29 & 37 & 124 & 0 & 3 & 0 & 3 & 253 & 327 & 475 & 30.2 & 15 & 10 & 54 & 2 \\
\hline 5 & 40948 & 8 & 30 & 47 & 122 & 0 & 4 & 2 & 6 & 249 & 309 & 453 & 30.2 & 15 & 10 & 54 & 2 \\
\hline 5 & 40948 & 8 & 33 & 6 & 118 & 0 & 2 & 0 & 2 & 241 & 257 & 404 & 30.2 & 15 & 10 & 54 & 2 \\
\hline 5 & 40948 & 8 & 34 & 17 & 116 & 0 & 4 & 2 & 6 & 172 & 287 & 393 & 30.2 & 15 & 10 & 54 & 2 \\
\hline 5 & 40948 & 8 & 35 & 26 & 114 & 1 & 2 & 0 & 2 & 170 & 190 & 326 & 30.2 & 15 & 10 & 54 & 2 \\
\hline 5 & 40948 & 8 & 37 & 46 & 138 & 0 & 4 & 1 & 5 & 254 & 322 & 451 & 30.2 & 15 & 10 & 54 & 2 \\
\hline
\end{tabular}




\begin{tabular}{|c|c|c|c|c|c|c|c|c|c|c|c|c|c|c|c|c|c|}
\hline 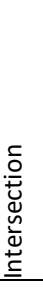 & $\begin{array}{l}\text { ग̃ } \\
\text { D̃ }\end{array}$ & $\begin{array}{l}\text { 亏े } \\
\text { 오 }\end{array}$ & $\begin{array}{l}\stackrel{0}{J} \\
\stackrel{S}{S}\end{array}$ & 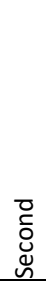 & 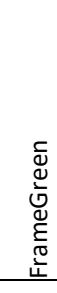 & 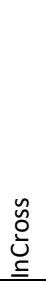 & $\begin{array}{l}\text { ○े } \\
\text { @ } \\
\end{array}$ & $\underset{\stackrel{0}{\tilde{D}}}{\stackrel{0}{\underline{E}}}$ & $\begin{array}{l}\stackrel{d}{\partial} \\
\stackrel{d}{\partial} \\
\underline{\sigma} \\
\underline{\underline{c}}\end{array}$ & 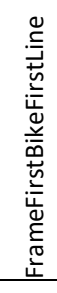 & 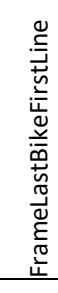 & 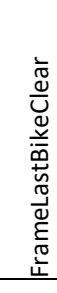 & 足 & $\begin{array}{l}-1 \\
\frac{1}{ \pm} \\
.0 \\
3 \\
3\end{array}$ & $\begin{array}{l}\frac{N}{5} \\
\frac{5}{0} \\
3 \\
3\end{array}$ & \begin{tabular}{l}
5 \\
\multirow{2}{*}{0} \\
0 \\
0
\end{tabular} & $\begin{array}{l}\frac{0}{0} \\
\frac{\pi}{0} \\
\end{array}$ \\
\hline 5 & 40948 & 8 & 38 & 56 & 136 & 0 & 1 & 1 & 2 & 235 & 243 & 402 & 30.2 & 15 & 10 & 54 & 2 \\
\hline 5 & 40948 & 8 & 40 & 6 & 134 & 0 & 2 & 2 & 4 & 194 & 272 & 396 & 30.2 & 15 & 10 & 54 & 2 \\
\hline 5 & 40948 & 8 & 41 & 15 & 132 & 0 & 6 & 4 & 10 & 246 & 334 & 519 & 30.2 & 15 & 10 & 54 & 2 \\
\hline 5 & 40948 & 8 & 42 & 25 & 130 & 0 & 3 & 8 & 11 & 227 & 484 & 588 & 30.2 & 15 & 10 & 54 & 2 \\
\hline 5 & 40948 & 8 & 43 & 35 & 128 & 0 & 2 & 1 & 3 & 208 & 257 & 402 & 30.2 & 15 & 10 & 54 & 2 \\
\hline 5 & 40948 & 8 & 44 & 45 & 124 & 0 & 4 & 2 & 6 & 184 & 338 & 479 & 30.2 & 15 & 10 & 54 & 2 \\
\hline 5 & 40948 & 8 & 45 & 55 & 122 & 0 & 1 & 1 & 2 & 228 & 253 & 366 & 30.2 & 15 & 10 & 54 & 2 \\
\hline 5 & 40948 & 8 & 48 & 14 & 118 & 0 & 2 & 1 & 3 & 197 & 257 & 394 & 30.2 & 15 & 10 & 54 & 2 \\
\hline 5 & 40948 & 8 & 50 & 34 & 112 & 0 & 1 & 2 & 3 & 170 & 222 & 334 & 30.2 & 15 & 10 & 54 & 2 \\
\hline 5 & 40948 & 8 & 52 & 54 & 138 & 1 & 2 & 1 & 3 & 227 & 283 & 414 & 30.2 & 15 & 10 & 54 & 2 \\
\hline 5 & 40948 & 8 & 54 & 4 & 136 & 1 & 1 & 1 & 2 & 225 & 238 & 370 & 30.2 & 15 & 10 & 54 & 2 \\
\hline 5 & 40948 & 8 & 57 & 33 & 128 & 0 & 3 & 2 & 5 & 211 & 324 & 449 & 30.2 & 15 & 10 & 54 & 2 \\
\hline 5 & 40948 & 8 & 58 & 43 & 124 & 0 & 3 & 1 & 4 & 192 & 297 & 422 & 30.2 & 15 & 10 & 54 & 2 \\
\hline 5 & 40949 & 6 & 53 & 53 & 130 & 1 & 3 & 1 & 4 & 239 & 361 & 511 & 30.3 & 15 & 10 & 54 & 2 \\
\hline 5 & 40949 & 7 & 25 & 25 & 132 & 0 & 3 & 1 & 4 & 211 & 305 & 449 & 30.4 & 15 & 10 & 54 & 2 \\
\hline 5 & 40949 & 7 & 38 & 14 & 116 & 0 & 1 & 3 & 4 & 186 & 299 & 386 & 30.3 & 15 & 10 & 54 & 2 \\
\hline 5 & 40949 & 7 & 42 & 53 & 136 & 0 & 4 & 0 & 4 & 218 & 307 & 437 & 30.3 & 15 & 10 & 54 & 2 \\
\hline 5 & 40949 & 7 & 45 & 13 & 101 & 0 & 3 & 1 & 4 & 200 & 287 & 449 & 30.3 & 15 & 10 & 54 & 2 \\
\hline 5 & 40949 & 7 & 48 & 43 & 126 & 0 & 3 & 2 & 5 & 209 & 254 & 418 & 30.3 & 15 & 10 & 54 & 2 \\
\hline 5 & 40949 & 7 & 51 & 2 & 122 & 1 & 4 & 2 & 6 & 221 & 293 & 437 & 30.3 & 15 & 10 & 54 & 2 \\
\hline 5 & 40949 & 7 & 52 & 12 & 120 & 0 & 2 & 2 & 4 & 217 & 294 & 429 & 30.3 & 15 & 10 & 54 & 2 \\
\hline 5 & 40949 & 7 & 53 & 22 & 118 & 0 & 2 & 2 & 4 & 192 & 280 & 410 & 30.3 & 15 & 10 & 54 & 2 \\
\hline 5 & 40949 & 7 & 58 & 2 & 140 & 0 & 3 & 2 & 5 & 253 & 331 & 483 & 30.3 & 15 & 10 & 54 & 2 \\
\hline 5 & 40949 & 7 & 59 & 12 & 138 & 0 & 3 & 4 & 7 & 270 & 371 & 513 & 30.2 & 15 & 10 & 54 & 2 \\
\hline 5 & 40949 & 8 & 6 & 17 & 124 & 0 & 3 & 2 & 5 & 230 & 334 & 508 & 30.2 & 15 & 10 & 54 & 2 \\
\hline 5 & 40949 & 8 & 7 & 27 & 122 & 0 & 2 & 2 & 4 & 243 & 301 & 445 & 30.3 & 15 & 10 & 54 & 2 \\
\hline 5 & 40949 & 8 & 9 & 47 & 120 & 0 & 3 & 4 & 7 & 190 & 301 & 469 & 30.3 & 15 & 10 & 54 & 2 \\
\hline 5 & 40949 & 8 & 12 & 7 & 114 & 1 & 1 & 4 & 5 & 206 & 299 & 420 & 30.3 & 15 & 10 & 54 & 2 \\
\hline 5 & 40949 & 8 & 16 & 46 & 108 & 0 & 4 & 0 & 4 & 206 & 336 & 473 & 30.3 & 15 & 10 & 54 & 2 \\
\hline 5 & 40949 & 8 & 19 & 6 & 134 & 0 & 3 & 1 & 4 & 234 & 273 & 422 & 30.3 & 15 & 10 & 54 & 2 \\
\hline 5 & 40949 & 8 & 20 & 16 & 132 & 0 & 3 & 2 & 5 & 245 & 313 & 435 & 30.3 & 15 & 10 & 54 & 2 \\
\hline 5 & 40949 & 8 & 21 & 26 & 130 & 0 & 2 & 2 & 4 & 204 & 269 & 465 & 30.3 & 15 & 10 & 54 & 2 \\
\hline 5 & 40949 & 8 & 26 & 5 & 122 & 0 & 4 & 4 & 8 & 223 & 338 & 463 & 30.3 & 15 & 10 & 54 & 2 \\
\hline
\end{tabular}




\begin{tabular}{|c|c|c|c|c|c|c|c|c|c|c|c|c|c|c|c|c|c|}
\hline 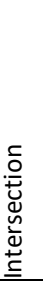 & 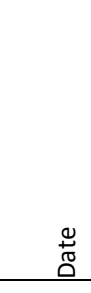 & $\begin{array}{l}\text { 亏े } \\
\text { 오 }\end{array}$ & $\stackrel{\stackrel{D}{J}}{\stackrel{ \pm}{\Xi}}$ & 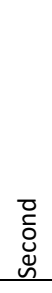 & 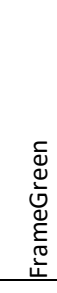 & 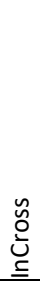 & 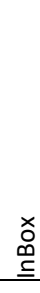 & 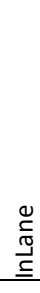 & $\begin{array}{l}\stackrel{d}{\partial} \\
\stackrel{d}{\partial} \\
\underline{\sigma} \\
\underline{\underline{c}}\end{array}$ & 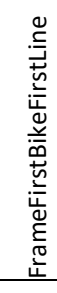 & 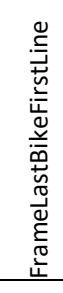 & 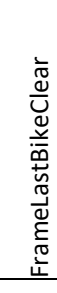 & 足 & $\begin{array}{l}-1 \\
\frac{1}{ \pm} \\
.0 \\
3 \\
3\end{array}$ & $\begin{array}{l}\frac{N}{5} \\
\frac{5}{0} \\
3 \\
3\end{array}$ & \begin{tabular}{l}
5 \\
\multirow{2}{*}{0} \\
0 \\
0
\end{tabular} & $\begin{array}{l}\frac{0}{0} \\
\frac{\pi}{0} \\
\end{array}$ \\
\hline 5 & 40949 & 8 & 27 & 15 & 120 & 0 & 2 & 2 & 4 & 200 & 285 & 426 & 30.3 & 15 & 10 & 54 & 2 \\
\hline 5 & 40949 & 8 & 28 & 25 & 116 & 1 & 2 & 2 & 4 & 236 & 342 & 477 & 30.4 & 15 & 10 & 54 & 2 \\
\hline 5 & 41453 & 6 & 58 & 58 & 42 & 0 & 3 & 2 & 5 & 70 & 95 & 145 & 9.9 & 15 & 10 & 54 & 2 \\
\hline 5 & 41453 & 7 & 15 & 18 & 42 & 0 & 2 & 4 & 6 & 74 & 114 & 156 & 10.0 & 15 & 10 & 54 & 2 \\
\hline 5 & 41453 & 7 & 26 & 59 & 40 & 0 & 3 & 4 & 7 & 79 & 112 & 144 & 10.0 & 15 & 10 & 54 & 2 \\
\hline 5 & 41453 & 7 & 29 & 18 & 46 & 0 & 4 & 2 & 6 & 74 & 110 & 152 & 10.1 & 15 & 10 & 54 & 2 \\
\hline 5 & 41453 & 7 & 35 & 7 & 40 & 1 & 4 & 2 & 6 & 68 & 98 & 140 & 9.9 & 15 & 10 & 54 & 2 \\
\hline 5 & 41453 & 7 & 44 & 27 & 33 & 1 & 4 & 2 & 6 & 51 & 75 & 118 & 10.0 & 15 & 10 & 54 & 2 \\
\hline 5 & 41453 & 7 & 46 & 47 & 40 & 1 & 4 & 4 & 8 & 66 & 118 & 157 & 10.0 & 15 & 10 & 54 & 2 \\
\hline 5 & 41453 & 7 & 47 & 57 & 35 & 2 & 3 & 4 & 7 & 60 & 94 & 125 & 10.0 & 15 & 10 & 54 & 2 \\
\hline 5 & 41453 & 7 & 50 & 17 & 41 & 1 & 2 & 5 & 7 & 75 & 152 & 182 & 10.0 & 15 & 10 & 54 & 2 \\
\hline 5 & 41453 & 7 & 56 & 7 & 49 & 0 & 4 & 4 & 8 & 85 & 117 & 154 & 10.0 & 15 & 10 & 54 & 2 \\
\hline 5 & 41453 & 7 & 58 & 28 & 39 & 0 & 4 & 4 & 8 & 65 & 104 & 153 & 10.0 & 15 & 10 & 54 & 2 \\
\hline 5 & 41453 & 7 & 59 & 37 & 51 & 0 & 4 & 3 & 7 & 90 & 129 & 170 & 10.0 & 15 & 10 & 54 & 2 \\
\hline 5 & 41453 & 8 & 0 & 48 & 46 & 0 & 4 & 3 & 7 & 72 & 106 & 150 & 10.0 & 15 & 10 & 54 & 2 \\
\hline 5 & 41453 & 8 & 1 & 57 & 41 & 0 & 6 & 2 & 8 & 82 & 113 & 157 & 10.0 & 15 & 10 & 54 & 2 \\
\hline 5 & 41453 & 8 & 6 & 38 & 38 & 1 & 4 & 3 & 7 & 73 & 111 & 150 & 10.0 & 15 & 10 & 54 & 2 \\
\hline 5 & 41453 & 8 & 13 & 37 & 56 & 2 & 3 & 6 & 9 & 97 & 172 & 210 & 10.0 & 15 & 10 & 54 & 2 \\
\hline 5 & 41453 & 8 & 20 & 37 & 27 & 0 & 4 & 2 & 6 & 61 & 92 & 142 & 10.0 & 15 & 10 & 54 & 2 \\
\hline 5 & 41453 & 8 & 22 & 58 & 34 & 0 & 8 & 6 & 14 & 64 & 171 & 206 & 10.0 & 15 & 10 & 54 & 2 \\
\hline 5 & 41453 & 8 & 24 & 8 & 45 & 0 & 4 & 8 & 12 & 82 & 160 & 193 & 10.0 & 15 & 10 & 54 & 2 \\
\hline 5 & 41453 & 8 & 28 & 47 & 57 & 0 & 4 & 2 & 6 & 87 & 130 & 166 & 10.1 & 15 & 10 & 54 & 2 \\
\hline 5 & 41453 & 8 & 38 & 7 & 29 & 1 & 4 & 2 & 6 & 67 & 101 & 147 & 9.9 & 15 & 10 & 54 & 2 \\
\hline 5 & 41453 & 8 & 49 & 47 & 45 & 0 & 2 & 4 & 6 & 70 & 112 & 145 & 9.9 & 15 & 10 & 54 & 2 \\
\hline 5 & 41453 & 8 & 50 & 57 & 41 & 0 & 3 & 4 & 7 & 77 & 104 & 155 & 9.9 & 15 & 10 & 54 & 2 \\
\hline 5 & 41453 & 8 & 55 & 37 & 37 & 0 & 2 & 4 & 6 & 62 & 113 & 152 & 9.9 & 15 & 10 & 54 & 2 \\
\hline 5 & 41453 & 8 & 59 & 7 & 38 & 0 & 2 & 4 & 6 & 81 & 113 & 142 & 9.9 & 15 & 10 & 54 & 2 \\
\hline 5 & 41453 & 9 & 29 & 27 & 52 & 1 & 2 & 3 & 5 & 91 & 110 & 145 & 10.0 & 15 & 10 & 54 & 2 \\
\hline 5 & 41456 & 6 & 49 & 39 & 28 & 0 & 5 & 2 & 7 & 50 & 95 & 140 & 10.0 & 15 & 10 & 54 & 2 \\
\hline 5 & 41456 & 6 & 57 & 49 & 11 & 0 & 4 & 2 & 6 & 33 & 79 & 122 & 10.0 & 15 & 10 & 54 & 2 \\
\hline 5 & 41456 & 7 & 5 & 59 & 56 & 0 & 4 & 1 & 5 & 96 & 120 & 163 & 9.9 & 15 & 10 & 54 & 2 \\
\hline 5 & 41456 & 7 & 11 & 49 & 31 & 1 & 1 & 5 & 6 & 60 & 120 & 156 & 9.9 & 15 & 10 & 54 & 2 \\
\hline 5 & 41456 & 7 & 26 & 59 & 31 & 0 & 1 & 4 & 5 & 66 & 93 & 130 & 10.0 & 15 & 10 & 54 & . \\
\hline
\end{tabular}




\begin{tabular}{|c|c|c|c|c|c|c|c|c|c|c|c|c|c|c|c|c|c|}
\hline 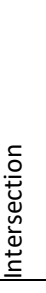 & \begin{tabular}{l} 
\pm \\
\multirow{0}{0}{} \\
0
\end{tabular} & $\begin{array}{l}\vdots \\
\text { 우 } \\
\text {. }\end{array}$ & 节 & $\begin{array}{l}\bar{D} \\
\bar{O} \\
\text { U్ } \\
\end{array}$ & 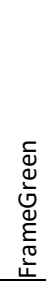 & $\begin{array}{l}\tilde{u} \\
\text { ơ } \\
\underline{\underline{\Xi}}\end{array}$ & $\begin{array}{l}\text { O } \\
\stackrel{\Phi}{\underline{\Xi}}\end{array}$ & $\begin{array}{l}\stackrel{0}{c} \\
\stackrel{0}{\Xi} \\
\underline{\underline{E}}\end{array}$ & 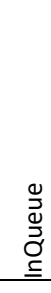 & 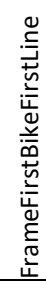 & 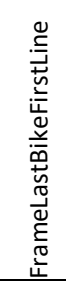 & 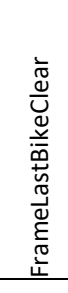 & 足 & $\begin{array}{l}-1 \\
\frac{1}{ \pm} \\
\frac{0}{3} \\
\end{array}$ & $\begin{array}{l}\tilde{N} \\
\frac{1}{ \pm} \\
\dot{0} \\
3\end{array}$ & 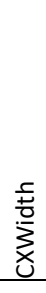 & $\begin{array}{l}\frac{0}{0} \\
\frac{\pi}{0} \\
\end{array}$ \\
\hline 5 & 41456 & 7 & 28 & 9 & 10 & 1 & 4 & 5 & 9 & 37 & 111 & 143 & 10.0 & 15 & 10 & 54 & 2 \\
\hline 5 & 41456 & 7 & 32 & 49 & 16 & 0 & 2 & 3 & 5 & 44 & 84 & 123 & 10.1 & 15 & 10 & 54 & 2 \\
\hline 5 & 41456 & 7 & 39 & 49 & 18 & 0 & 4 & 3 & 7 & 54 & 88 & 128 & 10.1 & 15 & 10 & 54 & 2 \\
\hline 5 & 41456 & 7 & 42 & 9 & 8 & 2 & 4 & 7 & 11 & 34 & 95 & 125 & 10.0 & 15 & 10 & 54 & 2 \\
\hline 5 & 41456 & 7 & 45 & 38 & 8 & 1 & 2 & 5 & 7 & 29 & 80 & 120 & 10.0 & 15 & 10 & 54 & 2 \\
\hline 5 & 41456 & 7 & 46 & 48 & 20 & 1 & 1 & 5 & 6 & 60 & 93 & 140 & 10.1 & 15 & 10 & 54 & 2 \\
\hline 5 & 41456 & 7 & 47 & 58 & 14 & 0 & 3 & 6 & 9 & 53 & 104 & 143 & 9.9 & 15 & 10 & 54 & 2 \\
\hline 5 & 41456 & 7 & 49 & 8 & 9 & 1 & 3 & 5 & 8 & 35 & 79 & 115 & 10.0 & 15 & 10 & 54 & 2 \\
\hline 5 & 41456 & 7 & 51 & 28 & 15 & 1 & 4 & 3 & 7 & 56 & 99 & 140 & 9.9 & 15 & 10 & 54 & 2 \\
\hline 5 & 41456 & 7 & 53 & 48 & 20 & 1 & 7 & 3 & 10 & 49 & 94 & 132 & 10.1 & 15 & 10 & 54 & 2 \\
\hline 5 & 41456 & 7 & 56 & 8 & 10 & 0 & 2 & 5 & 7 & 46 & 96 & 130 & 10.1 & 15 & 10 & 54 & 2 \\
\hline 5 & 41456 & 7 & 57 & 18 & 5 & 1 & 5 & 0 & 5 & 35 & 69 & 115 & 10.2 & 15 & 10 & 54 & 2 \\
\hline 5 & 41456 & 7 & 58 & 28 & 16 & 1 & 5 & 5 & 10 & 40 & 100 & 140 & 10.1 & 15 & 10 & 54 & 2 \\
\hline 5 & 41456 & 7 & 59 & 38 & 10 & 0 & 4 & 5 & 9 & 51 & 102 & 134 & 10.0 & 15 & 10 & 54 & 2 \\
\hline 5 & 41456 & 8 & 1 & 58 & 16 & 0 & 4 & 3 & 7 & 49 & 81 & 124 & 9.9 & 15 & 10 & 54 & 2 \\
\hline 5 & 41456 & 8 & 11 & 18 & 23 & 0 & 2 & 6 & 8 & 56 & 115 & 153 & 9.9 & 15 & 10 & 54 & 2 \\
\hline 5 & 41456 & 8 & 12 & 28 & 34 & 0 & 5 & 4 & 9 & 69 & 114 & 155 & 9.9 & 15 & 10 & 54 & 2 \\
\hline 5 & 41456 & 8 & 17 & 8 & 45 & 1 & 5 & 2 & 7 & 73 & 100 & 147 & 9.9 & 15 & 10 & 54 & 2 \\
\hline 5 & 41456 & 8 & 19 & 28 & 18 & 3 & 2 & 3 & 5 & 61 & 83 & 119 & 9.8 & 15 & 10 & 54 & 2 \\
\hline 5 & 41456 & 8 & 20 & 38 & -3 & 0 & 4 & 3 & 7 & 31 & 55 & 101 & 10.0 & 15 & 10 & 54 & 2 \\
\hline 5 & 41456 & 8 & 27 & 38 & 16 & 0 & 3 & 3 & 6 & 54 & 90 & 123 & 10.0 & 15 & 10 & 54 & 2 \\
\hline 5 & 41456 & 8 & 31 & 9 & 9 & 1 & 3 & 7 & 10 & 46 & 95 & 129 & 10.0 & 15 & 10 & 54 & 2 \\
\hline 5 & 41456 & 8 & 32 & 19 & 19 & 0 & 3 & 2 & 5 & 61 & 108 & 158 & 9.9 & 15 & 10 & 54 & 2 \\
\hline 5 & 41456 & 8 & 38 & 9 & 12 & 1 & 4 & 4 & 8 & 41 & 97 & 145 & 9.8 & 15 & 10 & 54 & 2 \\
\hline 5 & 41456 & 8 & 41 & 39 & 14 & 0 & 4 & 4 & 8 & 50 & 88 & 126 & 9.8 & 15 & 10 & 54 & 2 \\
\hline 5 & 41456 & 8 & 42 & 49 & 9 & 2 & 5 & 8 & 13 & 67 & 133 & 168 & 9.9 & 15 & 10 & 54 & 2 \\
\hline 5 & 41456 & 8 & 45 & 9 & 15 & 0 & 4 & 3 & 7 & 50 & 78 & 134 & 9.9 & 15 & 10 & 54 & 2 \\
\hline 5 & 41456 & 8 & 47 & 29 & 6 & 1 & 4 & 5 & 9 & 47 & 75 & 120 & 10.0 & 15 & 10 & 54 & 2 \\
\hline 5 & 41456 & 8 & 49 & 49 & 61 & 1 & 4 & 1 & 5 & 87 & 113 & 162 & 9.9 & 15 & 10 & 54 & 2 \\
\hline 5 & 41456 & 8 & 50 & 59 & 8 & 0 & 5 & 2 & 7 & 48 & 86 & 131 & 10.0 & 15 & 10 & 54 & 2 \\
\hline 5 & 41456 & 8 & 53 & 19 & 15 & 0 & 3 & 3 & 6 & 46 & 76 & 121 & 10.0 & 15 & 10 & 54 & 2 \\
\hline 5 & 41456 & 8 & 54 & 29 & 11 & 0 & 3 & 7 & 10 & 41 & 110 & 143 & 9.9 & 15 & 10 & 54 & 2 \\
\hline 5 & 41456 & 8 & 56 & 49 & 17 & 0 & 3 & 7 & 10 & 47 & 132 & 169 & 10.0 & 15 & 10 & 54 & 2 \\
\hline
\end{tabular}




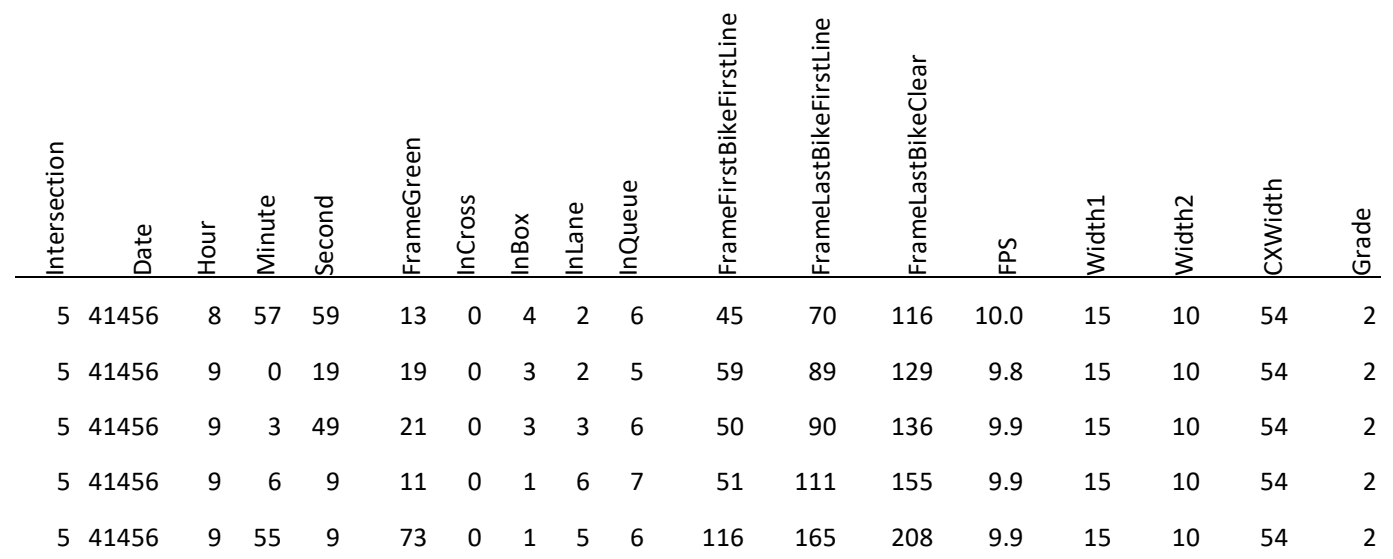

